MARIA CLARA RODRIGUES PINHEIRO

\title{
MODELO DE OTIMIZAÇÃO MULTI-PERÍODO PARA LOCALIZAÇÃO DE ARMAZÉNS APLICADO A OPERAÇÕES HUMANITÁRIAS
}


MARIA CLARA RODRIGUES PINHEIRO

\title{
MODELO DE OTIMIZAÇÃO MULTI-PERÍODO PARA LOCALIZAÇÃO DE ARMAZÉNS APLICADO A OPERAÇÕES HUMANITÁRIAS
}

\author{
Dissertação apresentada ao Departamento \\ de Engenharia de Produção da Escola Po- \\ litécnica da Universidade de São Paulo para \\ obtenção do título de Mestre em Ciências.
}




\title{
MODELO DE OTIMIZAÇÃO MULTI-PERÍODO PARA LOCALIZAÇÃO DE ARMAZÉNS APLICADO A OPERAÇÕES HUMANITÁRIAS
}

\author{
Versão Corrigida
}

Dissertação apresentada ao Departamento de Engenharia de Produção da Escola Politécnica da Universidade de São Paulo para obtenção do título de Mestre em Ciências.

Área de Concentração:

Gestão de Operações e Logística (GOL)

Orientador:

Hugo Tsugunobu Yoshida Yoshizaki 
Autorizo a reprodução e divulgação total ou parcial deste trabalho, por qualquer meio convencional ou eletrônico, para fins de estudo e pesquisa, desde que citada a fonte.

Este exemplar foi revisado e corrigido em relação à versão original, sob responsabilidade única do autor e com a anuência de seu orientador.

São Paulo, de de

Assinatura do autor:

Assinatura do orientador:

\section{Catalogação-na-publicação}

Pinheiro, Maria Clara Rodrigues

Modelo de otimização multi-período para localização de armazéns aplicado a operações humanitárias / M. C. R. Pinheiro - versão corr. - São Paulo, 2021.

$129 \mathrm{p}$.

Dissertação (Mestrado) - Escola Politécnica da Universidade de São Paulo. Departamento de Engenharia de Produção.

1.Logística humanitária 2.Problema de localização de instalações 3.Múltiplos períodos 4.Programação linear inteira mista 5.Otimização de malha logística I.Universidade de São Paulo. Escola Politécnica. Departamento de Engenharia de Produção II.t. 
Nome: PINHEIRO, Maria Clara Rodrigues

Título: Modelo de otimização multi-período para localização de armazéns aplicado a operações humanitárias

Dissertação apresentada à Escola Politécnica da Universidade de São Paulo para obtenção do Título de Mestre em Ciências.

Aprovado em: 6 de Julho de 2021

Banca Examinadora

Prof. Dr.: Hugo Tsugunobu Yoshida Yoshizaki

Instituição: Universidade de São Paulo - USP

Julgamento: Aprovada

Prof. Dr.: Miguel Cezar Santoro

Instituição: Universidade de São Paulo - USP

Julgamento: Aprovada

Profa. Dra.: Angelica Alebrant Mendes

Instituição: Universidade Federal do ABC - UFABC

Julgamento: Aprovada 


\section{AGRADECIMENTOS}

Dedico estes trabalho aos meus pais, Veneraldo e Cleonice, por não medirem esforços para apoiar meus sonhos e acreditarem no meu potencial.

Ao meu marido e amigo, Mohammad, por incentivos e equilibro em momentos de tribulação.

Ao professor Dr. Hugo Tsugunobu Yoshida Yoshizaki por todo apoio, paciência e oportunidades de aprendizado durante toda orientação deste trabalho.

Aos professores Dr. Irineu de Brito Junior e Dra. Angelica Alebrant Mendes por seus conselhos e direcionamentos.

Aos meus amigos sempre presentes em minha vida, e que estarão sempre em meu coração. Obrigada pelo companheirismo. Em especial aos meus também parceiros de vida acadêmica Filipe, Lorena e Laura que me acompanharam de perto nesta jornada.

A toda a equipe do CISLOG com quem partilhei minha experiência de mestrado.

Ao Conselho Nacional de Desenvolvimento Científico e Tecnológico (CNPq) pelo aporte financeiro concedido.

Muito Obrigada por tudo! 


\section{RESUMO}

Este trabalho teve como objetivo avaliar a coordenação entre agências humanitárias e a aplicabilidade da modelagem com múltiplos períodos na solução de problemas de localização de armazéns utilizados em suas operações. Dessa forma, foi desenvolvido um modelo de programação linear inteira mista aplicado a operação humanitária de resposta à Ofensiva de Mosul, Iraque, nos anos de 2016 e 2017. A fim de avaliar as hipóteses a respeito dos benefícios da cooperação, houve a proposição de um novo modelo de configuração da rede logística, que possibilita a mudança na dinâmica de interação entre as agências e elos da cadeia de suprimentos. Dessa forma, foram verificados ganhos financeiros relativos à centralização das operações e ao compartilhamento de recursos, bem como demonstrou-se o melhor emprego dos recursos e maior eficiência através da utilização de modelos com múltiplos períodos. Além disso, a distância de cobertura em contextos desta natureza é um fator crítico e tem um papel importante no projeto da rede, estabelecendo um trade-off entre a centralização, a qual permite ganhos de escala, e o nível de serviço desejado na operação. O modelo de localização com múltiplos períodos se ajusta melhor a problemas com alta variabilidade nas demandas, entretanto é necessário que se empregue um método robusto de previsão de demanda no planejamento para que este modelo se adéque às incertezas inerentes destes sistemas.

Palavras-Chave: Logística Humanitária, Problema de Localização de Instalações, Múltiplos períodos, Programação linear inteira mista, Otimização da malha logística. 


\section{ABSTRACT}

This work aimed to evaluate the coordination between humanitarian agencies and the applicability of modeling with multiple periods in the solution of location problems of warehouses used in their operations. In this way, a mixed-integer linear programming model was applied to the response operation during and after the Mosul Offensive, in Iraq and in the years 2016 and 2017. To evaluate the hypotheses regarding the benefits of cooperation, there was a proposal for a new model for the configuration of the logistical network, which makes it possible to change the dynamics of interaction between branches and links in the supply chain. Thus, there were financial gains related to the centralization of operations and the sharing of resources, as well as the better use of resources and greater efficiency through the use of models with multiple periods. In addition, the coverage distance in problems of this nature is a critical factor and plays an important role in the design of the network, establishing a trade-off between centralization, which allows for gains of scale, and the level of service desired in the operation. The model of location with multiple periods is better adjusted to problems with high variability in demands, however, it is necessary to employ a robust method of forecasting demand in planning so that this model adapts to the inherent uncertainties of these systems.

Keywords: Humanitarian logistics, Localization problem, Multi-period, Mixed integer linear programming, Optimization of the logistics network. 


\section{LISTA DE FIGURAS}

1 Avanço da batalha: Fases da ofensiva. . . . . . . . . . . . . . . . . 17

2 Número de deslocados internos e indivíduos em retorno ao longo do tempo. 18

3 Ocupação nos campos de deslocados levantados no estudo. . . . . . . . . . 19

4 Variação na demanda dos campos de outubro de 2016 à esquerda, e fevereiro de 2017 à direita. . . . . . . . . . . . . . . . . . . . . . . 20

5 Variação na demanda dos campos de agosto de 2017 à esquerda, e dezembro de 2017 à direita. . . . . . . . . . . . . . . . . . . . . . . . . 21

6 Ciclo de vida dos desastres. . . . . . . . . . . . . . . . . . . 24

$7 \quad$ Metodologia de pesquisa. . . . . . . . . . . . . . . 46

8 Etapas da pesquisa, técnicas e ferramentas adotadas. . . . . . . . . . . . 47

9 Cadeias de suprimentos da operação humanitária. . . . . . . . . . . . . . . . 49

10 Nova proposta de cadeia de suprimentos. . . . . . . . . . . . . . . . 50

11 Localização dos nós da malha logística. . . . . . . . . . . . . . . . . . 62

12 Histórico sobre a ocupação, disponibilidade e quantidade de campos planejados durante a operação. . . . . . . . . . . . . . . . . . . . . . 63

13 Processo de busca documental de demandas do ano de 2017. . . . . . . . . 64

14 Comparação entre as localizações de campos identificados nos dois processos de busca documental. . . . . . . . . . . . . . . . . . . . . . . . . . 65

15 Configuração da malha logística para $p=26$ do modelo de P-centros. . . . 67

16 Configuração da malha logística para $p=26$ do modelo de P-medianas minimizando a distância máxima e a soma total de distâncias. . . . . . . . . 68

17 Matriz de custos do estudo. . . . . . . . . . . . . . . . . 70

18 Custos de abertura. . . . . . . . . . . . . . . . 71

19 Custos variáveis de operação. . . . . . . . . . . . . . . . . . 73

20 Custos fixos de operação. . . . . . . . . . . . . . . . . . . . . . . 74 
21 Comparação entre a configuração da malha logística dos meses de fevereiro, maio e junho de 2017. . . . . . . . . . . . . . . . . . . . . . . . . . . . 80

22 Comparação entre a configuração da malha logística dos meses de outubro de 2016 , maio e junho de 2017 . . . . . . . . . . . . . . . . . . . 81

23 Locais candidatos selecionados na malha logística atual. . . . . . . . . . . 85

24 Locais candidatos selecionados na malha logística proposta. . . . . . . . . . 86

25 Ocupação agregada dos armazéns no horizonte de planejamento de 15 meses para o modelo estático e o modelo multi-período.

26 Ocupação dos armazéns no horizonte de 15 meses para a decisões do modelo multi-período.

27 Ocupação dos armazéns no horizonte de 15 meses para a decisões do modelo estático.

28 Comparação entre locais candidatos selecionados para cada período de replanejamento e os locais selecionados através do horizonte rolante. . . . . .

29 Continuação. Comparação entre locais candidatos selecionados para cada período de replanejamento e os locais selecionados através do horizonte rolante.

30 Continuação. Comparação entre locais candidatos selecionados para cada período de replanejamento e os locais selecionados através do horizonte rolante

31 Continuação. Comparação entre locais candidatos selecionados para cada período de replanejamento e os locais selecionados através do horizonte

32 Comparação da configuração da malha entre a abordagem de horizonte fixo e rolante do modelo multi-período em janeiro de $2017, p=3 \ldots$. . . . . . . 97

33 Comparação da configuração da malha entre a abordagem de horizonte fixo e rolante do modelo multi-período em maio de $2017, p=7 \ldots$. . . . . . . . 98

34 Comparação da configuração da malha entre a abordagem de horizonte fixo e rolante do modelo multi-período em junho de 2017, $p=8$.

35 Comparação da configuração da malha entre a abordagem de horizonte fixo e rolante do modelo multi-período em setembro de $2017, p=11$. . . . . 
36 Comparação da configuração da malha entre a abordagem de horizonte fixo e rolante do modelo multi-período em dezembro de 2017, $p=14$. . . . . . 99

37 Demanda agregada por clusters. . . . . . . . . . . . . . . . . 100

38 Variação dos custos totais pela distância de cobertura. . . . . . . . . . . . . 101

39 Variação na distância total percorrida pela distância de cobertura. . . . . . . 102

40 Variação na quantidade de armazéns média operando por período pela distância de cobertura . . . . . . . . . . . . . . . . . . . 103

41 Quantidade de armazéns operando para cada período do horizonte de 15 meses variando a restrição de cobertura. . . . . . . . . . . . . . . . . . . . 104

42 Instância de teste para modelo reduzido . . . . . . . . . . . . . . 128

43 Instância de teste para modelo reduzido . . . . . . . . . . . . . . . 129 


\section{LISTA DE TABELAS}

1 Características de desastres de origens naturais e antropogênicas. . . . . . 25

2 Classificação dos trabalhos selecionados quanto aos eventos analisados. . 41

3 Tabela de classificação dos trabalhos selecionados quanto as características da modelagem. . . . . . . . . . . . . . . . . . . . 42

4 Lista de conjuntos do modelo de localização. . . . . . . . . . . . . . . . . . 53

$5 \quad$ Lista de parâmetros do modelo de localização. . . . . . . . . . . . . . . . . 54

6 Lista de variáveis do modelo de localização. . . . . . . . . . . . . . . . . 55

7 Lista de conjuntos do modelo de agrupamento de campos. . . . . . . . . 56

8 Lista de parâmetros do modelo de agrupamento de campos. . . . . . . . . 57

$9 \quad$ Lista de variáveis do modelo de agrupamento de campos. . . . . . . . . . . 57

10 Categorização dos kits distribuídos. . . . . . . . . . . . . . . . . 60

11 Distância máxima obtida entre local candidato para instalação do armazém do agrupamento e seus respectivos campos integrantes. . . . . . . . . . . . 75

12 Distância total entre arcos da rede de distribuição formada. . . . . . . . . . 76

13 Comparação entre custos da malha atual otimizada e custos da malha proposta no estudo otimizada para os 15 meses de demanda. . . . . . . . . . . . 83

14 Economia por agência gerada pela adoção da nova estrutura de distribuição. 84

15 Legenda para leitura dos mapas comparativos entre horizonte fixo e rolante. 96

16 Lista de conjuntos do modelo de localização descentralizado. . . . . . . . . . 112

17 Lista de parâmetros do modelo de localização descentralizado. . . . . . . . . 113

18 Lista de variáveis do modelo de localização descentralizado. . . . . . . . . . . 114

19 Lista de conjuntos do modelo de localização estático. . . . . . . . . . . . . 115

20 Lista de parâmetros do modelo de localização estático. . . . . . . . . . . 116

21 Lista de variáveis do modelo de localização estático. . . . . . . . . . . . . . 116 
22 Listagem das coordenadas dos campos planejados. . . . . . . . . . . . . . . 118

23 Tabela 23 Lista de campos planejados durante a operação de resposta e suas respectivas ocupações durante o horizonte de análise. . . . . . . . . . 122 


\section{SUMÁRIO}

1 Introdução $\quad 15$

1.1 Contextualização . . . . . . . . . . . . . . . . . 16

1.2 Delimitação do problema . . . . . . . . . . . . . . . . . . . . . 19

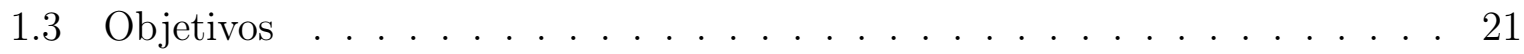

1.4 Organização do trabalho . . . . . . . . . . . . . . . . . . . 22

2 Revisão da Literatura 23

2.1 Definições e tendências em desastres . . . . . . . . . . . . . . . 23

2.2 Cadeias de distribuição humanitárias . . . . . . . . . . . . . . . 26

2.3 Problema de Localização de Instalações . . . . . . . . . . . . . . . . . . . . 28

2.3.1 Taxonomia em modelos de localização . . . . . . . . . . . . . . . 29

2.3.2 Modelos clássicos de localização de instalações . . . . . . . . . . . . . 31

2.3.2.1 Problemas de cobertura . . . . . . . . . . . . . . 31

2.3.2.2 Problema de $P$-centros . . . . . . . . . . . . . . . . 33

2.3.2.3 Problema de $P$-medianas . . . . . . . . . . . . . 35

2.3.2.4 Problemas de localização de instalações de cobrança fixa . 36

2.3.2.5 Extensões dos modelos de localização . . . . . . . . . . . . 38

2.3.3 Problemas de localização em logística humanitária . . . . . . . . . . . 39

3 Metodologia

4 Modelagem do Problema 48

4.1 Descrição da Operação Logística . . . . . . . . . . . . . . . . . . 48

4.2 Considerações e pressupostos . . . . . . . . . . . . . . . . . 50

4.3 Modelo de localização de armazéns multi-período . . . . . . . . . . . . . . 52 
4.3.1 Linearização do modelo de localização . . . . . . . . . . . . . . . 56

4.4 Modelo de agrupamento de campos . . . . . . . . . . . . . . . 56

4.5 Estratégias de solução . . . . . . . . . . . . . . . . . . . . . . 58

5 Análise e Preparação de Dados $\quad 60$

5.1 Produtos distribuídos aos beneficiários . . . . . . . . . . . . . . . 60

5.2 Levantamento dos nós da malha logística e demandas . . . . . . . . . . . 61

5.2.1 Determinação dos parâmetros de distância . . . . . . . . . . . . . . 65

5.2.2 Locais candidatos para armazenagem pública e agrupamentos de campos ......................... 66

5.3 Níveis de capacidade e tipos de instalações . . . . . . . . . . . . . . . . 68

5.4 Determinação dos custos logísticos . . . . . . . . . . . . . . . . . . 69

5.4.1 Custos de abertura ou incremento de capacidade . . . . . . . . . . 70

5.4.2 Custos de desativação ou decréscimo de capacidade . . . . . . . . . 71

5.4 .3 Custos de operação . . . . . . . . . . . . . . . . . . . 72

5.4 .4 Custos de Transporte . . . . . . . . . . . . . . . 73

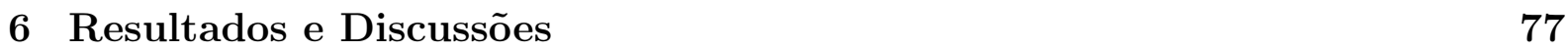

6.1 Impacto da adoção da estratégia de compartilhamento de recursos . . . . 78

6.2 Comparativo entre modelo estático e multi-período f . . . . . . . . . . 87

6.3 Comparativo entre horizontes fixo e rolante . . . . . . . . . . . . . . . . 91

6.4 Impacto da restrição de distância máxima na localização das instalações . . 100

7 Conclusões e Trabalhos Futuros

Referências

A.1 Modelagem matemática da malha logística descentralizada . . . . . . . . 112 
A.2 Modelagem matemática do horizonte estático . . . . . . . . . . . . . 115

A.3 Dados da rede de distribuição de insumos de ajuda humanitária . . . . . . 118

A.4 Verificação do modelo matemático . . . . . . . . . . . . . . . . . . . 128 


\section{INTRODUÇÃO}

Decisões sobre localização são críticas ao planejamento estratégico das organizações, sendo suas variações e aplicações amplas e com impacto direto no desempenho organizacional. Tratam-se de decisões com elevados custos associados e alta inércia, devido aos investimentos mobilizados para a construção de instalações e ou reposicionamento de estruturas.

Estas características fazem com que o impacto das decisões de localização sejam sentidos a longo prazo, de forma que deve-se considerar diversos fatores no processo decisório quanto a localização de instalações. A configuração deve atender não somente a condições atuais, mas deve ser robusta o suficiente para ainda se manter eficiente frente a mudanças no ambiente. São diversos os fatores que influenciam a configuração de malha logística como fatores ambientais, legais, políticos, mudanças no perfil e localização do mercado consumidor, tendências de mercado, entre outros.

Portanto, esta dissertação aprofunda-se no desenvolvimento de abordagens direcionadas à otimização de cadeias de suprimentos humanitárias. Através da modelagem matemática e tendo como objeto de estudo a crise humanitária do Iraque durante o período de outubro de 2016 e dezembro de 2017, ocasionada pelos eventos descritos nas seções subsequentes, pretende-se resolver o problema de localização e designação de instalações adotando múltiplos períodos e uma estratégia colaborativa de distribuição de itens de alívio.

O capítulo de introdução destina-se a uma breve apresentação do problema estudado, em que são analisados o conflito armado do estudo de caso, os deslocamentos de indivíduos no Iraque, as principais causas para o retardamento do retorno das famílias deslocadas, uma breve explicação sobre a operação logística estabelecida que suporta a operação de alívio, a delimitação do problema e os objetivos do trabalho. 


\subsection{Contextualização}

No ano de 2014, a forças do Estado Islâmico do Iraque e do Levante, também conhecido pelos acrônimos inglês ISIS ou ISIL, capturaram quase um terço do território Iraquiano. Em junho daquele ano, a cidade de Mosul, segunda maior do país e de maioria sunita, cerca de 1,4 milhões, foi conquistada (UN-HABITAT, 2016), e um novo califado foi anunciado pelo grupo extremista, responsável por inúmeros massacres enquanto detinha o controle da região.

A Guerra Civil do Iraque (2014-2017) resultou em um grave desastre humanitário, com mais de 60.000 mortes (ICB, 2019) e em mais de três milhões de pessoas deslocadas internamente (IOM, 2019). Em 10 de setembro de 2014, os EUA anunciaram a formação de uma ampla coalizão internacional para derrotar o Estado Islâmico do Iraque e da Síria (ISIS).

No período de 2015 a 2016, as Forças de Segurança do Iraque (ISF), grupos militantes e forças curdas, chamadas Peshmerga, contestaram o ISIS, retomando cidades iraqueinas como Tikrit, localizada a sudoeste de Mosul. Em outubro de 2016 forças Iraquianas e Curdas, apoiadas por uma coalizão internacional liderada pelos EUA iniciaram a luta contra o Levante (ISIS) pela retomada de Mosul. Mais de 30.000 combatentes participaram da campanha durante todo o período de reconquista, que durou 9 meses e provocou o deslocamento de mais de 94.000 cidadãos da cidade.

A expectativa de duração da Batalha de Mosul, iniciada no dia 16 de outubro de 2016, era de 3 meses. Em novembro daquele ano, um porta voz da coalizão anunciou que a ofensiva estava "adiantada", mas no mês de dezembro a batalha já apresentava impasses operacionais. O combate às forças do ISIS se estendeu até julho de 2017, cada vez mais intensa. E, embora a declaração de vitória tenha sido emitida no dia 9 de julho, combates isolados ainda perduraram por duas semanas. Uma das lições aprendidas sobre o combate é a de que em uma ofensiva a dificuldade aumenta a medida que a duração da operação se prolonga (ARNOLD; FIORE, 2019).

Arnold e Fiore (2019) dividem a ofensiva em três fases, observadas na Figura 1, em que pode se observar o avanço das frentes de batalha ao longo do período e que áreas foram reconquistadas durantes as três fases. No começo da batalha as forças combatentes estavam a $40 \mathrm{~km}$ de al-Nuri Mosque, localizada na região central da cidade. Uma semana após seu início essa distância se reduz para 20km, e em mais duas semanas essa distância passou a ser de $10 \mathrm{~km}$. A medida que as tropas adentravam a cidade essa taxa de avanço 
se desacelerava, chegando a apenas alguns metros nos estágios finais da operação.

Figura 1: Avanço da batalha: Fases da ofensiva.

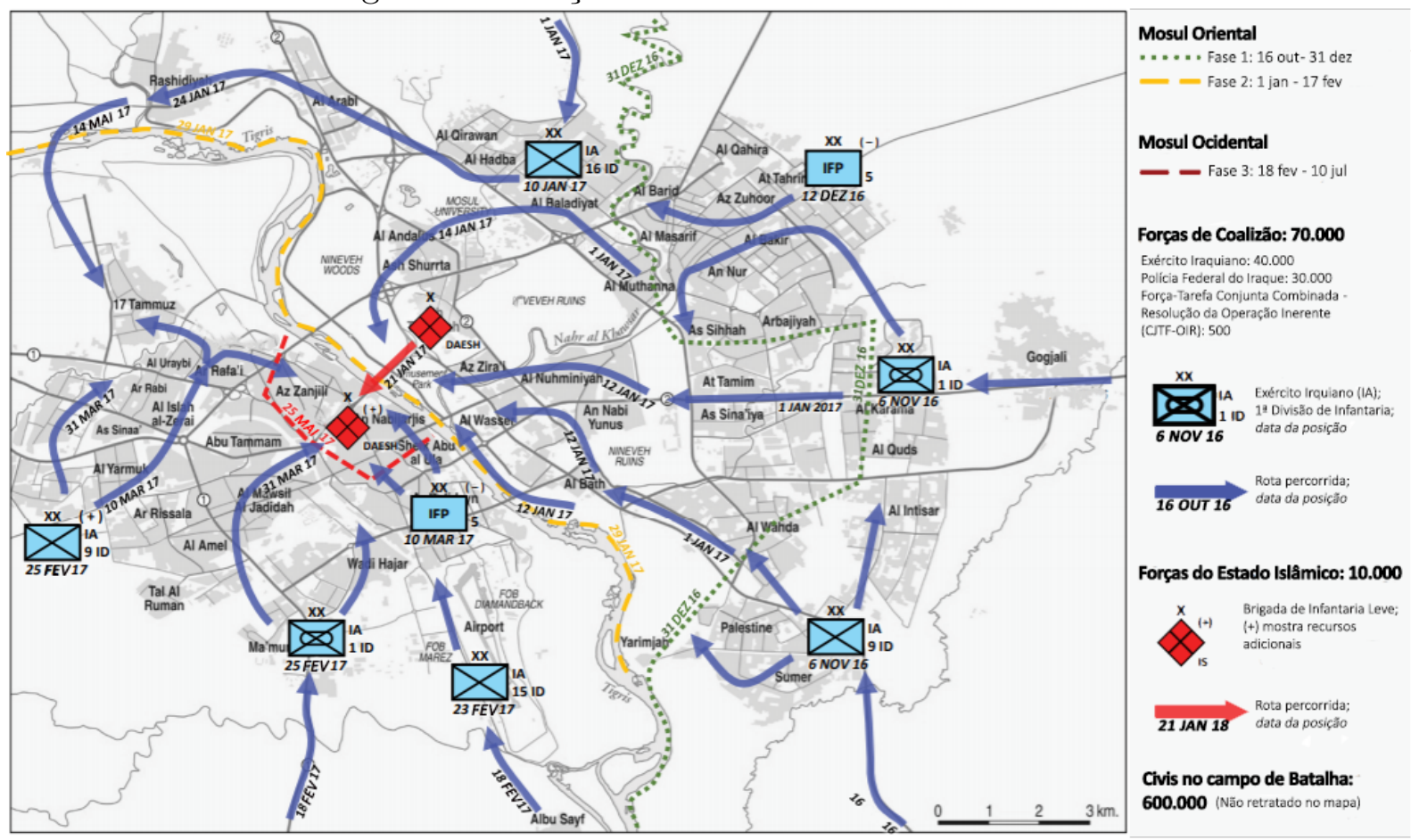

Fonte: Adaptado de Arnold e Fiore (2019)

$\mathrm{Na}$ primeira fase, tropas do exército iraquiano entraram nos arredores do leste de Mosul (porção a leste do rio Tigre) no início de novembro. Alguns dias depois, outras duas divisões do exército iraquiano atacaram ao sul e norte da cidade. Ao fim do mês, as forças combatentes já haviam retomado $30 \%$ de Mosul, na porção leste do rio Tigres.

No início de dezembro de 2016, forças de operações especiais da Polícia Federal do Iraque atacaram a porção leste da cidade. Ao final desse mês as forças iraquianas realizaram uma pausa na ofensiva para a recomposição das tropas. Em seguida, no mês de janeiro de 2017, as forças iraquianas continuaram avançando em três direções, segunda fase, gerando reações agressivas por parte do ISIS. O grupo terrorista tomou posse de uma das estradas estratégicas que liga Mosul a Bagdá, porém no mesmo mês o exército iraquiano retomou o controle da via e anunciou que detinha o controle de $85 \%$ do leste de Mosul.

Ao final de janeiro o governo anunciou a liberação total da porção leste da cidade dando início à terceira fase no dia 19 de fevereiro, momento em que al-Abadi (PrimerioMinisto do Iraque) anuncia a nova fase para recuperação da parcela ocidental da cidade. Os combates se intensificaram em março, com o adentramento das forças da coalizão e reconquista ocorrendo lentamente. As forças do estado islâmico foram gradativamente 
sendo pressionadas e cercadas no centro da cidade até a declaração de vitória, emitida pelo Comando de Operações Conjuntas no mês de julho.

Figura 2: Número de deslocados internos e indivíduos em retorno ao longo do tempo.

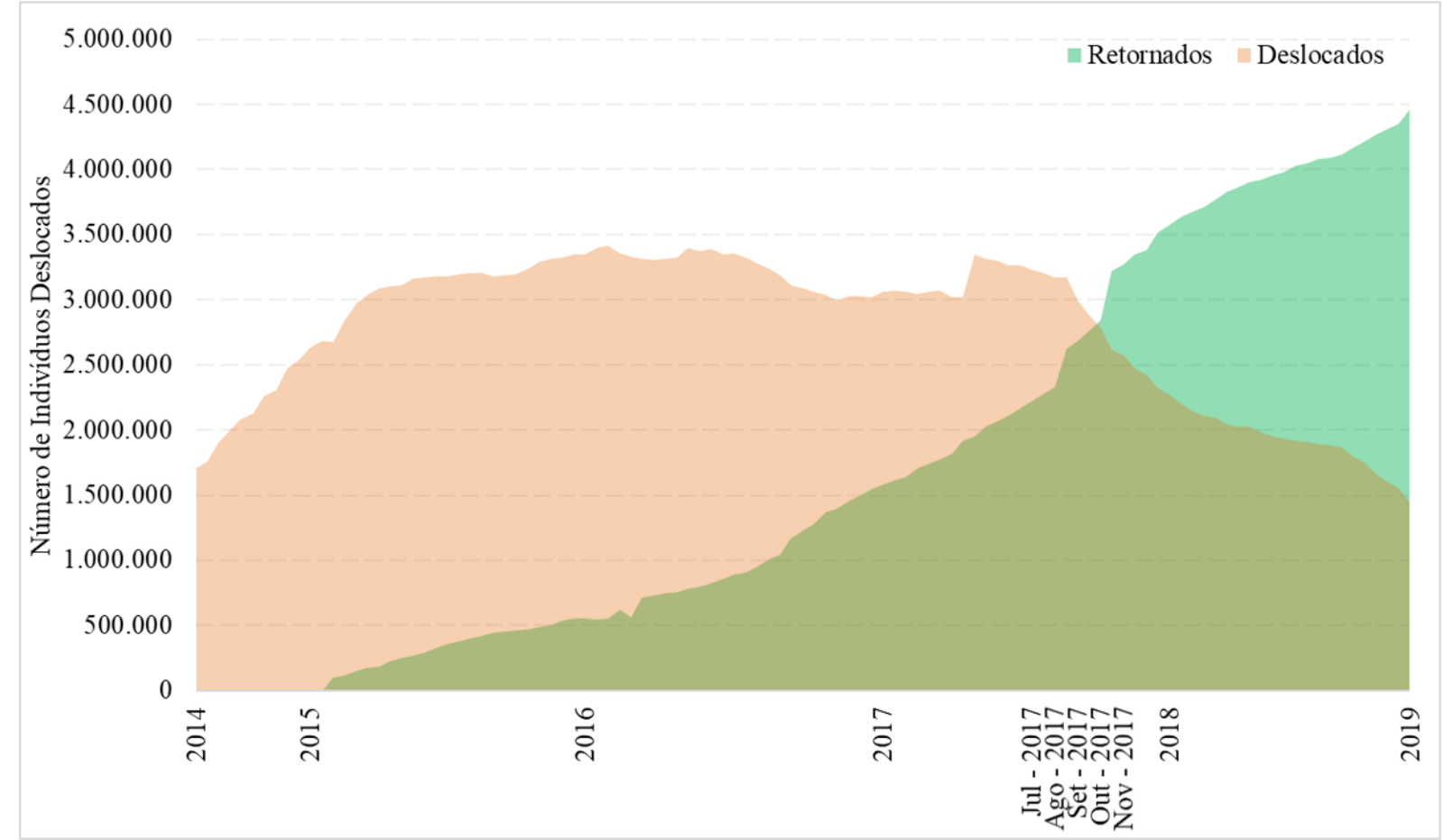

Fonte: Adaptado de IOM (2019).

A enorme quantidade de habitações e estruturas danificadas durante o combate foi um dos efeitos colaterais da crise do Estado Islâmico no Iraque (The New York Times, 2017). E estima-se que cerca de 1,3 milhões de indivíduos ainda permanecem em deslocamento devido ao conflito (IOM, 2020).

O padrão de retorno de pessoas com residências danificadas varia de acordo com o tipo de dano e o período em que o dano ocorreu (antes, durante ou depois do confronto direto). De acordo com os achados do estudo de Aymerich e Zeyneloglu (2019) o retorno da segurança no local de origem foi um motivo para retorno, e a sua ausência e presença de grupos de origem étnicas, religiosas ou tribais diferentes foram fatores de motivação para a permanência em deslocamento. Dessa forma, o fim do conflito não significou o término da operação humanitária, ainda estabelecida na região.

As Figuras 2 e 3 apresentam o valor de deslocados ao longo dos anos no Iraque e a ocupação dos campos de deslocados levantados nestas dissertação. Através de ambos, pode-se observar que a redução no número de pessoas em deslocamento é morosa. Ao final de julho de 2017, próximo ao término do conflito, existe uma diminuição do valor acumulado de deslocado. Entretanto, o declínio com maior expressividade só se inicia em 
outubro de 2017, Figura 2.

Figura 3: Ocupação nos campos de deslocados levantados no estudo.

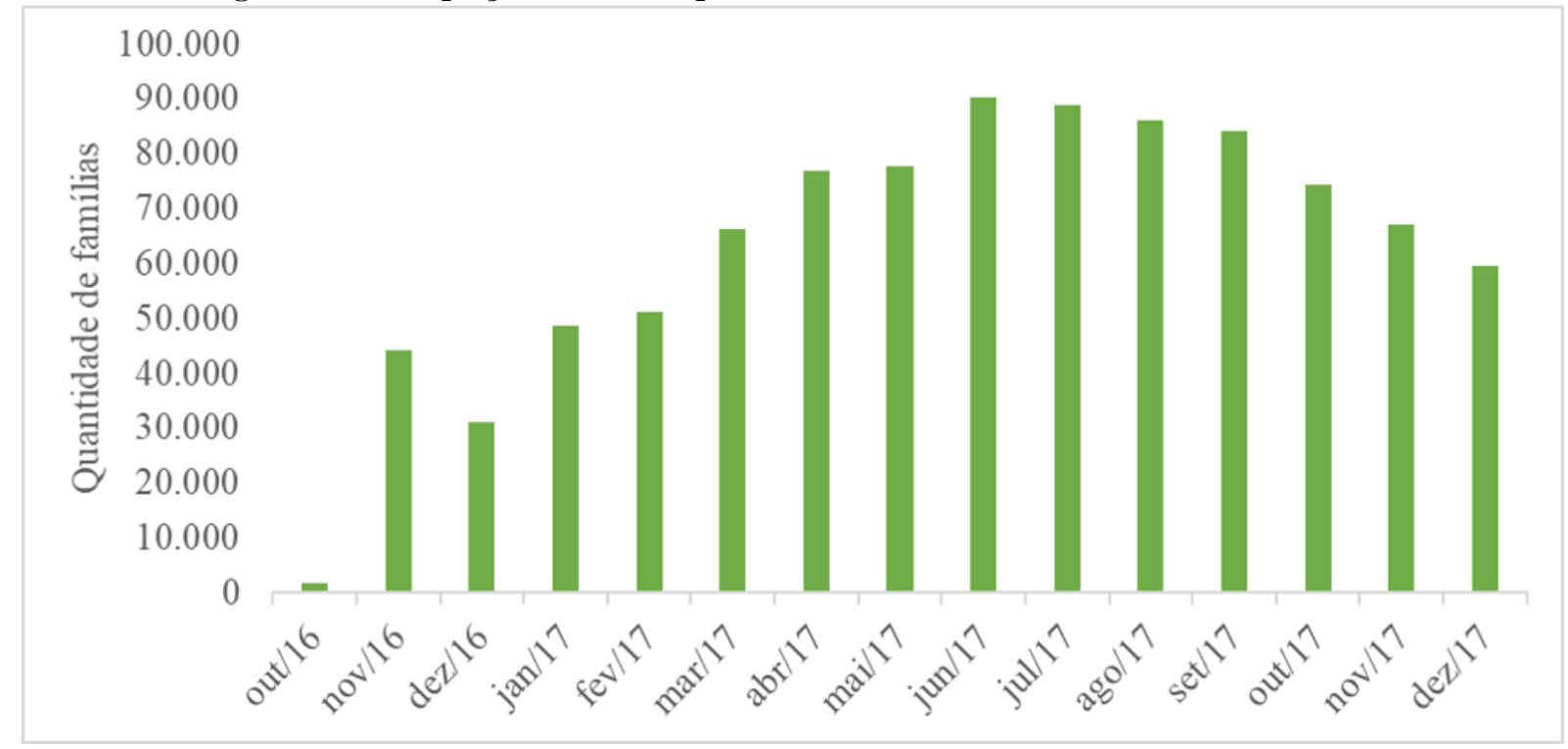

Fonte: Adaptado de ReliefWeb (2017) e CCCM Cluster (2017).

\subsection{Delimitação do problema}

O trabalho foca no projeto de malha logística para o posicionamento de estoques de itens de alívio humanitário através de uma abordagem de cooperação entre agências humanitárias nos estágios de preparação e resposta a emergências complexas no Curdistão Iraquiano.

A região é marcada por um histórico de conflitos armados, guerras e disputas entre grupos étnicos e a estratégia de armazenagem colaborativa e o compartilhamento de recursos podem proporcionar ganhos de escala sem o comprometimento da demanda coberta.

Outro ponto a ser destacado é a instabilidade inerente às emergências complexas, que costumam perdurar e causar sofrimento a população por longos períodos. No caso estudado tinha-se uma expectativa de retomada rápida do território iraquiano, mas que foi frustrada se estendendo ao longo de meses. O padrão de evacuação e ocupação dos campos acompanha a operação de retomada como pode ser observado nas Figuras 4 e 5, em que a demanda aumenta conforme a intensificação dos ataques. Ao fim da guerra este valor sofre um decréscimo, além de das alterações nos padrões de ocorrência geográficas ao longo do período.

A dinâmica do ambiente exige que a cadeia estabelecida seja flexível com a evolução 
Figura 4: Variação na demanda dos campos de outubro de 2016 à esquerda, e fevereiro de 2017 à direita.
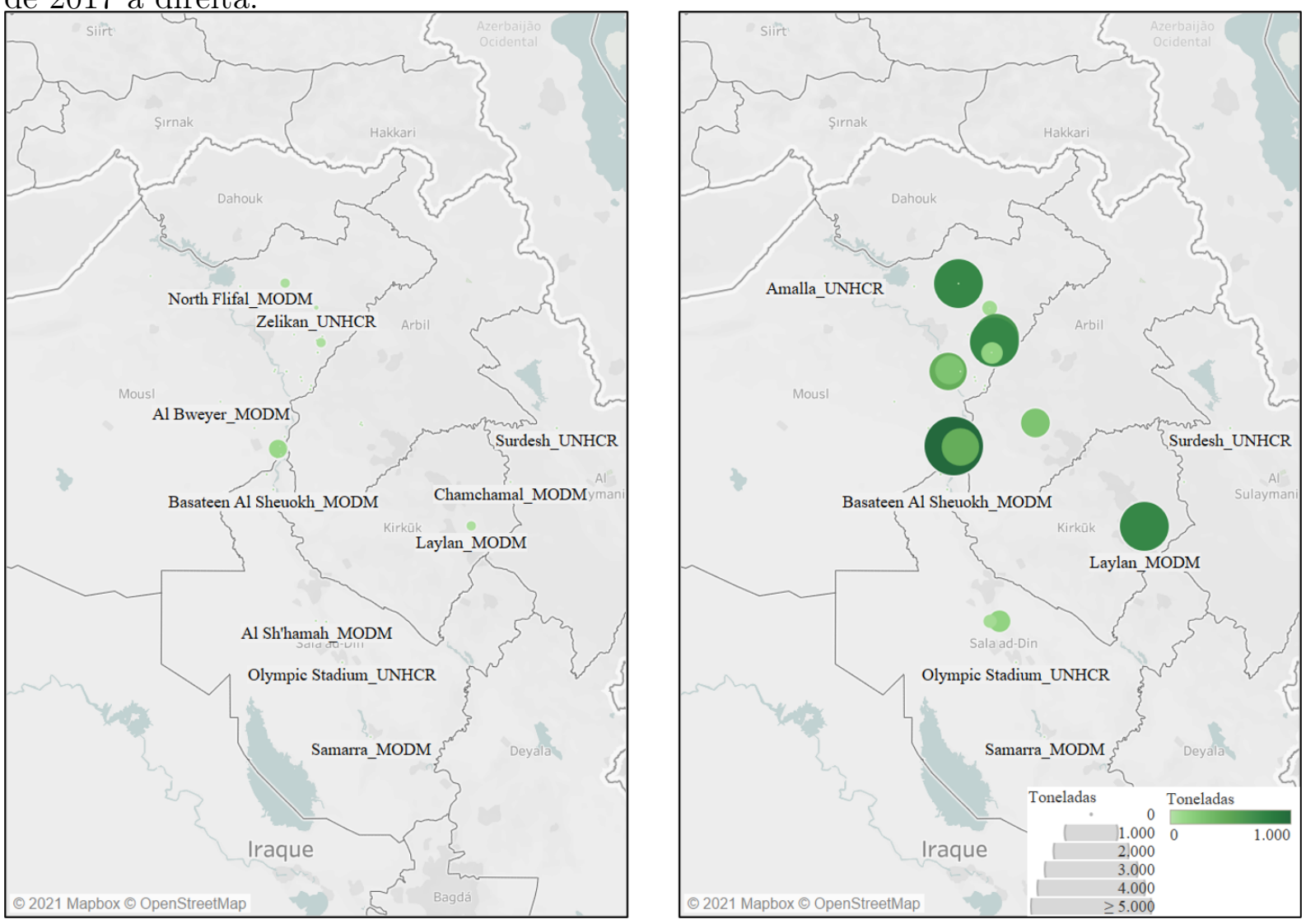

Fonte: Elaboração própria.

dos eventos, visando a redução dos custos sem o prejuízo a qualidade no nível de serviço aos beneficiários. Dessa forma, deve-se verificar como a evolução do desastre impacta as decisões sobre configuração da rede e atribuições das demandas ao longo do período analisado.

A proposta de preposicionamento colaborativo, então, apresenta uma abordagem destinada ao planejamento estratégico da capacidade de resposta em diferentes períodos. Mais especificamente o projeto da malha logística colaborativa determina i) o número e a localização dos armazéns estabelecidos no Iraque, ii) a capacidade dos armazéns instalados em cada período, iii) as decisões de expansão ou redução das capacidades instaladas, iv) o custo total empregado na instalação do armazéns, sua operação e transporte de insumos, v) a alocação dos campos aos armazéns compartilhados, e vi) a decisão sobre os tipos de instalações empregadas na rede. 
Figura 5: Variação na demanda dos campos de agosto de 2017 à esquerda, e dezembro de 2017 à direita.
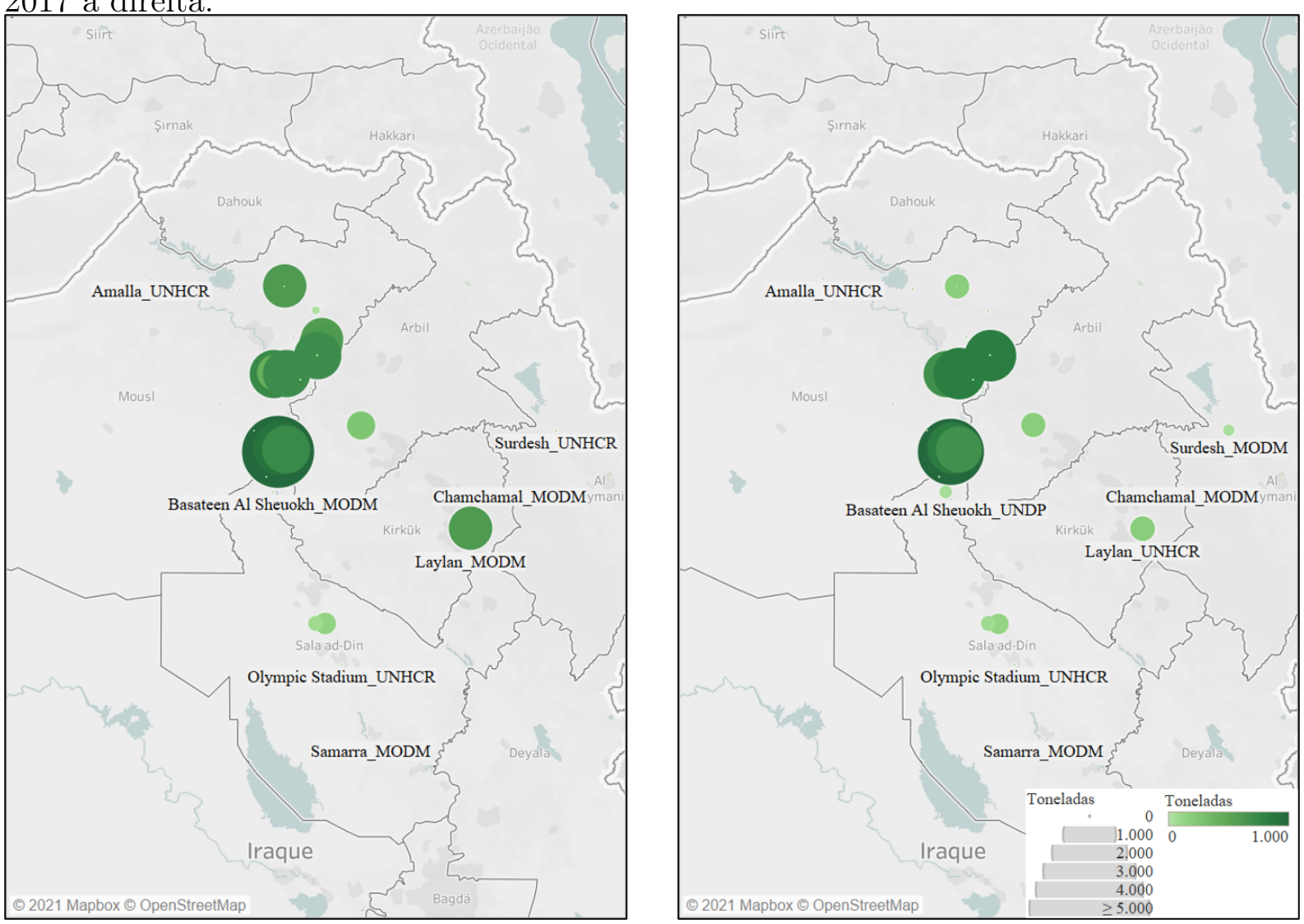

Fonte: Elaboração própria.

\subsection{Objetivos}

Portanto, este estudo objetiva a proposição e implementação de um modelo matemático de localização de instalações destinadas a operações humanitárias na fase de resposta e recuperação de emergências complexas. Embora o modelo seja aplicado a um caso específico, deseja-se proporcionar uma abordagem para a tomada de decisões em outros eventos de natureza similar.

Dessa forma, o objetivo principal do estudo é desenvolver uma modelagem flexível, capaz de determinar a configuração da malha logística ideal que minimize o custo total das operações logísticas da cadeia de suprimentos humanitária do Iraque, considerando múltiplos períodos e a cooperação inter-agência. Além de ser capaz de responder a algumas questões recorrentes no processo decisão quanto a localização de instalações:

- Quantas instalações devem ser instaladas?

- Onde deve-se localizar estas instalações? 
- Que tipos e tamanhos de instalação devem ser localizadas?

- Quando estas instalações devem ser instaladas?

Para atingir o objetivo geral desta pesquisa os seguintes objetivos específicos também devem ser avaliados:

- aplicar em um caso real a fim de demostrar a generalização do modelo matemático construído;

- avaliar os potencias ganhos da cooperação em ambientes humanitários;

- verificar a adequação da abordagem de múltiplos períodos ao planejamento estratégico humanitário para determinação de malhas flexíveis e responsivas;

- verificar o impacto do nível de serviço nas decisões de localização e por consequência na configuração da malha logística;

- avaliar o emprego do modelo sob a estratégia de horizontes rolantes de planejamento;

- desenvolver uma abordagem para determinação dos agrupamentos de campos para o compartilhamento de recursos.

\subsection{Organização do trabalho}

Esta dissertação organiza-se em 6 capítulos, o Capítulo 1 compreende a introdução, o Capítulo 2 apresenta conceitos relativos a logística humanitária e trabalhos encontrados na literatura que abordam problemas de localização de instalações em logística humanitária e múltiplos períodos. O Capítulo 3 apresenta a metodologia adotada para o desenvolvimento desta dissertação. No Capítulo 4 é descrita a formulação matemática e a estratégia de solução proposta, enquanto no Capítulo 5 é apresentada a preparação dos dados utilizados no estudo. O Capítulo 6 destina-se a apresentam dos resultados obtidos e análises realizadas. Por fim, o Capítulo 7 apresenta as considerações finais e perspectivas de trabalhos futuros. 


\section{REVISÃO DA LITERATURA}

O capítulo de revisão da literatura destina-se ao estabelecimento de conceitos e definições em que esta dissertação se ancora, de forma que o entendimento dos tópicos abordados é fundamental para o desenvolvimento do trabalho. Além disso, através da investigação do estado-da-arte, procura-se localizar o presente trabalho quanto a sua relevância acadêmica e oportunidades de desenvolvimento de estudos nos campos de conhecimento de pesquisa operacional e logística humanitária.

\subsection{Definições e tendências em desastres}

Vivencia-se uma tendência no crescimento de desastres em todo o mundo, assim como suas consequências devastadoras (EM-DAT, 2018). Esta situação se intensifica devido ao aumento na ocorrência de populações em áreas ou situações de risco. Assim como o aumento no número de eventos catastróficos, também existe um aumento na quantidade de pessoas expostas a tais eventos. Alguns autores afirmam que desastres ocorrem quando os mecanismos de enfrentamento das comunidades são parciais ou completamente destruídos, levando a incapacidade de reação aos riscos naturais ou provocados pelo homem, tornando comunidades vulneráveis ao sofrimento (Logistic Cluster, 2015).

A literatura existente sobre desastres procura categorizá-los quanto a suas características de evolução e seus fatores desencadeadores. Assim, os desastres podem ser divididos quanto a característica de início do evento como de início lento ou rápido (Logistic Cluster, 2015). Nas Emergências de início lento as organizações e governos são capazes de adotar medidas de mitigação dos efeitos do desastre, a fim de melhor se prepararem para o momento em que o evento ocorrer. Fato que deve contribuir para a redução no impacto causado à comunidade. Caso o evento ocorra, as entidades humanitárias e governos serão capazes de fornecer suprimentos e se coordenarão em tempo hábil, através das medidas de posicionamento prévio e mecanismos de coordenação.

As emergências de início súbito ou rápido se concentram nas etapas de resposta e 
Figura 6: Ciclo de vida dos desastres.

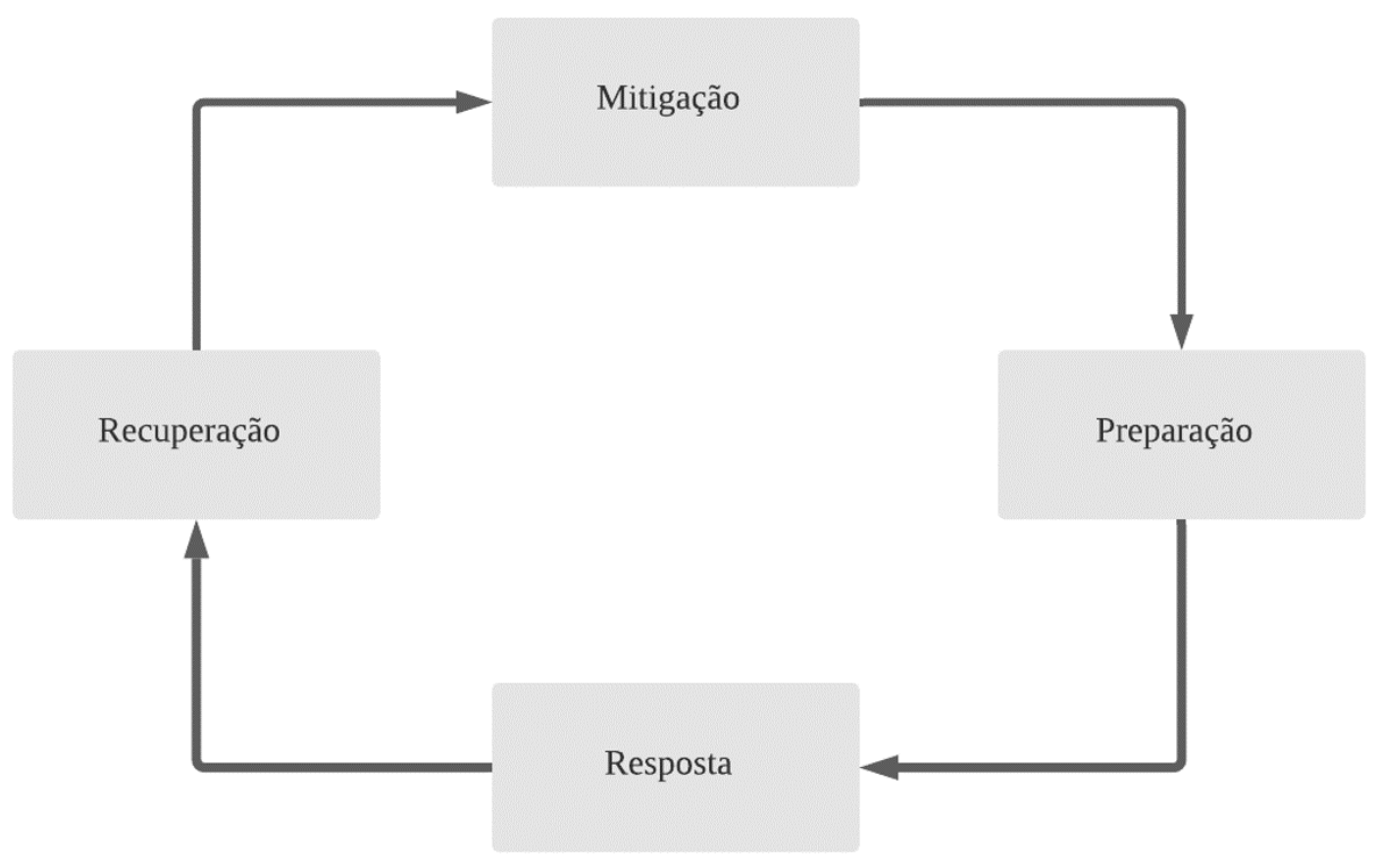

Fonte: Extraído de (FEMA, 2019).

recuperação do diagrama da Figura 6. O tempo de preparação é curto e a intervenção muito reativa. As atividades humanitárias se iniciam para responder às necessidades imediatas concomitantemente ao planejamento e preparação para o longo prazo. Esta categoria de desastre tem aumentado em termos de frequência, complexidade, escopo e capacidade destrutiva.

Quanto aos fatores causadores, os desastres se classificam quanto a natureza de origem do evento em naturais ou antropogênicos, isto é, provocados pelo homem (IFRC, 2019). Os desastres provocados pelo homem abrangem desastres que se resultam das atividades humanas, como degradação ambiental, poluição e acidentes (IFRC, 2019). Esta categoria ainda inclui desastres sócio-naturais, tecnológicos e aqueles que podem surgir das relações dentro de comunidades, também denominados emergências complexas. Os desastres socionaturais são resultado de uma combinação de fatores naturais e antropogênicos, os tecnológicos são originados de condições tecnológicas ou industriais incluindo acidentes, procedimentos perigosos etc., e podem surgir diretamente como resultado dos impactos de um perigo natural. (UNISDR, 2017). A tabela 1 apresenta exemplos de desastres naturais e antropogênicos e os classifica quanto a previsibilidade, impacto e extensão geográfica dos desastres. Observa-se que aqueles do tipo conflito armado, definidos também como emergências complexas, são classificados como de natureza antropogênica, possuem média 
capacidade de previsão, alto impacto e abrangência multinacional, isto é, a evolução dos eventos pode desencadear o envolvimento de múltiplas entidades e nações.

Tabela 1: Características de desastres de origens naturais e antropogênicas.

\begin{tabular}{lcccc}
\hline Tipo de desastre & Origem & Capacidade de previsão & Impacto potencial & Extensão geográfica \\
\hline Terremoto & Natural & Baixa & Alto & Dispersa (nacional) \\
Tsunami & Natural & Baixa & Alto & Dispersa (multinacional) \\
Tempestade ou furacão & Natural & Média & Médio/Alto & Dispersa (nacional) \\
Erupção vulcânica & Natural & Média & Alto & Dispersa \\
Pandemias & Ambos & Baixa & Alto & Dispersa (global) \\
Ataque terrorista & Antropogênica & Média & Médio & Local \\
Acidente de transporte & Antropogênica & Baixa & Médio & Local \\
Conflito armado & Antropogênica & Média & Alto & Dispersa (multinacional) \\
Deslizamento de terra & Natural & Média & Baixo & Local \\
Avalanche & Natural & Média & Baixo & Local \\
Acidente químico & Antropogênica & Baixa & Médio & Local \\
Acidente Nuclear & Antropogênica & Baixa & Alto & Dispersa (multinacional) \\
\hline
\end{tabular}

Fonte: Adaptado de Baldini et al. (2012).

As emergências complexas são situações de ruptura dos meios de subsistência e ameaças a vida, produzidas por conflitos externos ou internos, distúrbios civis e deslocamentos de populações em grande escala, em que o ambiente da resposta à emergência apresenta dificuldades políticas e de segurança, violência extensiva e danos generalizados à sociedade e à economia (WHO, 2019). A IASC (Inter-Agency Standing Committee) ainda as considera crises em que há uma quebra total ou considerável de autoridades em um país, região ou sociedade, resultando em conflitos internos e externos. Vale ressaltar que a terminologia da UNISDR não inclui conflitos armados e outras situações de instabilidade ou tensão social que estão sujeitas ao direito internacional humanitário e à legislação nacional em sua classificação de desastres.

O Logistic Cluster (2015) define que as características prováveis de uma emergência complexa incluem: um grande número de vítimas civis, populações situadas ou deslocadas, sofrimento humano em grande escala; muitas vezes é necessária uma assistência internacional substancial e a resposta vai além do mandato ou da capacidade de qualquer agência; a prestação de assistência humanitária é muitas vezes impedida pelas partes no conflito; e os riscos de segurança para trabalhadores humanitários que prestam assistência humanitária são altos, cada vez mais os trabalhadores humanitários estão sendo alvejados pelas partes no conflito.

Uma das principais causas geradoras de indivíduos em sofrimento na última década 
têm sido os conflitos armados. Segundo o Escritório das Nações Unidas para a Coordenação de Assuntos Humanitários (OCHA, 2019), o número de conflitos políticos no mundo tem aumentado desde o ano de 2006, que apresentou 278 conflitos, enquanto no ano de 2016 o número se elevou para 402 conflitos. Pettersson e Eck (2018), Dupuy e Rustad (2018) realizaram um levantamento quanto ao número de conflitos armados no mundo desde o ano de 1946, dividindo-os em quatro categorias. Os autores revelam a predominância de conflitos internos a um estado, embora muitas vezes envolvam atores estatais externos. Os dados do estudo são de conflitos militares organizados em um governo ou território envolvendo um ou mais governos estatais, que causaram pelo menos 25 mortes relacionadas a batalhas em um ano. Dessa forma, segundo a classificação adotada pelos autores, foram identificados 285 conflitos armados distintos desde o ano de 1946.

De acordo com os dados e tendências humanitárias mundiais de 2017 apresentados pela OCHA, cerca de $97 \%$ das operações humanitárias estavam destinadas ao acolhimento de pessoas em necessidade devido a causas complexas na última década. No ano de 2016 o número de indivíduos deslocados à força, por violência e conflitos atingiu 65,6 milhões de pessoas (OCHA, 2019), em sua maioria indivíduos do Afeganistão, Somália, Sudão do Sul e Síria. A vulnerabilidade de pessoas afetadas pela guerra ou conflitos armados é um tópico atual. Segundo a UNHCR (2019) o número de pessoas forçadas a se deslocar no mundo atingiu seu patamar mais elevado, desde a Segunda Guerra Mundial.

\subsection{Cadeias de distribuição humanitárias}

As operações de apoio humanitário surgem em resposta às necessidades da população afetada por desastres, chamados beneficiários. As organizações humanitárias não só provém produtos e serviços como alimentos, abrigo, cuidados com a saúde, mas também em conjunto com as agências de desenvolvimento contribuem para o desenvolvimento a longo prazo das sociedades, engajadas na reconstrução pós-desastre e no alívio, reabilitação e desenvolvimento (ZAREI; CARRASCO-GALLEGO; RONCHI, 2019). Proporcionar itens que aliviam e desenvolvem os beneficiários, para Zarei, Carrasco-Gallego e Ronchi (2019), envolve diversos desafios logísticos atrelados a incerteza e características atípicas do contexto humanitário.

As tendências no número e impacto dos desastres e a enorme escala dos esforços de assistência global chamam a atenção para a necessidade de operações eficazes e eficientes de resposta a desastres. É neste contexto que emergem as cadeias de suprimentos humanitárias. São cadeias dinâmicas e ágeis, e vêm ganhando a atenção de pesquisadores nos 
últimos anos. Leiras et al. (2014) realizaram uma pesquisa bibliográfica sobre o tema e constataram o aumento na publicação de artigos acadêmicos ligados a operações de alívio humanitário.

Kovacs e Spens (2012) afirmam que cadeias de suprimento de alívio são responsáveis pela resposta de mais de 500 desastres anualmente, que resultam em cerca de 75000 mortes e 200 milhões de afetados. Além disso, os custos das cadeias representam mais de $80 \%$ dos custos empregados em qualquer operação de socorro (SAHAY; GUPTA; Vinod Chandra Menon, 2015; KOVACS; SPENS, 2012).

O sistema de auxílio humanitário envolve muitos atores e stakeholders (beneficiários, governos locais e internacionais, organizações humanitárias, etc) e opera em um ambiente de alta incerteza e dinamicidade. As atividades de preparação e resposta das agências humanitárias variam de contexto para contexto dependendo das características e fatores de desencadeamento de cada crise. A incerteza e variabilidade no ambiente corroboram para que grande parte das decisões logísticas sejam tomadas após a ocorrência do desastre, o que exige rapidez na tomada de decisão. Em contraste a cadeias comerciais, decisões estratégicas em ambientes humanitários podem ter de ser tomadas em períodos curtos. A localização de instalações é um exemplo de decisão desta natureza, sendo um componente crítico para a preparação e resposta ao desastre, e para uma alta performance das operações.

No contexto empresarial, o gerenciamento da cadeia de suprimentos é fundamental para a redução dos custos e melhoria da competitividade das organizações, e o projeto da rede apresenta grande impacto no planejamento e performance da cadeia de suprimentos (TANCREZ; LANGE; SEMAL, 2012). Estes entendimentos podem ser estendidos ao ambiente humanitário, no qual deseja-se projetar redes com capacidade suficiente para processar todo o fluxo de itens de alívio aos beneficiários, reduzindo custos, pois cadeias humanitárias estão sujeitas a limitações de orçamento e doações. Entretanto, a maximização do nível de serviço oferecido às pessoas em sofrimento também é um objetivo, pois perdas no atendimento da demanda são fatores críticos nestas cadeias. Outros aspectos, relacionados ao nível de serviço oferecido, são a equidade e agilidade no atendimento.

Pesquisadores têm avaliado a adaptabilidade das cadeias de abastecimento comerciais ao ambiente humanitário e a viabilidade de que os mecanismos de operações e gestão da cadeia de suprimentos comercial possam ser aplicados ao ambiente humanitário, bem como o estabelecimento das divergências entre as duas cadeias. (BALCIK et al., 2009. BEAMON, 2004; KOVACS SPENS, 2007) Assim, como as cadeias comerciais, apresen- 
tam três mecanismos de gestão, que são gestão de compras, armazenagem ou estoques, e transporte. Organizações não governamentais internacionais proporcionam recursos necessários aos agentes de alívio locais e unem esforços para a operação de alívio ao desastre.

A maioria dos itens adquiridos pela cadeia humanitária ocorre após a ocorrência do desastre e são armazenados ao longo de cadeia através de pontos de estocagem intermediários. O suprimento de itens de alívio é crítico nos primeiros dias da operação, que são fornecidos por pontos de estocagem preposicionados na fase anterior ao desastre. Geralmente os pontos de estocagem preposicionados são posicionados em localizações que servem como Centros de Distribuição e tem acesso a maioria das regiões afetadas como forma de mitigação dos riscos do pós desastre.

Os centros de distribuição são com frequência geridos por organizações humanitárias que detém capital para manter os estoques a um longo período, alguns centros também podem ser estabelecidos temporariamente para oferecer suportes a operação logísticas estabelecida no pós desastre. Entretanto encontrar instalações seguras e viáveis economicamente é um desafio para a maioria das organizações humanitárias (BALCIK, BEAMON, 2008).

A gestão de transportes é fundamental na gestão da cadeia de suprimentos humanitária, pois pode ser um grande desafio realizar a implementação da operação de transporte devido a degradação da infraestrutura de transporte e a quantidade limitada de recursos. Devido ao aumento na procura por serviços de transporte ocasionados pelo desastre, os custos de transporte tendem a aumentar.

\subsection{Problema de Localização de Instalações}

Otimizar uma cadeia de suprimentos exige uma tomada de decisão eficiente, é neste sentido que os problemas de localização se tornam críticos. Tratam-se de problemas de natureza estratégica de diversos tipos de organizações, os quais abrangem decisões sobre a localização de novas instalações, redução ou realocação das instalações existentes. Esta categoria de problemas apresenta usualmente natureza de longo prazo pela necessidade de mobilização de recursos (materiais, humanos e de capital), por exemplo, para a construção de instalações.

Modelos de localização de instalações foram utilizados na literatura para selecionar ou localizar abrigos, centros de distribuição, depósitos e centros médicos, podendo determinar parâmetros como possível número de afetados, localização, capacidades, custos de 
transportes e custos fixos de operação. Estes parâmetros podem ser conhecidos e constantes ao longo do tempo, como no caso dos modelos determinísticos, que servem de base para modelos multi-período, estocásticos e robustos.

As repostas às questões apresentadas nos objetivos deste trabalho dependerão das condições e objetivos que delimitam cada problema. Em alguns casos, como em problemas de localização de postos de ambulância, deseja-se que as instalações estejam o mais próximo possível dos pontos de demanda. Em contra partida, quando se deseja localizar repositórios de resíduos radioativos procura-se por regiões geologicamente estáveis e o mais distante possível de grandes centros urbanos.

A resposta ao questionamento sobre quantidade de instalações selecionadas, assim como seu tamanho, está intimamente ligada ao trade-off entre custos e nível de serviço. A melhora na qualidade dos serviços proporcionada pelo aumento no número de instalações também é responsável pelo aumento nos custos. De forma geral, recursos financeiros são limitados, ou até mesmo escassos para certas operações, o que justifica a procura métodos capazes de gerar economias ou configurações logísticas mais eficientes dentro das limitações de recursos apresentadas.

Os modelos de localização também se concentram em questões sobre a alocação da demanda às instalações. Em alguns casos a demanda nos clientes não pode ser dividida e atendida por diferentes instalações devido a questões administrativas, em que a armazenagem dos suprimentos não pode ser divida em diferentes armazéns. Entretanto, outras situações como em serviços de atendimento móvel de urgência a demanda pode ser atendida por qualquer uma das unidades disponíveis. Os problemas de localização devem, então, refletir a diferentes políticas de alocação de demanda.

Além disso, determinar a estruturação da rede é tão importante quanto a sua reavaliação quando identificadas mudanças expressivas nos padrões de demanda, portfólio de produtos, processos de produção, estratégias de fornecimento e abastecimento, e custos das operações. A reavaliação contínua do estado da cadeia estabelece a ligação entre os modelos de localização e gerenciamento estratégico da cadeia de suprimentos.

\subsubsection{Taxonomia em modelos de localização}

Existem inúmeras variações de modelos para resolução do problema de localização, que dependerão do contexto e especificidades ao qual se aplicam. Retomando os exemplos sobre localização de ambulâncias e de armazéns em redes varejistas, é evidente a distinção 
entre as duas operações, e conseguintemente cada qual exigirá formulações específicas para atender às suas necessidades.

Dessa forma, com intuito de classificar e descrever de forma objetiva os diversos modelos de localização apresentados na literatura, alguns autores como Ballou (2007), Klose e Drexl (2005), Hall (2012), Daskin (2011) adotam taxonomias próprias para tal finalidade. Os autores possuem classificações próprias, entretanto apresentam pontos em comum em suas nomenclaturas, como quantidade de instalações, tipos de demandas, etc, que serão discutidos a seguir.

Daskin (2011) apresenta que os modelos são definidos quanto ao espaço utilizado para modelar o problema. Assim se dividiram em modelos analíticos, contínuos, em rede e discretos. Modelos analíticos correspondem a classe de modelos que podem ser resolvidos através de cálculo e técnicas simples, e em geral assumem que as demandas se distribuem continuamente no espaço. Os modelos contínuos consideram que as demandas são representadas em pontos discretos em qualquer lugar no plano. Modelos em rede realizam a representação do modelo em forma de árvore, em que as demandas surgem apenas nos nós da rede. Por fim, os modelos discretos, podem ou não utilizar distâncias em suas representações e os locais candidatos se restringem a um número finito de conjuntos de locais candidatos.

Daskin (2011) apresenta uma extensa lista de classificações que englobam por exemplo os aspectos sobre as métricas de distância adotados no modelo; número de instalações; relações com o tempo, que podem ser estáticos ou dinâmicos; variedade de produtos; setor, dividido entre privado e público; objetivo, único ou múltiplo; demanda, elástica ou inelástica; capacidade da instalação; alocação da demanda; hierarquia e desafabilidade das instalações.

Ballou (2009) classifica problemas de localização quanto a cinco aspectos, força direcionadora, número de instalações, descontinuidade das escolhas, grau de agregação dos dados e o horizonte de tempo. A força direcionadora é representada por fatores majoritariamente econômicos. Quanto ao número de instalações, o autor diferencia modelos que decidem sobre a localização de apenas uma instalação de problemas de localização de múltiplas instalações. Segundo o autor, a localização de uma única instalação evita a necessidade de se considerar forças competitivas ou a divisão das demandas. A descontinuidade de escolhas está associada as possibilidades de escolha dos locais de instalação, que podem ser contínuos ou discretos, que remete a classificação mais específica definida por Daskin (2011) sobre o espaço de modelagem. 
Para Ballou (2009), os modelos também podem ser classificados quanto ao grau de agregação, que permite o gerenciamento do problema. Isto é, o problema pode, por exemplo, representar a demanda com elevado grau de detalhamento, situação em que as demandas são representadas por regiões de uma cidade. Este modelo pode representar todas as demandas regionais de forma agregada ao nível de uma cidade. Por fim, os problemas podem ser classificados quanto ao horizonte de tempo considerado, assim podem ser de período único ou múltiplo.

\subsubsection{Modelos clássicos de localização de instalações}

Nesta seção os modelos de localização de instalações clássicos citados por Daskin (2011) são apresentados, bem como algumas extensões destes problemas.

\subsubsection{Problemas de cobertura}

Trata-se de problemas de programação linear inteira, e aplica-se a uma ampla variedade de problemas, em especial é adequado para a instalação de hospitais, locais de abrigo e de postos de atendimento de bombeiros. O objetivo do problema de cobertura é cobrir os pontos de demanda dentro dos limites de tempo e distância. Estes problemas podem se sub-dividir em problemas de Set covering e Max covering.

Os problemas de Set covering buscam a minimização do total de instalações ou do custo fixo total de abertura das instalações para a cobertura de todos os pontos de demanda. Este problema tem sido aplicado em uma gama de situações que vão desde a programação da tripulação de linhas aéreas até a seleção de ferramentas em sistemas de manufatura flexível. Este modelo, extensivamente abordado na literatura, possuí extensões para incluir uma série de objetivos secundários, que são muitas vezes importantes para a modelagem do problema de localização de instalações, como por exemplo selecionar a combinação de locais que maximiza o número de nós de demanda cobertos duas vezes entre os ótimos alternativos para o problema de Set covering. Este problema apresenta a modelagem descrita a seguir.

Parâmetros:

$$
\begin{aligned}
& a_{i j}= \begin{cases}1 & \text { se o local candidato } j \in J \text { pode atender a demanda no nó } i \in I \\
0 & \text { caso contrário }\end{cases} \\
& f_{j}=\text { custo de instalação no local candidato } j \in J
\end{aligned}
$$


Variáveis de decisão:

$$
X_{j}= \begin{cases}1 & \text { se é localizada uma instalação no local candidato } j \in J \\ 0 & \text { caso contrário }\end{cases}
$$

Tem como função objetivo:

$$
\operatorname{MIN} \sum_{j \in J} f_{j} X_{j}
$$

Sujeita a:

$$
\begin{gathered}
\sum_{j \in J} a_{i j} X_{j} \geq 1 \quad \forall i \in I \\
X_{j} \in\{0,1\} \quad \forall j \in J
\end{gathered}
$$

A função objetiva (Equação 2.1) minimiza o custo total das instalações, enquanto a Equação 2.2 estabelece que que cada nó $i \in I$ deve ser atendido por pelo menos um das instalações. Por fim, a Equação 2.3 representa a restrição de integralidade da variável $X_{j}$. Caso os custos de todas as instalações foram idênticos, a função objetiva pode ser reescrita de forma simplificada como: $\operatorname{MIN} \sum_{j \in J} X_{j}$

Um dos problemas associados ao modelo de cobertura é que o número de instalações necessárias para cobrir toda a demanda pode ser maior do que o número de instalações que serão de fato construídas, por exemplo devido a limitações de orçamento. Além disso, no Set covering locais com diferentes níveis de demanda tem um mesmo peso ou importância para localizar a instalações.

Partindo dessas preocupações, tem-se o Max covering, que se encarrega da localização e designação de um número $P$ de instalações em busca da maximização do total de demanda coberta respeitadas as limitações de distância. Este modelo se opõe ao anterior, em que desejava-se minimizar a quantidade de instalações e tratava-se a demanda em termos de nós cobertos com mesma importância.

Parâmetros:

$$
\begin{aligned}
& h_{i}=\text { demanda no nó } i \in I \\
& P=\text { número de instalações para localizar }
\end{aligned}
$$


Variáveis de decisão:

$$
Z_{i}= \begin{cases}1 & \text { se o nó } i \in I \text { é coberto } \\ 0 & \text { caso contrário }\end{cases}
$$

Tem como função objetivo:

$$
\operatorname{MAX} \sum_{i \in I} h_{i} Z_{i}
$$

Sujeita a:

$$
\begin{gathered}
Z_{i} \leq \sum_{j \in J} a_{i j} X_{j} \quad \forall i \in I \\
\sum_{j \in J} X_{j} \leq P \\
X_{j} \in\{0,1\} \quad \forall j \in j \\
Z_{i} \in\{0,1\} \quad \forall i \in I
\end{gathered}
$$

A função objetivo (Equação 2.4) maximiza a demanda coberta e é sujeita a restrição 2.5 que estabelece que a demanda no nó $i \in I$ não pode ser coberta ao menos que um dos locais candidatos que podem cobrir a demanda no nó $i \in I$ for selecionado. Bem como está sujeita a Equação 2.6 que limita a quantidade de instalação selecionadas ao valor máximo $P$. As Equações 2.7 e 2.8 representam, finalmente, as restrições de integralidade das variáveis de decisão.

\subsubsection{Problema de $P$-centros}

Também conhecido como problema de MinMax, busca minimizar o pior desempenho do sistema utilizando um número de instalações $P$, isto é, a minimização da máxima distância percorrida entre instalação e ponto suprido para cada uma das P instalações selecionadas. Essa classe de modelos se opõe aos modelos de cobertura, em que a distância de cobertura entre a demanda e a instalação mais próxima é especificada de forma exógena, nele o número de instalações necessárias para cobrir a demanda pode ser enorme. Nos modelos $P$-centro é adotada outra estratégia, em que ainda deseja-se cobrir toda a demanda, mas a distância de cobertura deixa de ser definida externamente ao modelo. A notação apresentada a seguir é utilizada para descrever o modelo de $P$-centros. 
Parâmetros:

$$
\begin{aligned}
& I=\text { conjunto de nós de demanda } \\
& J=\text { conjunto de locais candidatos } \\
& d_{i j}=\text { distância do nó de demandai } \in \text { Iaté o local candidato } j \in J \\
& h_{i}=\text { demanda no nó } i \in I \\
& P=\text { número de instalações a serem selecionadas }
\end{aligned}
$$

Variáveis de decisão:

$$
\begin{aligned}
& X_{j}=\left\{\begin{array}{cc}
1 & \text { se o local candidato } j \in J \text { for selecionado } \\
0 & \text { caso contrário }
\end{array}\right. \\
& Y_{i j}=\text { fração da demanda no nó } i \in I \text { que será atendido pela instalação } j \in J \\
& W=\text { distância máxima entre o nó de demanda e a instalação mais próxima }
\end{aligned}
$$

Tem como função objetivo:

$$
\text { MIN } W
$$

Sujeita a:

$$
\begin{gathered}
\sum_{j \in J} Y_{i j}=1 \quad \forall i \in I \\
\sum_{j \in J} X_{j}=P \\
Y_{i j} \leq X_{j} \quad \forall i \in I ; j \in J \\
W \geq \sum_{j \in J} d_{i j} Y_{i j} \quad \forall i \in I \\
X_{j} \in\{0,1\} \quad \forall j \in J \\
Y_{i j} \geq 0 \quad \forall i \in I ; j \in J
\end{gathered}
$$

A função objetivo se encarrega, conforme descrito, da minimização da máxima distância entre os nós de demanda e a instalação mais próxima. As restrições 2.11 definem que toda a demanda no npo $i \in I$ deve ser designada a uma instalação em um dos nós $j \in J$ para todos os nós $i \in I$. As equações 2.12 impõem a quantidade de instalação a serem selecionadas, enquanto as restrições 2.13 definem que a do nó $i \in I$ só pode ser 
atribuía ao nó $j \in J$, caso uma instalação seja localizada no nó $j \in J$. Em seguida, as restrições 2.14 determinam que a distância máxima $(W)$ entre um nó de demanda e a instalação mais próxima do nó deve ser maior do que a distância entre qualquer nó de demanda $i$ inI e a instalação $j$ in J ao qual está atribuído. Por fim, as restrições 2.14 e 2.15 garantem a integralidade e não negatividade do problema.

\subsubsection{Problema de $P$-medianas}

Nestes problemas a discussão quanto a maximização dos benefícios e do número total de demandas cobertas se transformam em minimização dos custos. Dessa forma, o problema de $P$-medianas se encarrega de localizar $P$ instalações na malha, de forma que o custo total ou distância total de transporte entre os pontos de demanda e as instalações selecionadas sejam minimizados (também podendo ser representados por tempo). Estes modelos também são conhecidos como MinSum quando apresentam restrição de capacidade.

A formulação abaixo apresenta a modelagem algébrica para este problema.

Parâmetros:

$$
\begin{aligned}
& h_{i}=\text { demanda no nó } i \in I \\
& d_{i j}=\text { distância entre a demanda no nó } i \in I \text { e o local candidatoj } j \in J \\
& P=\text { número de instalações a serem selecionadas }
\end{aligned}
$$

Variáveis de decisão:

$$
\begin{aligned}
& X_{j}= \begin{cases}1 & \text { se o local candidato } j \in J \text { for selecionado } \\
0 & \text { caso contrário }\end{cases} \\
& Y_{i j}= \begin{cases}1 & \text { se a demanda no nó } i \in I \text { é atendida pela instalação do nó } j \in J \\
0 & \text { caso contrário }\end{cases}
\end{aligned}
$$

Tem como função objetivo:

$$
\operatorname{MIN} \sum_{i \in I} \sum_{j \in J} h_{i} d_{i j} Y_{i j}
$$


Sujeita a:

$$
\begin{gathered}
\sum_{j \in J} Y_{i j}=1 \quad \forall i \in I \\
\sum_{j \in J} X_{j}=P \\
Y_{i j}-X_{j} \leq 0 \quad \forall i \in I ; j \in J \\
X_{j} \in\{0,1\} \quad \forall j \in J \\
Y_{i j} \in\{0,1\} \quad \forall i \in I ; j \in J
\end{gathered}
$$

Dessa forma, a função objetivo (Equação 2.16 minimiza a distância ponderada pela demanda total entre cada nó e a instalação mais próxima. A restrição 2.17 exige que cada nó de demanda $i \in I$ seja necessariamente atribuído a uma instalação $j \in J$. As equações 2.18 impõem a implantação de $P$ instalações, enquanto o grupo de restrições 2.19 ligam as variáveis $X_{j}$ às variáveis ${ }_{i j}$. Finalmente, as restrições 2.20 e 2.21 apresentam as condições de integralidade do problema.

\subsubsection{Problemas de localização de instalações de cobrança fixa}

Nos modelos apresentados o número de instalações a serem localizados tratava-se de uma parâmetro exógeno, exceto pelo modelo de Max-Covering. Ao otimizar uma função objetivo sujeita a uma restrição que limita a quantidade de instalação a um número fixo, está sendo feita a separação implícita dos custos operacionais dos custos de instalação ou construção. De forma que, os custos de implantação das instalações são idênticos para todos locais candidatos, que pode não ser válido para certas situações.

Para lidar com esta questão, os modelos de localização de instalações de cobrança fixa incorporam este custos explicitamente, normalmente utilizados em problemas de localização do setor privado em que um único ator ou empresa paga os custos e percebe os benefícios e custos envolvidos na decisão.

A formulação a seguir apresenta o modelo de localização de instalações de cobrança fixa não capacitado, em que é minimizada a soma dos custos das instalações e os custos de transporte. 
Parâmentros:

$$
\begin{aligned}
& f_{j}=\text { custo fixo de localização do local candidato } j \in J \\
& h_{i}=\text { demanda no nó } i \in I \\
& d_{i j}=\text { distância entre o nó de demanda } i \in I \text { e o local candidato } j \in J \\
& \alpha=\text { custo por unidade de distância e demanda }
\end{aligned}
$$

Variáveis de decisão:

$X_{j}= \begin{cases}1 & \text { se o local candidato } j \in J \text { for selecionado } \\ 0 & \text { caso contrário }\end{cases}$

$Y_{i j}=$ fração da demanda do nó $i \in I$ que será servida pela instalação do local candidato $j \in J$

Tem como função objetivo:

$$
\operatorname{MIN} \sum_{j \in J} f_{j} X_{j}+\alpha \sum_{i \in I} \sum_{j \in J} h_{i} d_{i j} Y_{i j}
$$

Sujeita a:

$$
\begin{gathered}
\sum_{j \in J} Y_{i j}=1 \quad \forall i \in I \\
Y_{i j} \leq X_{j} \quad \forall i \in I ; j \in J \\
X_{j} \in\{0,1\} \quad \forall j \in J \\
Y_{i j} \geq 0 \quad \forall i \in I ; j \in J
\end{gathered}
$$

Neste modelo, a função objetivo minimiza o custo total, representado pelo custo das instalações e de transporte, calculado através da distância ponderada pela demanda em cada. A restrição estipula que cada instalação deverá ser atendida por apenas um local candidato. Enquanto a estabelece a ligação entre as duas variáveis de decisão do problema, deforma que o campo $i$ emI só será suprido caso uma instalação seja alocada ao local candidato $j$ em $J$.

Observa-se que a principal diferença deste modelo para o de $P$-medianas apresentado previamente é a inclusão dos custos fixos de localização e a ausência das restrição de número de locais selecionados. 
Os modelos tratados até o momento não apresentavam restrições de capacidade. Dessa forma, o modelo a seguir apresenta um modelo geral para problema de localização de instalação de carga fixa. Muito semelhante ao modelo acima, este se diferencia pela introdução do grupo de restrições 2.30 .

Tem como função objetivo:

$$
\operatorname{MIN} \sum_{j \in J} f_{j} X_{j}+\alpha \sum_{i \in I} \sum_{j \in J} h_{i} d_{i j} Y_{i j}
$$

Sujeita a:

$$
\begin{gathered}
\sum_{j \in J} Y_{i j}=1 \quad \forall i \in I \\
Y_{i j} \leq X_{j} \quad \forall i \in I ; j \in J \\
\sum_{i \in I} h_{i} Y_{i j} \leq k_{j} X_{j} \quad \forall j \in J \\
X_{j} \in\{0,1\} \quad \forall j \in J \\
Y_{i j} \geq 0 \quad \forall i \in I ; j \in J
\end{gathered}
$$

\subsubsection{Extensões dos modelos de localização}

Decisões sobre localização de instalações são inerentemente estratégicas e de longo prazo. Portanto, é provável a existências de múltiplos critérios ou objetivos conflitantes ou concorrentes envolvidos nesta tomada decisão. No problema de localização de armazéns pode-se desejar ter um equilíbrio entre a distância média entre clientes e o depósito mais próximo e a extensão de cobertura da demanda.

A distância total percorrida pelo veículo está provavelmente relacionada a distância total ponderada pela demanda e reduzir a quilometragem percorrida, reduz os custos. Em contra partida, a cobertura e capacidade de entregar mercadorias aos clientes em tempo hábil é cada vez mais importante, devido a preocupação crescente com o atendimento ao cliente. A capacidade de entregar mercadorias aos clientes no prazo de um dia tem se tornado uma tendência e uma vantagem competitiva, mas que leva ao trade-off entre minimização da distância total ponderada pela demanda total e maximização do número de clientes que recebem o serviço adequadamente. O primeiro objetivo prioriza a redução no custo, mas pode permitir que alguns clientes tenham níveis de serviço inferiores aos dos demais.

Outra extensão dos modelos clássicos é o problema de localização de instalações in- 
desejadas ou problemas de dispersão. Em contraste aos problemas apresentados anteriormente, procura estabelecer as localizações distantes dos pontos de demanda. São utilizados na localização de fábricas de produtos químicos, reatores nucleares, lixões, estações de tratamento de águas residuais. Alterando os modelos das subseções anteriores ao novo objetivo teremos os modelos MaxSum, Min covering e MaxMin das distâncias entre pontos de demanda e local selecionado.

Os problemas de localização também podem ser hierárquicos, ou podem se combinar a decisões de níveis planejamento tático ou operacionais como nos modelos de localização e roteirização ou nos modelos integrados de localização e estoques, bem como podem incluir em sua modelagem aspectos de confiabilidade e ou tratamento de falhas esperadas.

\subsubsection{Problemas de localização em logística humanitária}

Os problemas de localização de instalações em logística humanitária incluem a identificação de locais como bombeiros, abrigos de emergência, centros de distribuição, armazéns, locais de remoção de entulhos e centros médicos.

A maioria dos modelos de otimização de localização de logística humanitária foram combinados com outros problemas de logística, como posicionamento prévio de estoque, distribuição de socorro, transporte de vítimas, planejamento de evacuação, alocação de recursos, fluxos de mercadorias e outras operações.

A pesquisa bibliográfica sobre problemas de localização de instalações aplicados a logística humanitária resultou em 123 artigos analisados quanto ao tipo de desastre, seu início, estágio do ciclo de vida do desastre, abordagem multi-período e multi-objetivo. Dessa forma, quanto ao tipo de desastre foram obtidos 7 artigos sobre desastres ocasionados pelo homem e 70 artigos abordando desastres naturais, e 46 não apresentavam aplicação a um desastre específico.

Dentre os estudos aplicados a desastres naturais obteve-se trabalhos aplicados a terremotos (34), furacões (16), fome (3), enchente (4), deslizamentos de terra (3) e epidemias (2), enquanto aqueles artigos abordando causas oriundas da atuação humana abordaram essencialmente casos relativos a terrorismo, há apenas um em que conflitos armados são abordados.

A análise sobre o tipo de início do desastre revelou 66 artigos de início súbito, 49 não definidos e 8 de início lento. Sobre o estágio do desastre, 41 abordaram os estágios de preparação e resposta, 38 resposta, 31 preparação e 13 não definidos. Observa-se um 
predomínio de modelos tratando horizontes únicos, em que se identificou 93 trabalhos, que contrastam aos 25 artigos em que aborda-se o problema de localização utilizando múltiplos períodos.

Em relação a quantidade de objetivos, 50 artigos consideraram múltiplos objetivos, enquanto 72 abordaram um objetivo único. No conjunto de trabalhos com múltiplos objetivos, 49 apresentavam objetivos econômicos e apenas 1 econômico e ambiental. Dentre aqueles com objetivo único, 35 focaram na análise econômica, 29 em nível de serviço e 8 apresentaram outros interesses.

Dos 123 artigos foram filtrados 19 para serem analisados quanto a aspectos mais específicos desta dissertação. Assim, as Tabelas 2 e 3 caracterizam estes artigos quanto a suas aplicações, modelagem proposta e métodos de solução utilizados. 
Tabela 2: Classificação dos trabalhos selecionados quanto aos eventos analisados.

\begin{tabular}{|c|c|c|c|c|c|}
\hline Artigo & Tipo de desastre & Tipo de início & Estágio do desastre & Aplicação & País \\
\hline Nezhadroshan, Fathollahi-Fard, Hajiaghaei-Keshteli (2020) & Natural & Súbito & Preparação e Resposta & Terremoto & Irã \\
\hline Rodriguez-Espindola, Alem, Da Silva (2020) & Natural & Lento & Preparação & Inundações & México \\
\hline Balcik et al. (2019) & Natural & Lento & Preparação & Furacões & Caribe \\
\hline Li , Ramshani, Huang (2018) & Geral & Geral & Geral & Geral & Geral \\
\hline Meng et al. (2018) & Antrópico & Súbito & Resposta & Geral & - \\
\hline Wang, Shi , Hu (2019) & Geral & Geral & Geral & Geral & Geral \\
\hline Alizadeh, Nishi (2020) & Natural & Súbito & Preparação e Resposta & Terremoto & Japão \\
\hline Xiang, Wei (2020) & Antrópico & Súbito & Geral & Ataques Terroristas & China \\
\hline Bashiri (2018) & Geral & Geral & Geral & Geral & Geral \\
\hline Doodman et al. (2019) & Natural & Súbito & Preparação & Terremoto & Irã \\
\hline Klibi, Ichoua, Martel (2018) & Natural & Geral & Preparação e Resposta & Diversos & USA \\
\hline Velasquez, Mayorga, Cruz (2019) & Natural & Lento & Preparação & Ciclone, Furacão & USA \\
\hline Hasani, Mokhtari (2018) & Natural & Súbito & Resposta & Terremoto & Irã \\
\hline Fang et al. (2018) & Geral & Súbito & Geral & Geral & Geral \\
\hline Gazani, Niaki, Niaki (2021) & Geral & Geral & Geral & Geral & Geral \\
\hline Inca, Nikorn (2019) & Natural & Súbito & Resposta & Terremoto & Sumatra \\
\hline Wang, Situ, Yu (2020) & Natural & Súbito & Resposta & Terremoto & China \\
\hline Ghasemi et al. (2019) & Natural & Súbito & Resposta & Terremoto & Irã \\
\hline Munyaka, Yadavalli (2020) & Antrópico & Lento & Preparação & Conflitos Armados & Congo \\
\hline Pinheiro (2021) & Antrópico & Lento & Preparação e Resposta & Conflitos Armados & Iraque \\
\hline
\end{tabular}


Tabela 3: Tabela de classificação dos trabalhos selecionados quanto as características da modelagem.

\begin{tabular}{|c|c|c|c|c|c|c|c|c|}
\hline Artigo & $\begin{array}{l}\text { Múltiplos } \\
\text { períodos }\end{array}$ & $\begin{array}{l}\text { Instalações } \\
\text { dinâmicas }\end{array}$ & $\begin{array}{l}\text { Quantidade } \\
\text { de produtos }\end{array}$ & $\begin{array}{l}\text { Coordenação } \\
\text { inter-agência }\end{array}$ & $\begin{array}{l}\text { Capacidade de } \\
\text { Armazenagem }\end{array}$ & $\begin{array}{c}\text { Considera tempo } \\
\text { ou cobertura }\end{array}$ & $\begin{array}{l}\text { Demanda } \\
\text { estocástica }\end{array}$ & $\begin{array}{c}\text { Quantidade de } \\
\text { Objetivos }\end{array}$ \\
\hline Nezhadroshan, Fathollahi-Fard, & - & - & - & - & $\mathrm{x}$ & $\mathrm{x}$ & $\mathrm{x}$ & 3 \\
\hline \multicolumn{9}{|l|}{ Hajiaghaei-Keshteli (2020) } \\
\hline Rodriguez-Espindola, Alem, Da Silva (2020) & - & - & $\mathrm{x}$ & $\mathrm{x}$ & $\mathrm{x}$ & - & $\mathrm{x}$ & 2 \\
\hline Balcik et al. (2019) & $\mathrm{x}$ & - & - & $\mathrm{x}$ & $\mathrm{x}$ & - & $\mathrm{x}$ & 1 \\
\hline Li , Ramshani, Huang (2018) & - & - & & $\mathrm{x}$ & - & $\mathrm{x}$ & $\mathrm{x}$ & 1 \\
\hline Meng et al. (2018) & - & - & - & - & - & - & - & 1 \\
\hline Wang, Shi , Hu (2019) & $\mathrm{x}$ & $\mathrm{x}$ & - & - & $\mathrm{x}$ & - & - & 2 \\
\hline Alizadeh, Nishi (2020) & $\mathrm{x}$ & $\mathrm{x}$ & - & - & $\mathrm{x}$ & - & - & 1 \\
\hline Xiang, Wei (2020) & - & - & - & - & - & - & - & 1 \\
\hline Bashiri (2018) & $\mathrm{x}$ & $\mathrm{x}$ & - & - & - & - & - & 1 \\
\hline Doodman et al. (2019) & $\mathrm{x}$ & - & $\mathrm{x}$ & - & $\mathrm{x}$ & - & $\mathrm{x}$ & 2 \\
\hline Klibi, Ichoua, Martel (2018) & $\mathrm{x}$ & - & - & - & $\mathrm{x}$ & - & $\mathrm{x}$ & 1 \\
\hline Velasquez, Mayorga, Cruz (2019) & - & - & $\mathrm{x}$ & $\mathrm{x}$ & $\mathrm{x}$ & - & - & 1 \\
\hline Hasani, Mokhtari (2018) & $\mathrm{x}$ & $\mathrm{x}$ & $\mathrm{x}$ & - & $\mathrm{x}$ & $\mathrm{x}$ & - & 1 \\
\hline Fang et al. (2018) & $\mathrm{x}$ & - & - & - & - & - & - & - \\
\hline Gazani, Niaki, Niaki (2021) & - & - & - & & $\mathrm{x}$ & - & - & 1 \\
\hline Inca, Nikorn (2019) & $\mathrm{x}$ & - & - & - & - & - & - & 1 \\
\hline Wang, Situ, Yu (2020) & $\mathrm{x}$ & - & - & - & - & - & - & 3 \\
\hline Ghasemi et al. (2019) & $\mathrm{x}$ & - & $\mathrm{x}$ & - & $\mathrm{x}$ & - & $\mathrm{x}$ & 2 \\
\hline Munyaka, Yadavalli (2020) & - & - & - & - & - & - & - & 1 \\
\hline Pinheiro (2021) & $\mathrm{x}$ & $\mathrm{x}$ & - & $\mathrm{x}$ & $\mathrm{x}$ & $\mathrm{x}$ & - & 1 \\
\hline
\end{tabular}




\section{METODOLOGIA}

A pesquisa operacional é uma abordagem científica de auxílio do processo de tomada de decisão, que busca determinar o melhor projeto, planejamento e operação de sistemas (ARENALES et al., 2007). A modelagem quantitativa é parte central da metodologia de pesquisa operacional, que inicialmente voltou sua aplicação para a resolução de problemas reais relativos a gestão ou administração da produção e operações, nos primórdios do século XX. Posteriormente novas vertentes emergiram mais voltadas à resolução de problemas idealizados.

Portanto, o trabalho se classifica como pesquisa empírica quantitativa, orientada a descobertas e medidas empíricas, em que se deseja garantir a adesão entre observações da realidade e o modelo elaborado a partir da realidade analisada. Assim, a modelagem matemática é utilizada para abordar parte de uma situação do mundo real e propõe a definição de um modelo conceitual, a partir do qual são identificadas as principais informação para definir as variáveis do estudo e suas relações causais. Assim, descreve-se o sistema real através de expressões algébricas que representam o problema, e são feitas análises em que se aplicam técnicas e métodos para identificar sua adequação para inferir decisões no problema real. A avaliação destas decisões demonstra sua viabilidade prática ou se sua modelagem deve ser refinada, o que implica na repetição do ciclo metodológico apresentado por Bertrand e Fransoo (2002) e Cauchik et al. (2010). Esta pesquisa visa o desenvolvimento de políticas estratégias e ações para gerar melhorias ao sistema atual, classificando-se também como normativa. Diferentemente de pesquisas descritivas, as pesquisas normativas baseiam-se em modelos prescritivos de tomada de decisão para o problema estudado, apoiando-se em modelos de otimização matemática.

Este trabalho investigou o problema de planejamento de redes humanitárias de distribuição de insumos no Iraque, através de um estudo de caso sobre a operação de resposta à Ofensiva de Mosul (2016-2017), Iraque. A partir do estudo de caso, foram levantados os principais desafios para o planejamento da rede de distribuição humanitárias. Assim, foi proposta uma formulação matemática, abordando o problema estratégico, que envolve 
decisões de localização, as definições de fluxos, capacidade de armazenagem e esquema de abertura e desativação de armazéns.

Dessa forma, o processo metodológico desta dissertação foi composto pelas etapas de (1) definição do problema e seu escopo, (2) coleta de dados, (3) construção do modelo matemático, (4) verificação preliminar do modelo, (5) determinação do método de solução, (6) aplicação do modelo proposto ao estudo de caso, (7) e análise dos resultados obtidos, apresentadas na Figura 7. A Figura 8 apresentada um resumo das etapas do processo metodológico, suas fontes de dados e ferramentas utilizadas.

A etapa de definição do problema foi realizada através de revisões bibliográficas, buscas documentais e entrevistas realizadas a agentes humanitárias atuantes na operação de resposta investigada. Durante a revisão bibliográfica pode-se obter fontes de informações e adquirir entendimento sobre conceitos, análises e interpretação de resultados de um tema específico (ROWLEY; SLACK, 2004). Esta etapa é determinante tanto para o entendimento do contexto ao qual o estudo se aplica, quanto para a identificação de possibilidades de pesquisa e estado da arte sobre problemas de localização. Deste modo, buscou-se compreender como os autores encontrados consideraram os problemas de localização, bem como suas formas de modelagem e resolução dos problemas.

A pesquisa bibliográfica foi realizada através das bases Web of Science, Science Direct, Scopus e Emerald, utilizando a combinação de palavras-chave "(Location Analysis OR Distribution Center OR Facility Location) And (Disaster or Humanitarian Logistics OR Pre-Positioning OR Emergency)". A pesquisa resultou em 769 artigos revisados por pares relacionados ao tema de projeto de malha logística em desastres. Destes primeiros artigos, foi realizada uma primeira filtragem dos artigos, em que foram retirados os artigos que não apresentavam enfoque humanitário, ou que fossem anteriores ao ano de 2013. Em seguida, foram selecionados aqueles artigos que fossem pertinentes a temática da dissertação, isto é, posicionamento de instalações de suprimentos humanitários. Entretanto foram mantidos e analisados artigos que tratassem sobre desastres antropológicos, mesmo que não diretamente relacionados a localização de pontos de armazenagem.

Após as filtragens, formou-se uma base de artigos contendo 126 publicações, que foram analisadas quanto ao tipo de desastre, tipo de início, estágio do desastre abordado, estudo de caso, perspectiva geográfica do caso, horizonte de tempo, quantidade de objetivos e tipo de objetivos. Destes artigos ainda realizou-se uma última filtragem que selecionou aqueles artigos que apresentassem aspectos semelhantes ou relevantes ao escopo desta dissertação, o que resultou em 21 trabalhos, que foram analisados sob a perspectiva de quantidade 
de produtos distribuídos, tipo de problema, modelagem, método de solução, abordagem quanto a coordenação entre agências, capacidade de armazenagem, consideração quanto a limitação de tempo de entrega ou cobertura e tipo de demanda.

O trabalho foi conduzido através de pesquisas a bases de dados de artigos acadêmicas; a bases de dados de agências e organizações não-governamentais, como bases do Relief Web, do HDX (Humanitarian Data Exchange) e da IOM (International Organization for Migration); além de buscas a mídias virtuais que cobriram o acontecimento no Iraque e livros acadêmicos sobre tópicos relacionados aos campos de conhecimento que se combinam neste estudo. Além destas fontes, um agente humanitário foi consultado através de entrevistas, que proporcionaram o entendimento sobre a operação humanitária estabelecida no Iraque.

O modelo matemático estabelecido foi definido através de um processo iterativo de construção e verificação, ao passo em que o conhecimento sobre a problemática se aprofundou, assim como a partir da identificação de necessidades de correção. Para a verificação do modelo matemático proposto, foram construídas instâncias ilustrativas de pequeno porte, cujo objetivo foi a verificação da adequação da modelagem algébrica aos objetivos de planejamento da abertura de pontos de armazenagem com múltiplos períodos desta dissertação.

Após esta verificação se estabelece um novo ciclo de atividades em que se procurou identificar os métodos adequados de resolução do problema, em que se utilizou instâncias de porte real a partir dos dados coletados sobre a operação no Iraque. Realizou-se análises utilizando dados sobre as ocupações de campos de indivíduos em deslocamento iraquianos encontrados para o período entre outubro e 2016 a dezembro de 2017, oriundos de dois principais provedores Relief Web e CCCM-Iraq.

O processo de consolidação dos dados sobre a demanda real é descrito no Capítulo 5, que apresenta os dados utilizados nos experimentos do trabalho. No capítulo a seguir será apresentado o modelo matemático proposto e seus pressupostos. 
Figura 7: Metodologia de pesquisa.

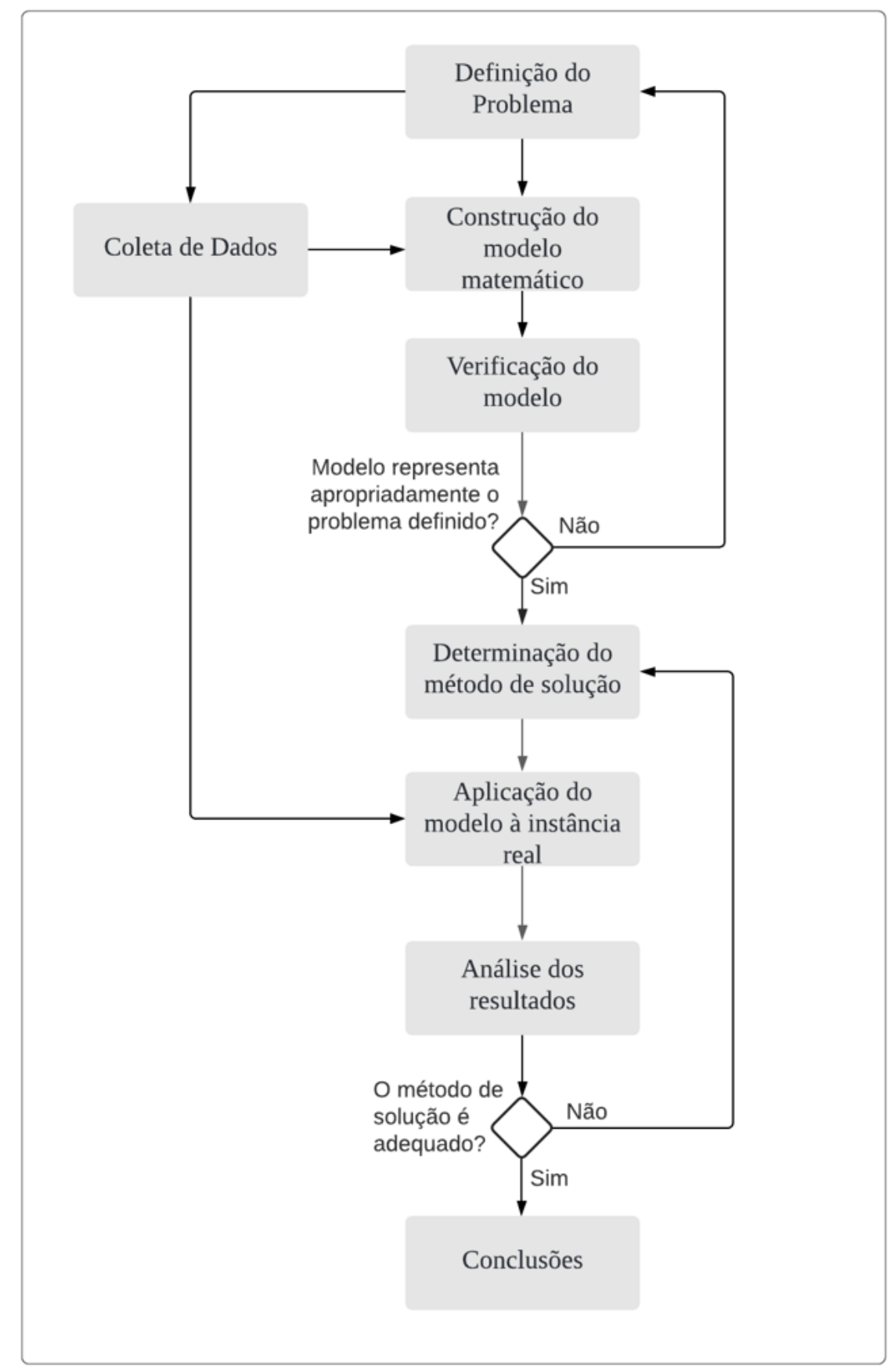

Fonte:Elaboração própria. 
Figura 8: Etapas da pesquisa, técnicas e ferramentas adotadas.

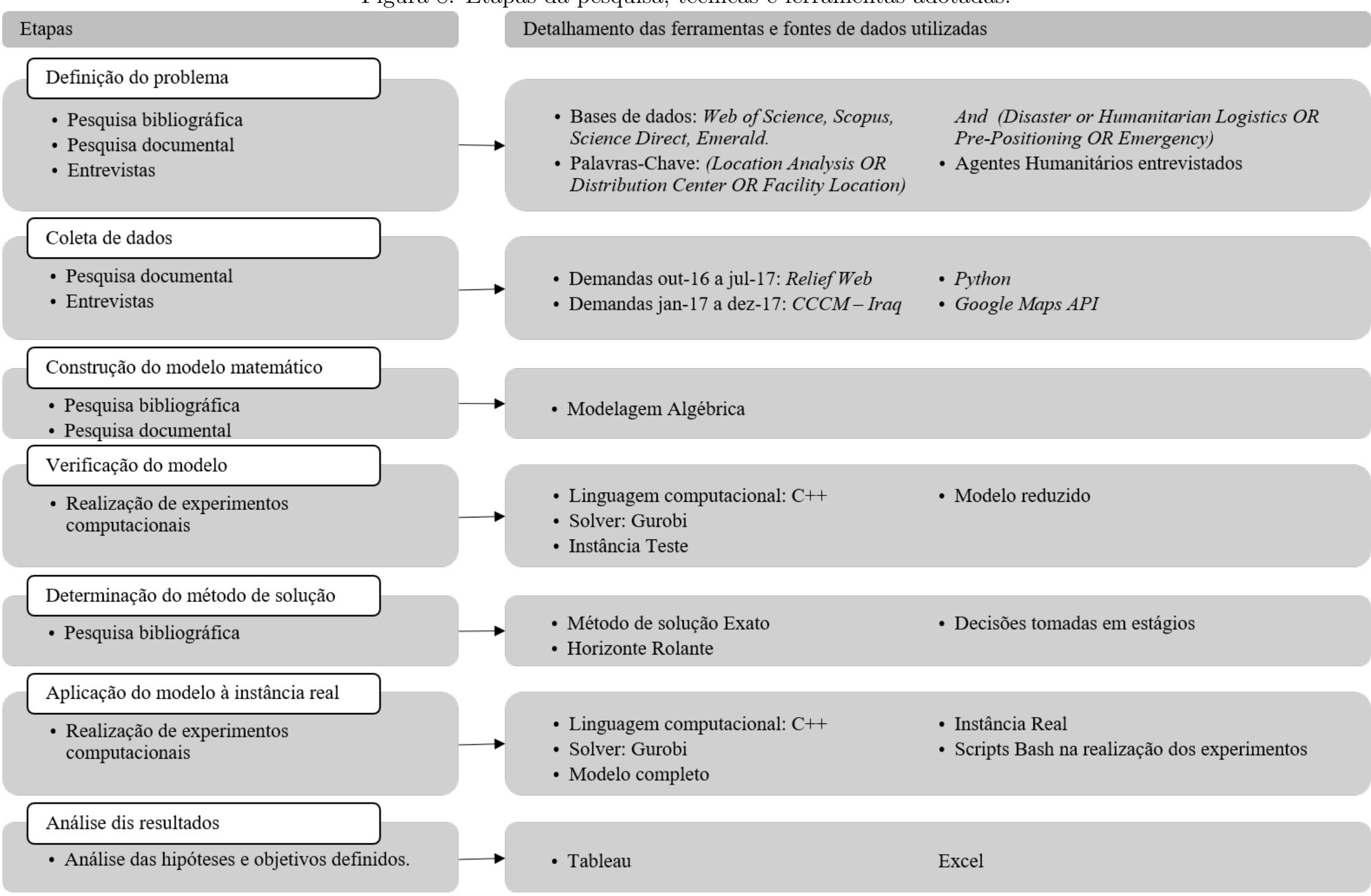

Fonte: Elaboração própria. 


\section{MODELAGEM DO PROBLEMA}

A proposta deste trabalho é formular um modelo de programação matemática para apoiar as decisões estratégicas envolvidas na determinação da configuração da rede de distribuição de itens de ajuda humanitária. Neste capítulo serão apresentadas as considerações e pressupostos para a modelagem do problema, levantados a partir do estudo de caso realizado sobre a operação de acolhimento de indivíduos em deslocamento no Iraque. A partir destas premissas é proposto um modelo de otimização para o planejamento da malha logística da operação.

\subsection{Descrição da Operação Logística}

Durante a operação iraquiana identificou uma discussão sobre o plano operacional de resposta a operação de retomada de Mosul.

Os armazéns são fundamentais em ambientes humanitários, funcionando como pontos de consolidação e preparação dos suprimentos em kits para distribuição aos necessitados. Além de serem utilizados como base de apoio para a assistência na última milha.

Dessa forma, o Logistics Cluster (mecanismo de coordenação estabelecido pela IASC Inter-Agency Standing Committee) deve determinar a localização dos armazéns para que as demandas dos campos sejam atendidas. Os integrantes do cluster são então responsáveis por decisões que determinarão a configuração da malha logística, bem como sobre a centralização ou descentralização da rede.

Estas decisões são estratégicas para a operação, pois recursos preposicionados em locais e quantidades inadequadas podem implicar em elevados custos de não atendimento de populações em necessidade, podendo causar efeitos secundários como revoltas e problemas de segurança. Além do que o remanejamento e transporte do excesso de suprimentos para outras localidades eram dificultados por agentes de segurança.

Outro ponto determinante à operação de resposta humanitária é a disponibilidade de 
recursos financeiros, frequentemente escassos. Dessa forma, preza-se pela minimização dos custos operacionais, na tentativa de garantir a maior cobertura possível aos beneficiários.

A operação iraquiana também se destaca pela presença de rupturas na infraestrutura da cadeia de suprimentos. Durante o período de conflito armado, o fluxo de veículos e pessoas era retardado pela presença de pontos de checagem de documentação, por exemplo. As checagens eram realizadas tanto por Forças de Segurança Iraquianas e Curdas, quanto por milícias paramilitares que atuavam nas forças de coalizão. Estas estações de checagem apresentavam uma localização geralmente estável e eram evitadas pelos agentes humanitários, pois podiam impactar nos tempos de entrega e ocasionar atrasos.

Santos (2021) afirma que a rede logística de abastecimento dos campos era tanto descentralizada geograficamente, possuindo um grande número de instalações próximas aos pontos de demanda, quanto descentralizada do ponto de vista de cooperação interagências, isto é, estabeleceram-se redes com objetivos e itens a serem distribuídos semelhantes que operavam paralelamente.

Dessa forma, o escopo desta dissertação se restringe a análise da operação a partir da consolidação dos produtos de alívio nos armazéns principais ( $h u b s$ ) localizados no território iraquiano, estruturas de transbordo dos itens doados ou adquiridos para a distribuição, localizados em três cidades Dohuk, Erbil e Bagdá (Logistic cluster, 2017). A partir dos hubs os produtos eram transportados através de caminhões para os armazéns móveis ( $m o$ bile storage unit - MSU) localizados próximos aos campos. As dimensões de MSUs mais comuns são de 10x20 metros, que armazena entre 350-500 toneladas métricas, e de 10x32 metros, com capacidade de ocupação entre 500-750 toneladas métricas (CRS, 2019). Em geral, cada organização detinha instalações próprias orientadas a suas operações.

Figura 9: Cadeias de suprimentos da operação humanitária.

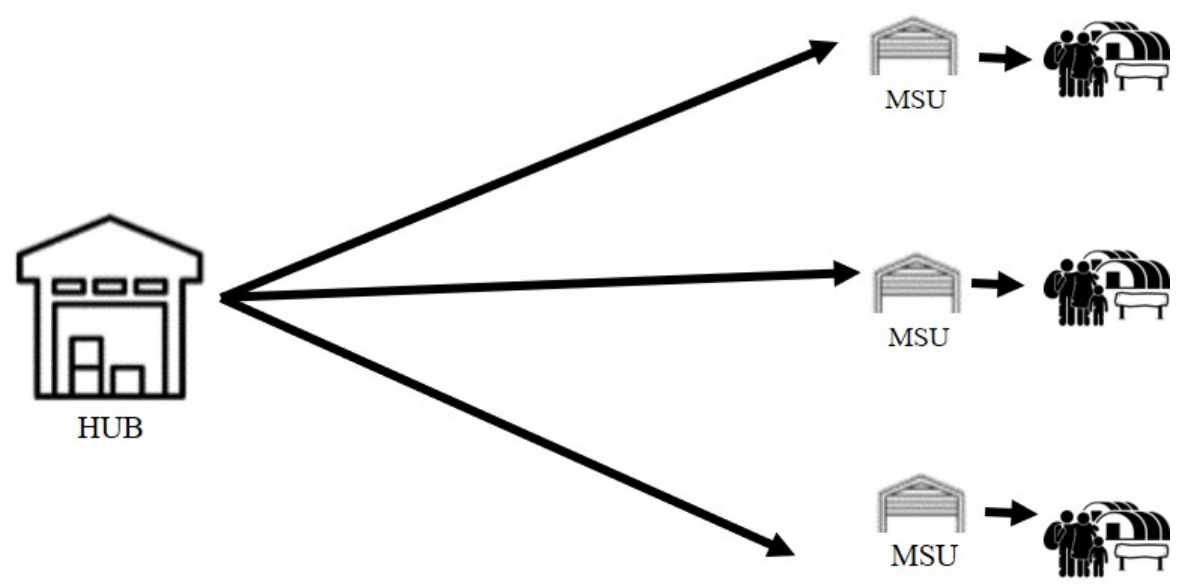

A Figura 9 ilustra a rede logística estabelecida na operação, que era composta por 
Figura 10: Nova proposta de cadeia de suprimentos.

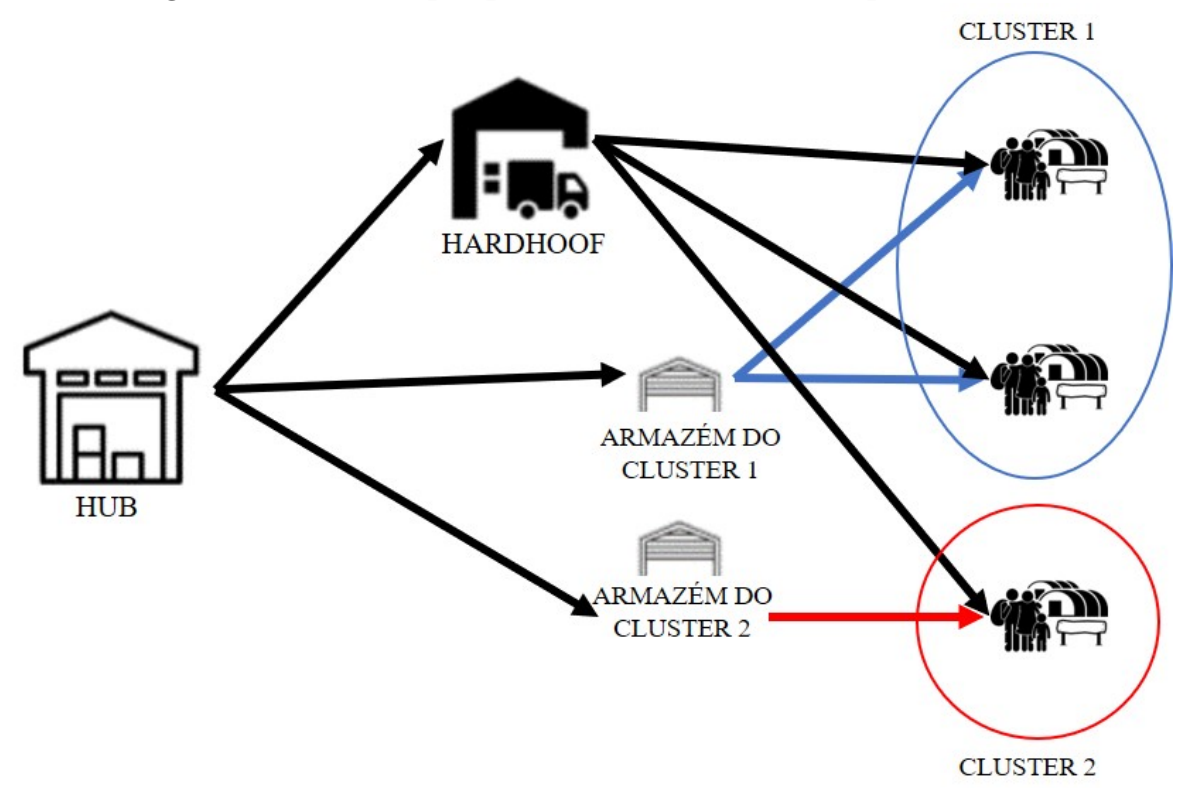

diversas redes independentes, cada qual com diversos armazéns e rotas de distribuição, muitas vezes redundantes por distribuírem itens semelhantes. Além de gerar grandes estoques nos campos, pois o suprimento ocorria in loco, esta configuração de rede também gera o emprego ineficiente dos recursos financeiros da operação. Por exemplo os custos fixos das instalações, como custos gerenciais, de manutenção etc, podem ser reduzidos através do compartilhamento de instalações, pois durante a operação era comum a existência de campos de abrigamento com localizações próximas entre si.

O modelo investigado nesta dissertação busca centralizar as redes, favorecendo o compartilhamento de recursos e estruturas utilizados na distribuição de bens aos beneficiários. De forma que, a distribuição no último trecho do percurso será realizada diretamente dos veículos, eliminando estoques nos campos (Figura 10) e buscando um melhor desempenho financeiro.

\subsection{Considerações e pressupostos}

A rede de distribuição de produtos humanitária é composta por centros de distribuição centrais (hubs), armazéns intermediários e pontos de entrega aos desabrigados (campos). A conexão entre os nós da rede é feita por meio de transporte rodoviário, aspecto que pode variar de uma operação humanitária a outra dependendo da infraestrutura da região ou país afetado. Todos os produtos são enviados às famílias através dos armazéns intermediários, ou seja, não são enviados produtos diretamente dos hubs aos beneficiários. A 
Figura 10, apresentada na seção anterior, mostra a estrutura geral da rede de distribuição a ser analisada.

Para a modelagem do problema, assumiu-se que a localização dos hubs é conhecida, dessa forma, as decisões de localização consistem em determinar quais dos locais predefinidos como candidatos serão selecionados para a operação dos armazéns intermediários. Para identificação do esquema de abertura, expansão e redução da capacidade de armazenagem para a mobilização de recursos, são considerados níveis de capacidade no modelo proposto. Além disso, a decisão sobre os locais candidatos para os agrupamentos de campos, isto é, locais para instalação dos armazéns dedicados aos clusters, é tomada anteriormente a resolução do modelo de localização dos pontos de armazenagem pública.

Os diversos produtos enviados aos pontos de distribuição apresentam diferenças em volume, peso, e frequência de entrega. Neste trabalho, estes insumos são agregados em uma taxa utilizada para determinar a demanda básica de insumos por mês para cada família.

Como a proposta deste trabalho é a avaliação de decisões estratégicas sobre localização em um ambiente dinâmico de variação de demanda, considerou-se um horizonte de planejamento multi-período. Assim, a decisão sobre a localização dos armazéns pode se alterar ao longo do horizonte considerado, bem como pode-se desempenhar revisões sobre o esquema de abertura e expansão confirme se obtenha dados atualizados sobre a demanda e novas previsões.

O modelo matemático proposto considera dois tipos de armazéns, móveis e de alvenaria. Conforme a descrição da operação humanitária, as redes instaladas no período de crise utilizaram essencialmente armazéns móveis para o recebimento dos insumos e montagem dos kits, localizados nos próprios pontos de demanda (campos de deslocados). A opção alternativa é a utilização de armazéns em estruturas de alvenaria, chamados Hardroofs. Desse modo, os armazéns de alvenaria seriam opções de instalações para a cidades candidatas selecionadas, enquanto os campos abrigariam armazéns móveis.

Ao longo do horizonte de operação a capacidade dos armazéns móveis pode ser incrementada ou decrementada. Em contra partida, os armazéns de alvenaria apresentam menor flexibilidade quanto a este aspecto, uma vez que entende-se que são estabelecidos contratos de locação a longo prazo. Desta forma, estes armazéns permanecem fixos após sua abertura.

Adota-se que os armazéns devem estar posicionados em até 1 hora de distância dos pontos de demanda, para que se tenha tempo hábil para a desempenhar o cronograma de 
distribuição de itens de alívio aos beneficiários.

A seguir encontram-se sumarizadas as considerações feitas no estudo:

- a localização dos hubs é fixa, enquanto a localização dos pontos de demanda varia no horizonte de tempo considerado;

- os armazéns intermediários, por sua vez, são decisões do modelo e também variam no horizonte planejado;

- a demanda só pode ser satisfeita pelos armazéns intermediários, ou seja, não existe fluxo entre hubs e campos;

- os armazéns intermediários recebem apenas produtos dos hubs, isto é, não existe fluxo entre armazéns;

- a quantidade de produtos disponíveis nos hubs é suficiente para atender a demanda dos clientes em todos os períodos;

- são adotados níveis de armazenagem nos locais candidatos;

- são adotados dois tipos de instalações de armazenagem;

- os pontos de checagem, gargalos no transporte, não são considerados;

- para garantir um nível de serviço satisfatório no atendimento da demanda é considerada uma restrição quanto ao tempo de transporte entre armazéns intermediários e pontos de distribuição.

\subsection{Modelo de localização de armazéns multi-período}

O problema de projeto e planejamento da rede de distribuição de insumos humanitários pode ser formulado como um modelo de programação linear inteira mista. Nesta seção é apresentado o modelo utilizado para representação da malha logística centralizada, proposta nestes estudo. Para a formulação matemática deste problema foi considerada notação expressa nas Tabelas 4, 5 e 6.

A função objetivo minimiza o custo total da rede, Equação 4.1, a qual abrange os custos de transporte relativos ao primeiro e segundo trecho da malha logística. O primeiro termo de custo refere-se ao custo entre hubs e armazéns intermediários, e o segundo ao trecho entre armazéns intermediários e campos. Os demais termos referem-se aos custos 
Tabela 4: Lista de conjuntos do modelo de localização.

\begin{tabular}{cl}
\hline Conjuntos & Descrição \\
\hline$i \in \mathrm{I}$ & Hubs fornecedores de produtos. \\
$j \in \mathrm{J}$ & Locais candidatos a receber armazéns intermediários. \\
$k \in \mathrm{K}$ & Campos para abrigamento de famílias deslocadas. \\
$t \in \mathrm{T}$ & Horizonte de operação. \\
$r \in \mathrm{R}$ & Índice de capacidade final da instalação no instante $t=1$ \\
& $\mathrm{R}=\{0,1, \ldots, 11\}$, onde $R$ é o conjunto das capacidades. \\
$s \in \mathrm{S}$ & Índice de capacidade inicial da instalação no instante $t ;$ \\
& $S=\{0,1, \ldots, 11\}$, onde $S$ é o conjunto das capacidades. \\
\hline
\end{tabular}

das instalações, fixos de operação, de abertura ou expansão, de desativação ou redução, e por fim os custos variáveis de operação. O último termo, de custo variável, torna o modelo não linear que será linearizado posteriormente e discutido nas seções subsequentes.

A restrição 4.2 do modelo estabelece o balanço de massa para cada local candidato em cada período, de forma que não é considerada a formação de estoque de um período a outro. Assim cada armazém receberá os insumos necessários para suprir a demanda no intervalo de cada período. A Equação 4.3, por sua vez, garante a demanda de cada campo em cada período deverá ser atendida, de forma que não é permitida a falta. A Equações 4.4 e 4.5 são utilizadas na determinação das atribuições dos campos, em que a primeira equação estabelece uma ligação entre as variáveis $X_{j k t}$ e $Y_{j k t}$, enquanto a segunda indica que cada campo em cada período será suprido por apenas um armazém. Em seguida a Equação 4.6 estabelece que a capacidade instalada no local candidato deve ser suficiente para atender ao volume de produtos entregues aos campos sob a responsabilidade deste armazém.

$$
\begin{aligned}
\text { Min Custo Total }=\sum_{t \in T} \sum_{j \in J}\left(\sum_{i \in I} f_{i j} X_{i j t}+\sum_{k \in K} f_{j k} X_{j k t}\right) \\
+\sum_{t \in T} \sum_{j \in J} \sum_{r \in R} \sum_{s \in S}\left(\left(c f_{s} W_{r s j t}+c a_{r s} O_{r s j t}+c f_{r s} Z_{r s j t}\right)+\sum_{k \in K} c v_{r s} X_{j k t} W_{r s j t}\right) \\
\qquad \sum_{i \in I} X_{i j t}-\sum_{k \in K} X_{j k t}=0 ; \forall t \in T, j \in J
\end{aligned}
$$


Tabela 5: Lista de parâmetros do modelo de localização.

\begin{tabular}{|c|c|c|}
\hline Parâmetro & Descrição & Unidade \\
\hline $\mathrm{a}_{s j}$ & $\begin{array}{l}\text { Parâmetro binário que possuí } \\
\text { valor igual a } 1 \text { se o local candidato } j \\
\text { pode receber armazém do tipo } s \text {. }\end{array}$ & Adimensional \\
\hline$q$ & Volume médio do kit. & Toneladas/mês x família \\
\hline $\mathrm{d}_{k t}$ & $\begin{array}{l}\text { Demanda, famílias no campo } k \text { no } \\
\text { período } t \text {. }\end{array}$ & Famílias \\
\hline $\mathrm{f}_{i j}$ & Frete entre o $h u b i$ e o campo $j$ & USD/tonelada \\
\hline $\mathrm{f}_{j k}$ & Frete entre o local candidato $j$ e o campo $k$. & USD/tonelada \\
\hline $\mathrm{d}_{i j}$ & Distância entre o local candidato $i$ e o campo $j$. & Quilômetros \\
\hline $\mathrm{d}_{\max }$ & Frete entre $h u b i$ e campo $j$. & Quilômetros \\
\hline $\mathrm{cf}_{s}$ & Custo fixo de operação mensal do armazém $s$. & USD/mês \\
\hline $\mathrm{Cv}_{s}$ & Custo variável de operação mensal do armazém $s$. & USD/tonelada \\
\hline $\mathrm{ca}_{r s}$ & $\begin{array}{l}\text { Custo de abertura dos armazéns } \\
\text { do tipo } r \in\{0, R-1\} \text { para o tipo } s \in\{r+1, R\} \text {. }\end{array}$ & USD \\
\hline $\mathrm{cf}_{r s}$ & $\begin{array}{l}\text { Custo de desativação dos armazéns do tipo } \\
r \in\{r+1, R\} \text { para o tipo } s \in\{0, r\} \text {. }\end{array}$ & USD \\
\hline $\operatorname{cap}_{r s}$ & $\begin{array}{l}\text { Capacidade disponível após a mudança } \\
\text { de capacidade de } r \text { para } s \text {. }\end{array}$ & Toneladas/mês \\
\hline M & Valor suficientemente grande. & Adimensional \\
\hline
\end{tabular}

$$
\begin{gathered}
\sum_{j \in J} a_{j k} X_{j k t} \geq q d_{k t} ; \forall t \in T, k \in K \\
X_{j k t} \leq M Y_{j k t} ; \forall t \in T, j \in J, k \in K \\
\sum_{j \in J} Y_{j k t}=1 ; \forall t \in T, k \in K \\
\sum_{r \in R} \sum_{s \in S} a_{s j} \operatorname{cap}_{r s} W_{r s j t} \geq \sum_{k \in K} X_{j k t} ; \forall t \in T, j \in J \\
W_{r s j t}=Z_{r s j t} ; \forall t>0 \in T, j \in J, r \in R, s \in S \mid(r>s) \\
W_{r s j t}=O_{r s j t} ; \forall t \in T, j \in J, r \in R, s \in S \mid(r<s) \\
\sum_{r \in R} W_{r a j(t-1)} \geq \sum_{s \in S} W_{a s j t} ; \forall t>0 \in T, j \in J, a \in R
\end{gathered}
$$


Tabela 6: Lista de variáveis do modelo de localização.

\begin{tabular}{|c|c|c|}
\hline Variável & Descrição & Unidade \\
\hline $\mathrm{X}_{i j t}$ & $\begin{array}{l}\text { Variável de fluxo entre o hub } i \text { e o local } \\
\text { candidato } j \text { no período } t \text {. }\end{array}$ & Toneladas \\
\hline $\mathrm{X}_{j k t}$ & $\begin{array}{l}\text { Variável de fluxo entre o local candidato } j \text { e } \\
\text { o campo de indivíduos em deslocamento } k \text { no período } t \text {. }\end{array}$ & Toneladas \\
\hline $\mathrm{O}_{r s j t}$ & $\begin{array}{l}\text { 1, se o local candidato } j \text { no período } t \text { sofre } \\
\text { uma mudança de nível de } n \text { para } m \text { indicando } \\
\text { aumento de capacidade, } r<s \text {. }\end{array}$ & Binária \\
\hline $\mathrm{W}_{r s j t}$ & $\begin{array}{l}\text { 1, se o local candidato } j \text { opera no período } t \\
\text { com a capacidade disponível após a mudança } \\
\text { de estado (nível) } r \rightarrow s \text {. }\end{array}$ & Binária \\
\hline $\mathrm{Z}_{r s j t}$ & $\begin{array}{l}1 \text {, se o local } j \text { no período } t \text { sofre uma } \\
\text { mudança de nível de } \mathrm{r} \text { para s indicando } \\
\text { diminuição de capacidade, } r>\mathrm{s} \text {. }\end{array}$ & Binária \\
\hline $\mathrm{Y}_{j k t}$ & $\begin{array}{l}\text { 1, se o cliente } k \text { é atribuído ao local } \\
\text { candidato } j \text { no período } t \text {. }\end{array}$ & Binária \\
\hline
\end{tabular}

$$
\begin{gathered}
W_{0 a j 0} \geq \sum_{s \in S} W_{a s j 1} ; \forall j \in J, a \in R \\
\sum_{r \in R} \sum_{s \in S} W_{r s j t}=1 ; \forall t \in T, j \in J \\
\mathrm{~d}_{\mathrm{jk}} * Y_{\mathrm{jkt}} \leq \mathrm{d}_{\max } ; \quad \forall t \in T, j \in J, \mathrm{k} \in \mathrm{K} \\
X_{\mathrm{jkt}} \geq 0, X_{i j t} \geq 0 \\
O_{r s j t} \in\{0,1\}, W_{r s j t} \in\{0,1\}, \\
Z_{r s j t} \in\{0,1\}, Y_{j k t} \in\{0,1\}
\end{gathered}
$$

Para estabelecer as condições necessárias para a modelagem com multi-períodos permitindo aberturas, mudanças de capacidade e encerramento de atividades no local é necessário que se adote os grupos de restrições das Equações de 4.7 a 4.11 . A expressão 4.7 e 4.8 capturam o comportamento da variável $W_{r s j t}$. As próximas duas restrições do modelo, 4.9 e 4.10 são responsáveis por estabelecer uma relação temporal entre os períodos através da variável $W_{r s j k}$, em que os índices $r$ e $s$ permitem que exista uma memória entre períodos e que os estados do sistema possam ser herdados de um período $t-1$ a 
t. A Equação 4.12 permite o estabelecimento de um limite de distância máximo para a cobertura da demanda, assumindo que em alguns casos a distribuição ocorrerá diretamente dos veículos. Assim, a distribuição deverá ocorrer dentro do intervalo de distância estabelecido para que a demanda não seja afetada.

\subsubsection{Linearização do modelo de localização}

Para tratar a não linearidade apresentada no último termo da função objetivo foi necessária a introdução de uma nova variável de decisão $C V A R_{r s j t}$ contínua, que o substituirá. Também é necessário que se adicione três equações (4.16, 4.17 e 4.18).

$$
\begin{gathered}
C V A R_{r s j t} \leq M W_{r s j t} ; \forall t>0 \in T, j \in J, r \in R, s \in S \\
C V A R_{r s j t} \leq \sum_{k \in K} c v_{r s} X_{j k t} ; \forall t>0 \in T, j \in J, r \in R, s \in S \\
C V A R_{r s j t} \leq \sum_{k \in K} \mathrm{c} v_{r s} X_{j k t}+M\left(W_{r s j t}-1\right) ; \forall t>0 \in T, j \in J, r \in R, s \in S
\end{gathered}
$$

\subsection{Modelo de agrupamento de campos}

A determinação dos agrupamentos de campos e o levantamento dos locais candidatos para instalação dos armazéns foi realizada a partir de variações dos modelos tradicionais de P-medianas e P-centros, testados e avaliados quanto a qualidade dos agrupamentos formados em relação ao objetivo do trabalho. Dessa forma, as tabelas com a descrição dos conjuntos, parâmetros e variáveis utilizados nos modelos são apresentadas a seguir, Tabelas 7,8 e 9 .

Tabela 7: Lista de conjuntos do modelo de agrupamento de campos.

\begin{tabular}{ll}
\hline Conjuntos & Descrição \\
\hline$j \in J$ & Locais candidatos a receber armazéns \\
& intermediários \\
$k \in K$ & Campos para abrigamento de famílias deslocadas \\
\hline
\end{tabular}

A Equações 4.19 a 4.21 referem-se ao modelo clássico de P-medianas em que deseja-se localizar $P$ instalações buscando a minimização dos custos relativos ao atendimento do nó $k$ pelo nó $j$, aqui representado pela distância percorrida no arco $\widehat{j k}$. 
Tabela 8: Lista de parâmetros do modelo de agrupamento de campos.

\begin{tabular}{cll}
\hline Parâmetro & Descrição & Unidade \\
\hline $\mathrm{a}_{K}$ & Demanda do nó $k$ & Famílias \\
$\mathrm{d}_{\text {total }}$ & Demanda ou população total & Famílias \\
$\mathrm{d}_{j k}$ & Distância do nó $j$ ao nó $k$ & $\mathrm{~km}$ \\
$\mathrm{p}$ & número de instalações a localizar & Adimensional \\
\hline
\end{tabular}

Tabela 9: Lista de variáveis do modelo de agrupamento de campos.

\begin{tabular}{clc}
\hline Variável & Descrição & Unidade \\
\hline $\mathrm{X}_{j k}$ & 1 se o nó $k \in K$ for designado ao & Binária \\
& nó $j \in J$ e 0 em caso contrário & \\
$\mathrm{W}_{j}$ & $\begin{array}{c}1 \text { se o nó } j \in J \text { é usado como } \\
\end{array}$ & Binstalação e 0 em caso contrário \\
\hline
\end{tabular}

$$
\begin{gathered}
\min \sum_{j \in J} \sum_{k \in K} d_{j k} X_{\mathrm{jk}} \\
\sum_{j \in J} X_{\mathrm{jk}}=1 \\
W_{j} \geq X_{\mathrm{jk}} \\
\sum_{j \in J} W_{j}=p \\
X_{\mathrm{jk}} \in\{0,1\}, W_{j} \in\{0,1\}
\end{gathered}
$$

O segundo modelo avaliado foi o de P-centros, em que o modelo passa a minimizar a máxima distância percorrida entre os arcos do modelo. A função objetivo do modelo anterior, então, é substituído pelas Equações 4.24 e 4.25 .

$$
\begin{gathered}
\min D_{M A X} \\
d_{j k} X_{\mathrm{jk}} \leq D_{M A X} ; \forall j \in J, k \in K
\end{gathered}
$$

Outro modelo avaliado corresponde a uma adaptação do modelo de P-centros anterior, em que deseja-se minimizar a máxima distância ponderada pela demanda (modelo de P-centros ponderado). Para inclusão dessa nova condição as Equações 4.24 e 4.25 são substituídas pelas Equações 4.26 e 4.27 a seguir, em que $M$ corresponde a máxima 
distância ponderada.

$$
\begin{gathered}
\min M \\
\frac{a_{k} d_{j k} X_{\mathrm{jk}}}{d_{\text {total }}} \leq M ; \forall j \in J, k \in K
\end{gathered}
$$

Por fim, um quarto modelo é proposto, cujo objetivo é minimizar a distância máxima entre os pontos de suprimento e demandas, bem como minimizar a distância total percorrida. Dessa forma, as Equações 4.28 e 4.29 combinam a função objetivo dos modelos clássicos de P-medianas e de P-centros.

Para garantir que a máxima distância seja prioridade na otimização considera-se um número suficientemente grande $(M)$ como peso do primeiro termo da função objetivo. Isto garante que se obtenha a mínima distância máxima, mas também que a distância total seja minimizada.

$$
\begin{gathered}
\min M * D_{M A X}+\sum_{j \in J} \sum_{k \in K} d_{j k} X_{j k} \\
d_{j k} X_{\mathrm{jk}} \leq D_{M A X} ; \forall j \in J, k \in K
\end{gathered}
$$

\subsection{Estratégias de solução}

Os modelos construídos para o problema serão otimizados utilizando o solver comercial Gurobi em sua versão acadêmica. Assim como é adotada uma abordagem em estágios de tomada de decisão, em que as decisões sobre a determinação dos agrupamentos de campos e a determinação dos locais candidatos para as instalações são definidas anteriormente através de um modelo adaptado de p-medianas, estágio que será apresentado no capítulo de preparação dos dados. Em seguida, as demais decisões são consideradas no modelo de localização de armazéns com múltiplos períodos, no qual são determinados quais locais serão abertos ou fechados, o instante no horizonte no qual ocorrem as decisões de abertura e desativação, e as capacidades necessárias nas instalações. Também são determinadas as atribuições das demandas respeitando as decisões quanto aos agrupamentos da decisão anterior.

O modelo de localização multi-período será utilizado para a análise da estratégia de cooperação inter-agências versus estratégia sem a cooperação. Para tanto, foi necessária a modificação do modelo que deixou de apresentar clusters e hardroofs, em que os locais candidatos são os próprios campos de indivíduos em deslocamento, e cada armazém deve suprir apenas o campo no qual se instalou. Esta adaptação é apresentada no Apêndice 


\section{A.1.}

Para as análises comparativas entre a aplicação de modelos estáticos e com múltiplos períodos em problemas de localização em operações humanitárias, o modelo também sofre uma pequena alteração exposta no Apêndice A.2. Neste modelo o índice $t$ referente aos períodos analisados deixa de existir e utiliza-se a média das demandas observadas para a análise.

Por fim, aplicou-se o modelo de localização utilizando uma abordagem de horizontes rolantes, em que pretende-se avaliar a utilização do modelo aplicado ao planejamento e sua performance em relação às novas informações recebidas pelo sistema.

No capítulo a seguir serão comentados de forma mais detalhada os parâmetros apresentados neste capítulo, bem como as análises sobre os locais candidatos para localização dos armazéns dos agrupamentos de campos, em que agências compartilham as instalações.

(RODRÍGUEZ-ESPÍNDOLA; ALEM; Pelegrin Da Silva, 2020) (BALCIK et al., 2019) (LI; RAMSHANI; HUANG, 2018) (MENG et al., 2018) (WANG; SHI; HU, 2019) (ALIZADEH; NISHI, 2020) (XIANG; WEI, 2020) (BASHIRI et al., 2018) (DOODMAN et al., 2019) (KLIBI; ICHOUA; MARTEL, 2018) (VELASQUEZ; MAYORGA; CRUZ, 2019) (HASANI; MOKHTARI, 2018) (FANG et al., 2018) (GAZANI; Akhavan Niaki; Akhavan Niaki, 2020) (INCA; NIKORN, 2019) (WANG; SITU; YU, 2019) (GHASEMI et al., 2019) (MUNYAKA; YADAVALLI, 2020) 


\section{ANÁLISE E PREPARAÇÃO DE DADOS}

O capítulo tem como objetivo a descrição dos dados utilizados na resolução do modelo matemático proposto. Desse modo, são apresentados a preparação dos dados coletados sobre a operação e valores estimados para o modelo, bem como são definidos os agrupamentos de campos e os entes que compõe ou poderão compor a nova cadeia proposta neste estudo.

\subsection{Produtos distribuídos aos beneficiários}

Durante a operação estabelecida no Iraque os produtos enviados aos deslocados eram consolidados em kits dentro dos padrões estabelecidos pelo projeto Sphere (2011). Nele encontram-se os procedimentos e condições para que as agências atuem de forma efetiva e responsável, apresentando informações específicas, por exemplo, sobre volumes de água necessários para atividades como higiene pessoal e preparo de alimentos.

Tabela 10: Categorização dos kits distribuídos.

\begin{tabular}{lllll}
\hline Rede & Descrição & $\begin{array}{l}\text { Frequência } \\
\text { semestral }\end{array}$ & $\begin{array}{l}\text { Massa uni- } \\
\text { tária }(\mathrm{kg})\end{array}$ & $\begin{array}{l}\text { Massa total } \\
(\mathrm{kg}) / \text { semestre }\end{array}$ \\
\hline A & Itens não alimentares & 2 & 50 & 100 \\
A & Botijão de gás & 2 & 15 & 30 \\
A & Alimentos de resposta rápida & 1 & 8 & 8 \\
A & kit de higiene de resposta rápida & 1 & 5 & 5 \\
A & kit de água de resposta rápida & 1 & 25 & 25 \\
A & kit de higiene & 6 & 7 & 42 \\
A & kit dignidade & 7 & 3 & 21 \\
A & kit para bebês & 7 & 0.8 & 5.6 \\
B & kit familiar de alimentos & 6 & 70 & 420 \\
\hline
\end{tabular}

Fonte: Santos (2021).

Os beneficiários recebem kits de diversas categorias, sendo as informações apresenta- 
das na Tabela 10 sobre cada categoria obtidas através de um especialista. Nela é apresentada a frequência de entrega dos itens em uma escala semestral, e os valores unitários de massa para cada kit foram gerados considerando que estes seriam entregues a famílias com 6 integrantes em média.

A distribuição de suprimentos em cadeias humanitárias pode ser divida em duas redes distintas com diferentes categorias de produtos. Santos (2021) utiliza dois valores de densidades diferentes para cada tipo de kit, em que a rede A corresponde a suprimentos alimentares, cuja densidade é de $500 \mathrm{Kg} / \mathrm{m}^{3}$. A rede B, por sua vez, possuí densidade de $250 \mathrm{Kg} / \mathrm{m}^{3}$.

Nesta dissertação estabeleceu-se uma taxa média mensal agregada em quilogramas por família, que se apresenta mais adequada ao problema proposto cujos horizontes de planejamento possuem períodos mensais de análise. Assim, obtém-se uma massa média mensal de $40 \mathrm{~kg}$ de produtos da rede $\mathrm{A}$ e $70 \mathrm{~kg}$ de produtos da rede $\mathrm{B}$, com volumes por pacote de 0,16 e $0,14 \mathrm{~m}^{3}$, respectivamente. Destes valores adota-se um volume médio mensal que agrega todos os produtos descritos, cujo peso médio é de 109,43kg.

\subsection{Levantamento dos nós da malha logística e deman- das}

A cadeia de suprimentos analisada apresenta três níveis, que podem ser observados na Figura 11, que apresenta os nós correspondentes aos armazéns centrais (hubs), aos nós dos locais candidatos (campos e cidades candidatas) e aos pontos de demanda/campos levantados no trabalho. Para informações mais detalhadas sobre os entes da cadeia, a Tabela 23 no apêndice deste documento lista todos os campos planejados e suas ocupações durante o período, além de detalhar as agências responsáveis por cada um dos locais através dos sufixos nos nomes.

Como pode-se observar as agências se distribuem no território iraquiano para atender as demandas. De forma que, um determinado campo pode apresentar campos adjacentes ou vizinhos sendo geridos por agências distintas. Estes campos apresentam estruturas independentes e as cadeias de distribuição dos itens de alívio são estabelecidas de forma independente, uma vez que no cenário base analisado cada campo era suprido por armazéns próprios e exclusivos das agências responsáveis.

A lista de locais candidatos para o problema é composta pelos campos de deslocados que foram planejados e/ou ocupados durante o horizonte de operação e por cidades can- 
didatas selecionadas. Para a definição das cidades candidatas foram adotados critérios como proximidade dos beneficiários, segurança, e facilidade de acesso à mão-de-obra e serviços. Assim, os parâmetros utilizados nesta determinação foram: (i) a distância entre a cidade candidata e Mosul deveria ser de até $230 \mathrm{~km}$ e (ii) a população do local deveria ser superior a 40 mil habitantes (SANTOS, 2021).

Figura 11: Localização dos nós da malha logística.
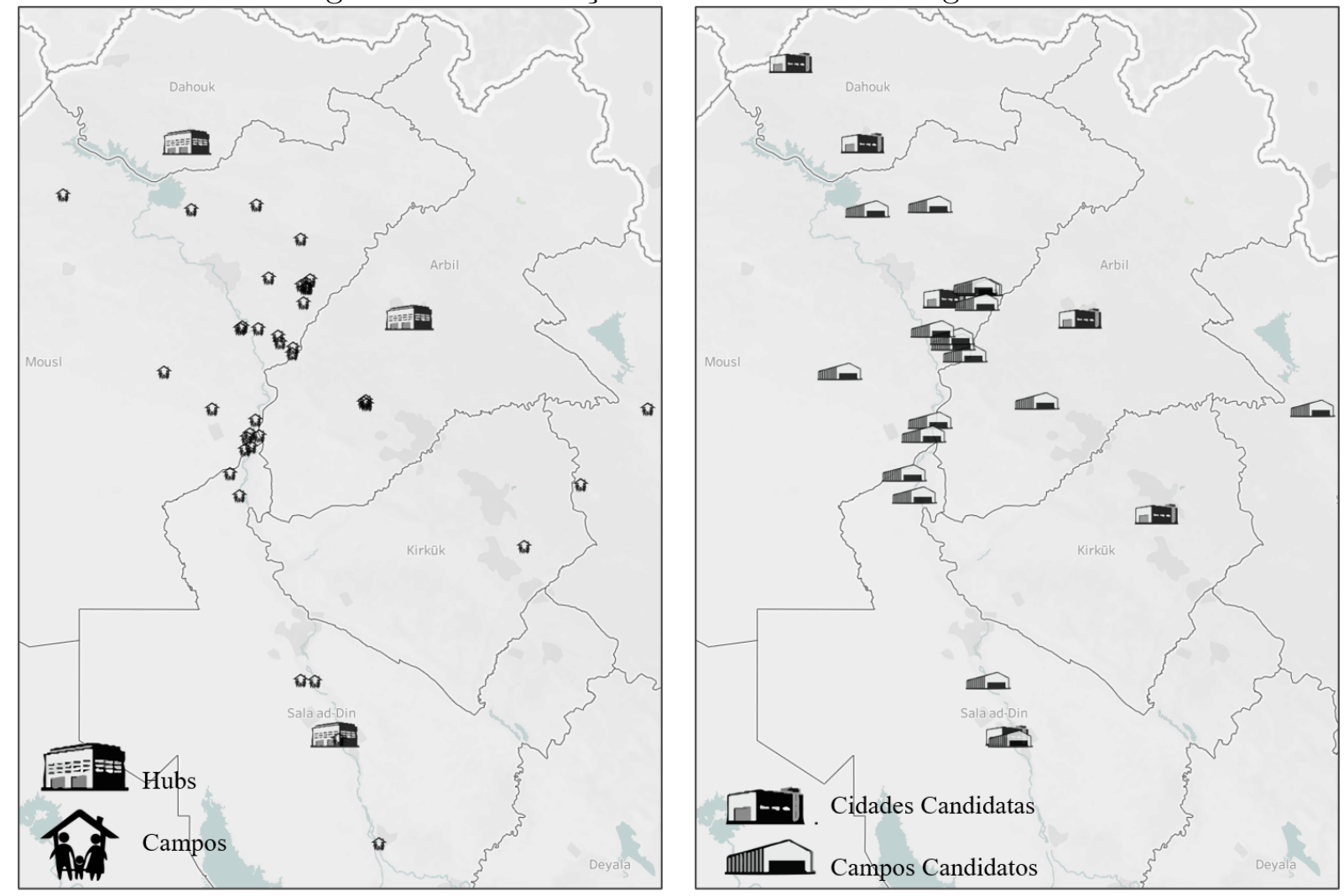

Fonte: Elaboração própria.

Para levantar as demandas dos campos de deslocados foram utilizados relatórios disponibilizados digitalmente e publicamente no ReliefWeb (repositório disponibilizados pelo Escritório das Nações Unidas para Coordenação de Assuntos Humanitários) e no CCCMIRAQ (que monitora e realiza a documentação dos deslocados internamente no Iraque).

Na primeira base foram coletados 49 relatórios publicados entre o período de outubro de 2016 e julho de 2017, com informações sobre a capacidade planejada, disponível e ocupada nos campos. Os dados foram unificados e tratados, e a nomeação de diversos campos padronizada. Observou-se que diversos campos foram planejados sem que suas implementações ocorressem de fato. Esta identificação foi possível, pois estes campos apresentavam apenas informações sobre o planejamento de suas capacidades. O mapa a esquerda na Figura 12 representa todos os campos planejados encontrados neste primeiro levantamento. 
Figura 12: Histórico sobre a ocupação, disponibilidade e quantidade de campos planejados durante a operação.

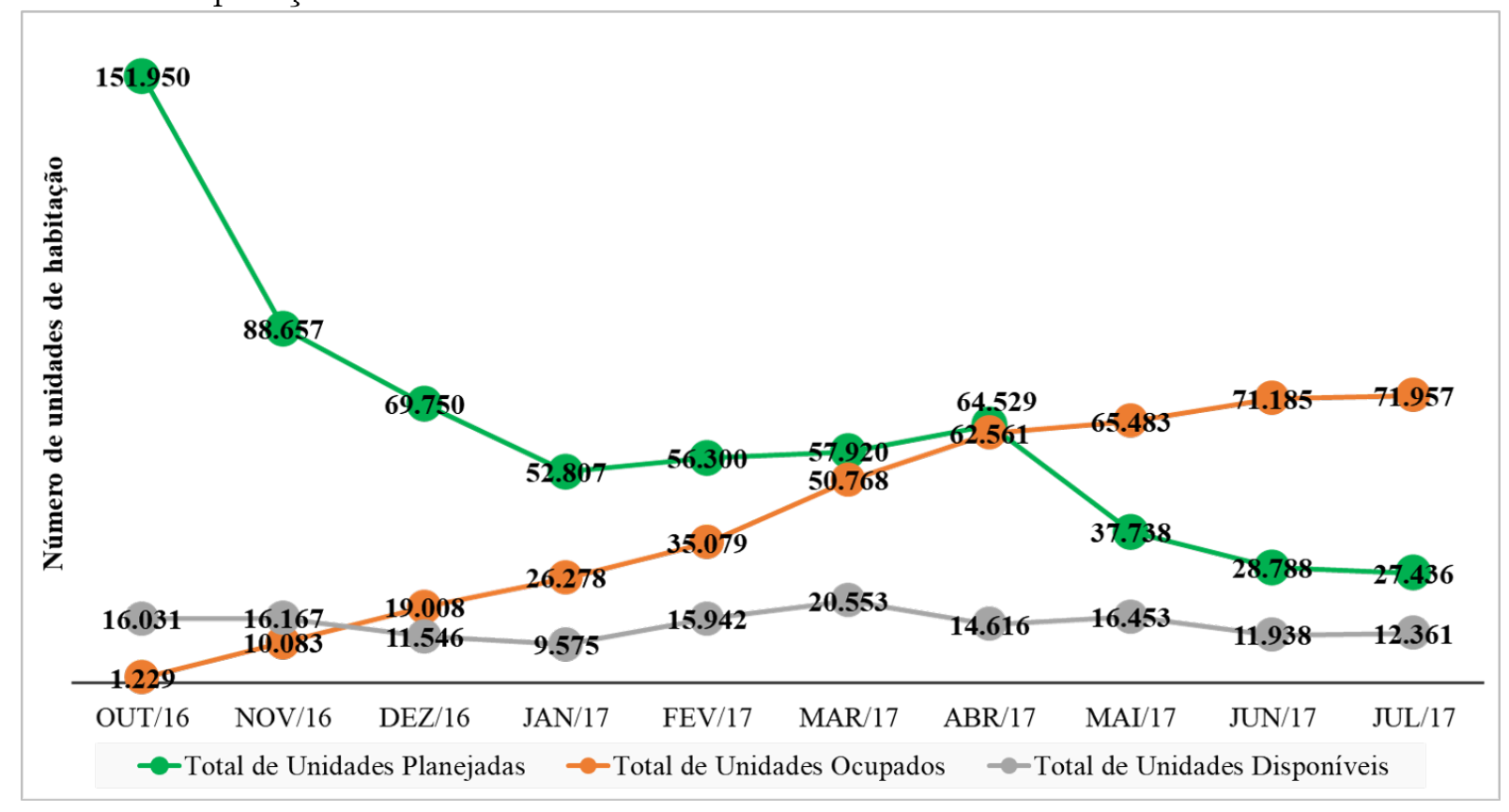

Fonte: Elaboração própria.

A Figura 12 apresenta a progressão da quantidade de unidades de abrigo ocupadas, disponíveis e planejadas nos campos durante o período, em que as unidades disponíveis são aquelas construídas mas não foram ocupadas. Em geral adotava-se uma família composta por 6 indivíduos para cada unidade habitacional. Observa-se que a ocupação aumenta conforme o avanço da operação, e que a curva de projeção da quantidade de habitações planejadas apresenta grandes variações ao longo do horizonte, o que pode representar a dificuldade de planejamento neste tipo de operações, que apresentam alta imprevisibilidade, fazendo com que os tomadores de decisão adotem estratégias como a de projeção de cenários (SANTOS, 2021).

A segunda base utilizada proveniente da CCCM apresentava uma estrutura de armazenagem dos dados diferente da anterior, em que encontrou-se 2124 arquivos com extensão do tipo "PDF". Estes arquivos continham informações mais detalhadas sobre o perfil de cada campo, referentes ao período entre janeiro de 2017 e dezembro de 2017. Traziam informações sobre o perfil de idade e gênero dos abrigados, assim como a quantidade de integrantes por família, além de avaliações sobre as condições de educação, sanitárias e de saúde do local. As informações relevantes utilizadas neste trabalho foram: (i) quantidade de unidades de habitação ocupadas, (ii) disponíveis e (iii) o total de unidades de cada local. A Figura 13 sumariza o processo de busca documental que será detalhado a seguir.

A extração de informações dos dois mil arquivos foi feita através da utilização da 
Figura 13: Processo de busca documental de demandas do ano de 2017.

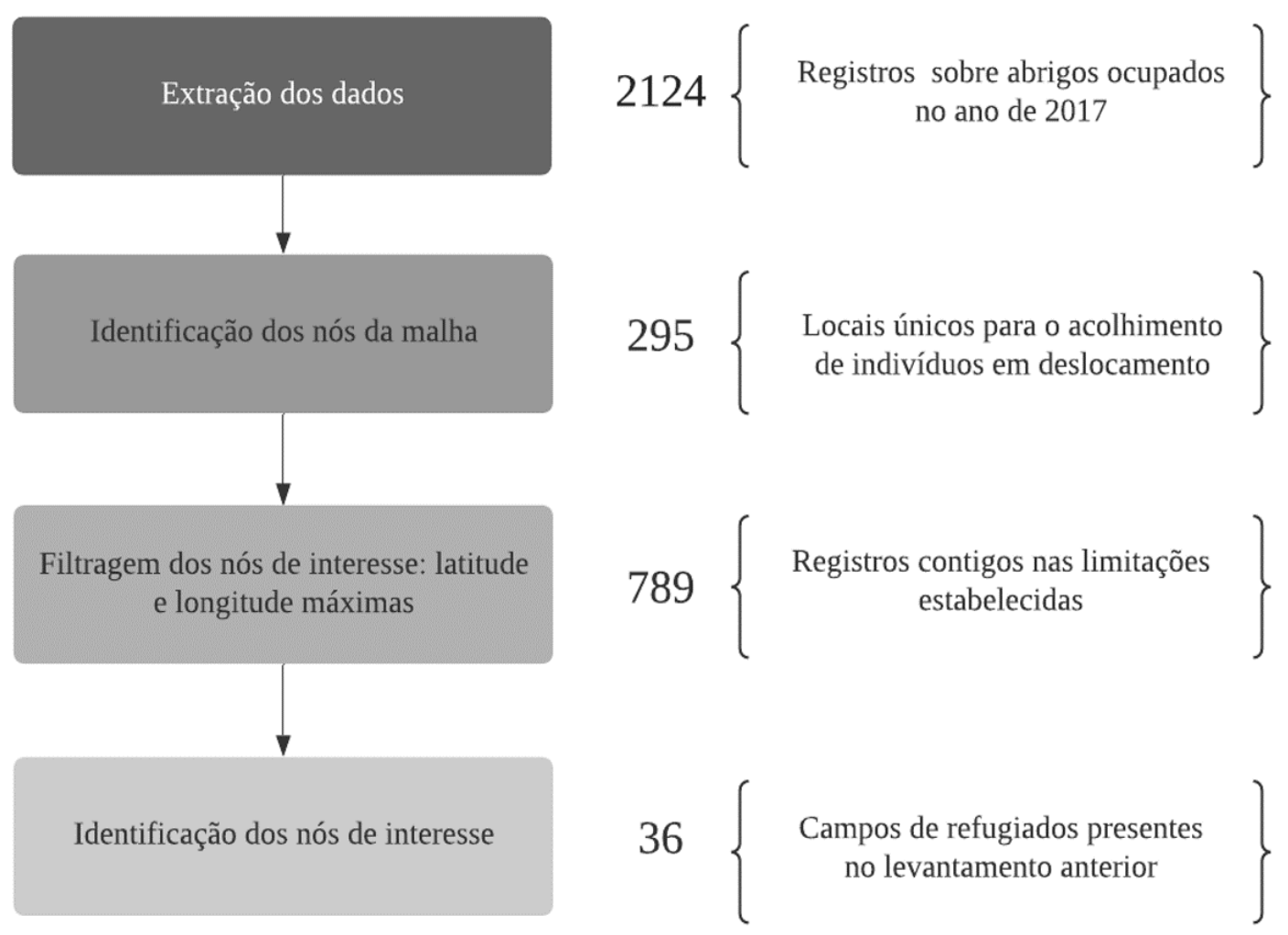

Fonte: Elaboração própria.

biblioteca Python "PyPDF2", utilizada para dividir, mesclar, cortar e transformar páginas de "PDFs". Entretanto, mais do que isso, é possível que se extraia texto e metadados dos "PDFs"através desta. Em parte dos documentos obteve-se erro na utilização do módulo "PYPDF2". Para estes documentos utilizou-se outros dois módulos, o "PIL"que oferece recursos de edição de imagens, e a "pytesseract"utilizada para extrair textos de imagens de "PDFs".

Após a leitura identificou-se a presença de 295 abrigamentos na base formada. Isto significa que dos dois mil registros encontrados para 12 meses de operação, identificou-se quase 300 nomes únicos utilizados para designação dos locais de abrigo. A partir destes locais únicos, procurou-se combinar os dados das duas fontes adotando-se os campos planejados encontrados na primeira base como locais de referência para as filtragens na segunda base coletada. Dessa foram, realizou-se uma primeira filtragem dos campos contidos no polígono formado pelas latitudes e longitudes máximas e mínimas da base de outubro de 2016 a julho de 2017. Os campos resultantes da primeira filtragem correspondem a 789 registros. 
Por fim, uma comparação manual foi realizada para que as duas bases fossem combinadas. Desta forma, o mapa a esquerda da Figura 14 apresenta os campos planejados encontrados na primeira busca documental, que abrange outubro de 2016 a julho de 2017 . Enquanto a direita da figura encontra-se o mapa dos os campos levantados nos relatórios do ano de 2017. É válido destacar que os campos não previstos no planejamento da operação de Resposta à batalha de Mosul, isto é, não observados na primeira busca, não foram considerados no trabalho e estão destacados no mapa a direita da Figura 14.

Figura 14: Comparação entre as localizações de campos identificados nos dois processos de busca documental.
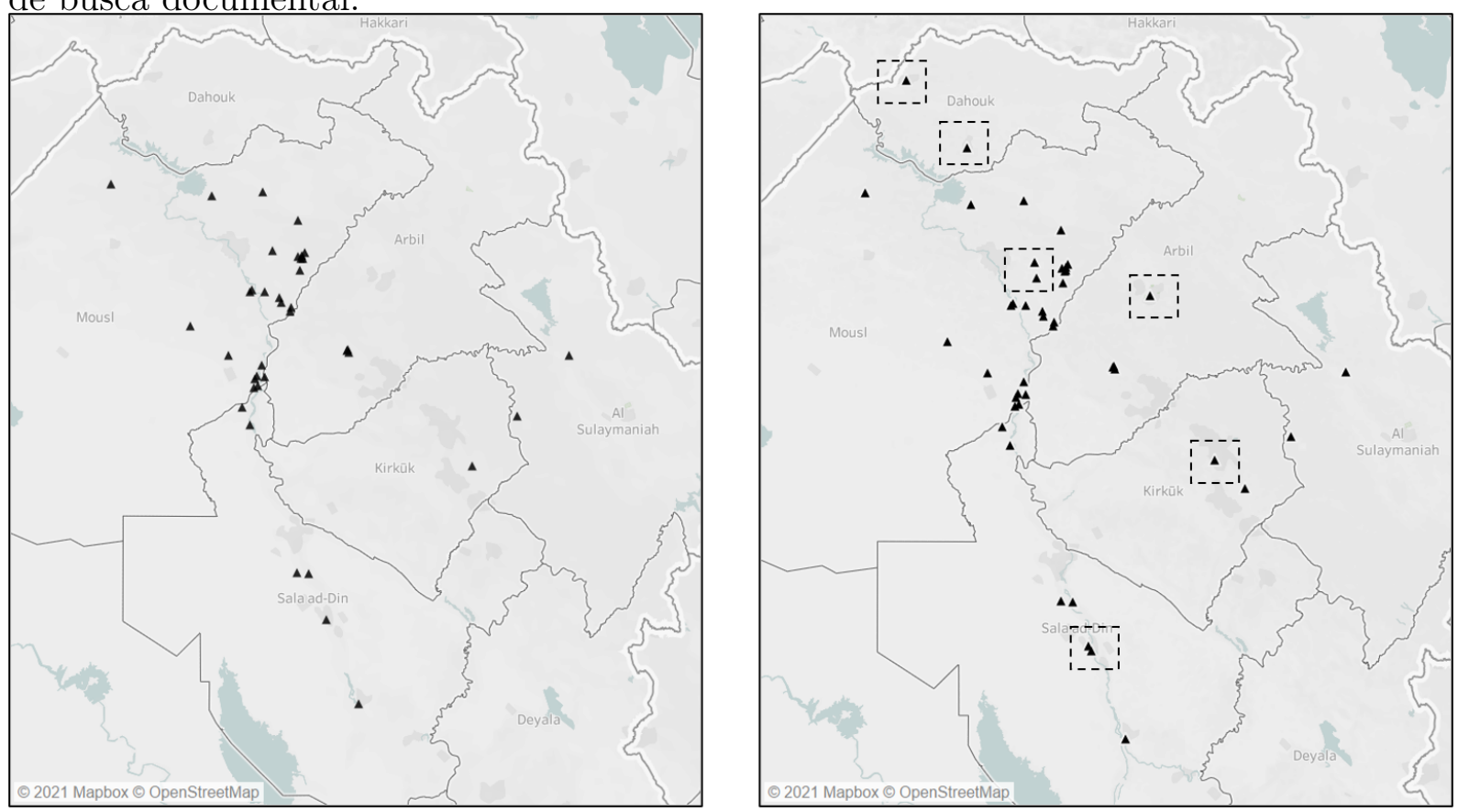

Fonte: Elaboração própria.

Dessa forma, considerou-se os campos planejados levantados no estudo para as análises dos locais candidatos deste trabalho, isto é, a definição inicial dos clusters teve como ponto de partida os locais planejados para a operação.

\subsubsection{Determinação dos parâmetros de distância}

A cadeia de suprimentos representada apresenta três níveis de instalações, conforme descrito no levantamento dos nós da malha. Dessa forma, obteve-se as distâncias entre os elos da cadeia através do Python Client do Google Maps Services. 


\subsubsection{Locais candidatos para armazenagem pública e agrupamen- tos de campos}

A tomada de decisão do problema segue em estágios, em que as decisões sobre as formação dos clusters são independentes e anteriores ao modelo de definição do plano de abertura de armazéns. Dessa forma, são considerados dois problemas que são resolvidos de forma sequencial em duas fases. Esta seção tratará sobre a primeira fase de definição dos locais candidatos e seus respectivos agrupamentos de campos.

Para a identificação da melhor abordagem para a definição dos agrupamentos e dos locais candidatos a armazenagem pública, utilizou-se variações do modelo de p-medianas. Através da variação do parâmetro de número de instalações verificou-se as distâncias máximas obtidas a fim de selecionar o modelo e a quantidade de locais candidatos de armazenagem adequados.

Na Tabela 11, o modelo 1 corresponde ao problema tradicional de P-medianas, enquanto o modelo 2 representa o modelo de P-centros ponderado, que considera a minimização da máxima distância percorrida ponderada pelas demandas nos campos. O modelo 3 corresponde ao modelo tradicional de P-centros, que realiza a minimização da distância máxima percorrida, de forma que todos os nós apresentam igual peso na decisão. E por fim, no quarto modelo deseja-se minimizar tanto a máxima distância percorrida quanto a distância total percorrida.

Os resultados obtidos demostram que os modelos 3 e 4 apresentam os melhores valores de máxima distância, gerando agrupamentos com melhor qualidade. Entretanto, observa-se através das Figuras 15 e 16 que modelo 4 apresenta resultados mais adequados a realidade tratada. O modelo 3 minimiza a máxima distância, mas pode gerar agrupamentos em que a os campos não são adjacentes ou aqueles mais próximos. O modelo 4 resolve este problema através de minimização da distância máxima e do total percorrido, mas assume-se um peso maior a primeira decisão de máxima distância, para que esta seja dominante no modelo. A Tabela 12 apresenta os resultados da distância total percorrida obtidos nos modelos 3 e 4 e a variação na distância obtida.

Por fim, a partir dos resultados obtidos pelo modelo 4, define-se o conjunto de locais candidatos para pontos de armazenagem comum, que serão parâmetros de entrada para o modelo de localização proposto. O conjunto adotado neste trabalho foi o obtido para um número $P$ de instalações igual a 26. 
Figura 15: Configuração da malha logística para $p=26$ do modelo de P-centros.

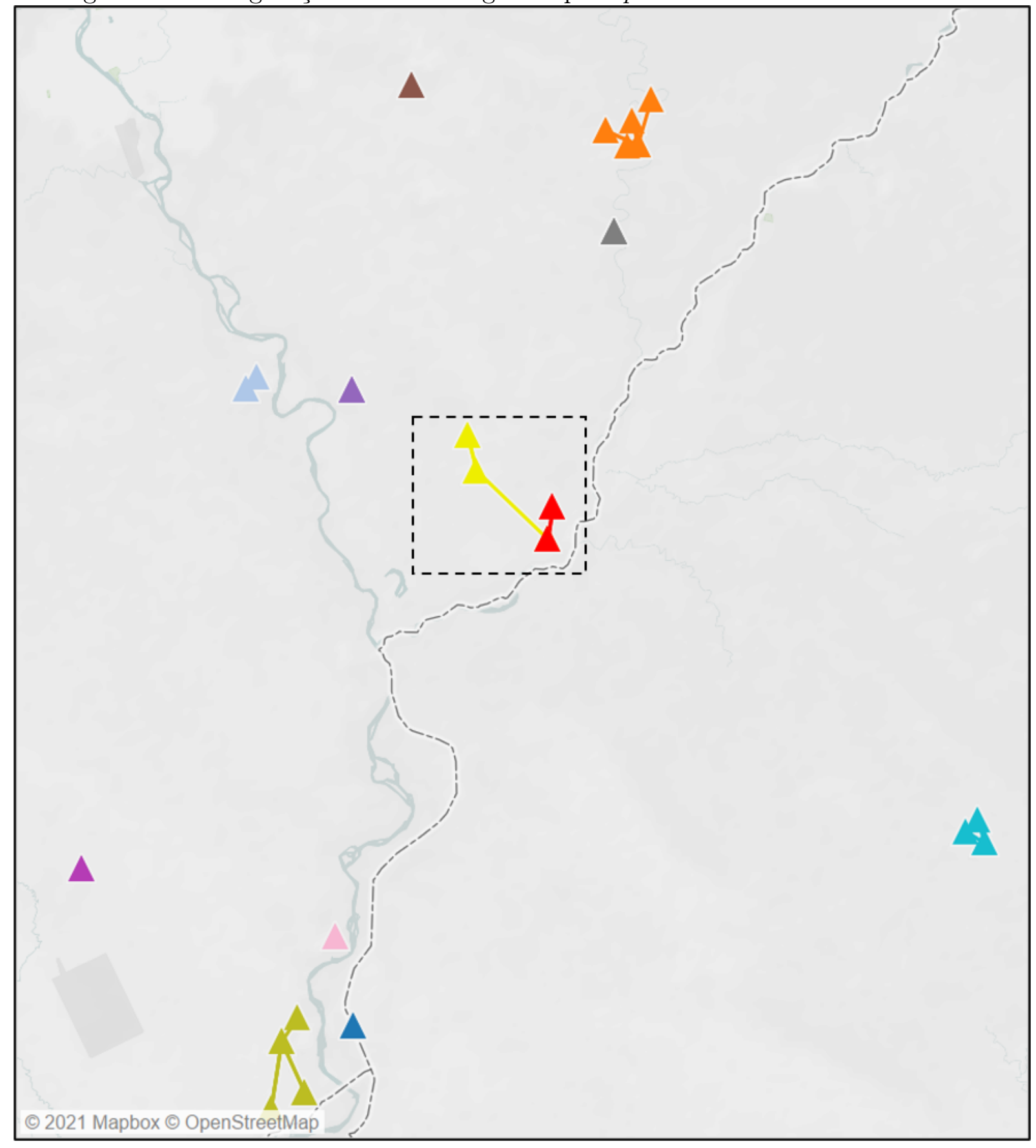

Fonte: Elaboração própria. 
Figura 16: Configuração da malha logística para $p=26$ do modelo de P-medianas minimizando a distância máxima e a soma total de distâncias.

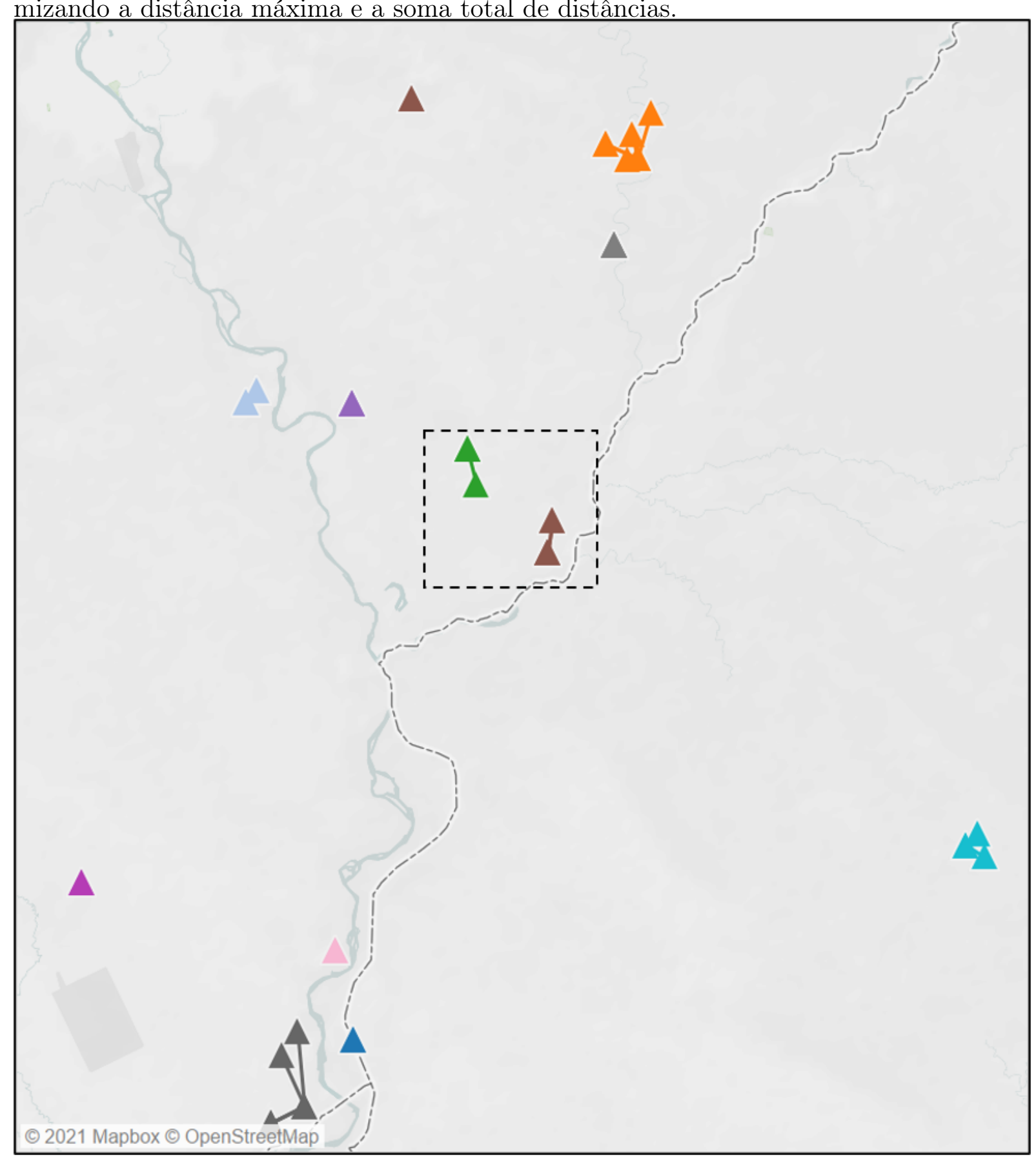

Fonte: Elaboração própria.

\subsection{Níveis de capacidade e tipos de instalações}

Esta dissertação considera dois tipos de armazéns, móveis e de alvenaria. Os armazéns móveis exigem um preparo do terreno. Posteriormente as estruturas modulares são montadas sobre a fundação, o que incorre em diferentes custos de abertura se comparado 
aos armazéns de alvenaria.

Para o cálculo das capacidades, custos de operação e abertura dos MSUs foi adotado o tamanho padrão de 10x32m e altura máxima de 2,5m, além de 6 opções de configurações de MSUs. Para o cálculo das capacidades de armazenagem considera-se uma área útil igual a $70 \%$ para o armazenamento e um giro quinzenal de estoque.

No caso dos armazéns de alvenaria optou-se por 5 níveis de capacidade com tamanhos próximos aos níveis de armazenagem móveis. Dessa forma, tem-se a possibilidade de escolha entre 11 níveis, respeitando as restrições de localização dos dois tipos de instalação. Isto é, os armazéns do tipo hardroof (alvenaria) podem ser localizados nas cidades candidatas, e os armazéns moveis nos próprios campos.

Devido ao caráter de duração transitória das operações humanitárias a construção de instalações de alvenaria é limitada, optando-se pela utilização de instalações alugadas do tipo hardroofs. Neste trabalho, este tipo de instalação é atribuído às cidades candidatas selecionadas. Em contra partida, os MSUs são utilizados nos campos de deslocados.

\subsection{Determinação dos custos logísticos}

Os custos foram calculados utilizando dados disponibilizados pelo agente colaborador sobre os recursos e operações desempenhadas nos armazéns. Por exemplo, tinha-se informações sobre a quantidade e o custo homem/dia para atividades rotineiras como de rearranjo, limpeza e tarefas sem envolvimento de movimento de entrada/saída; custos de manuseio e das empilhadeiras, nas opções em que o volume de movimentações justifica a utilização destas; custos relacionados a equipe administrativa; veículos; equipamentos de escritório; segurança; entre outros.

A Figura 17 apresenta a estrutura de custos aplicada ao problema, composta por custos fixos e variáveis de operação, abertura e expansão, desativação ou decréscimo de capacidade e custos de transporte. Estes custos variam conforme o nível de capacidade instalada no local e tipo de instalação. Dessa forma, para os MSUs, tem-se custos operacionais fixos, variáveis, de incremento e decréscimo variando conforme o número das unidades móveis instaladas. Os tamanhos de hardroofs abordados também apresentam componentes de custos semelhantes, entretanto com algumas especificidades que serão melhor detalhadas.

Os custos de transporte, por sua vez, variam conforme o veículo selecionado para o transporte entre os níveis da rede. As sessões subsequentes apresentam um detalhamento 
maior sobre cada um dos componentes do custo apresentados na Figura 17.

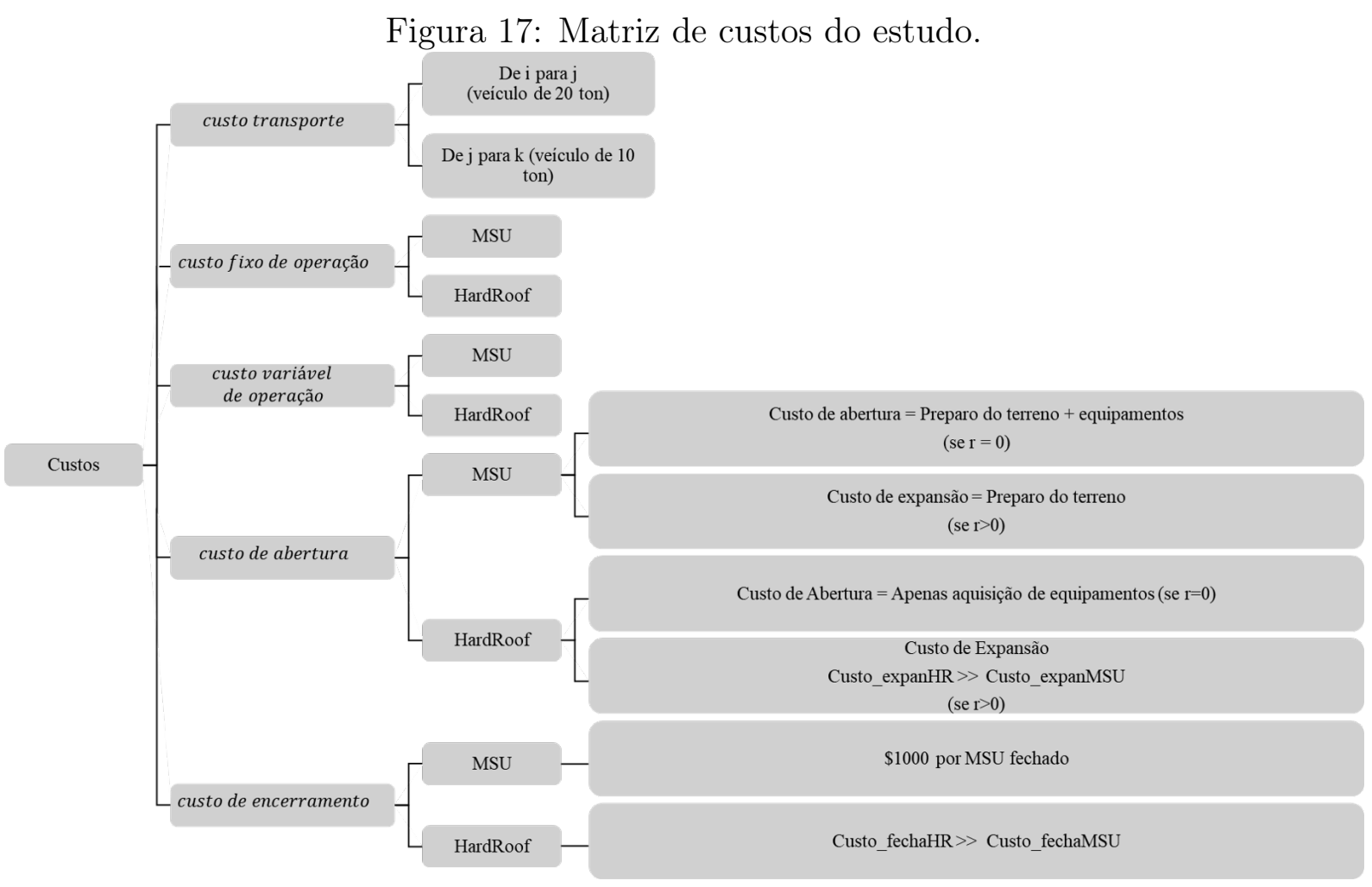

Fonte: Elaboração própria.

\subsubsection{Custos de abertura ou incremento de capacidade}

Os custos de abertura e incremento dependem da capacidade de movimentação e do tipo de armazém escolhido. Dessa forma, a Figura 18 elenca os 11 níveis de capacidade classificados por tipo e tamanho, além de apresentar seus respectivos custos de abertura. Neste estudo adota-se o termo custo de abertura como o custo de se implantar uma instalação inicialmente, isto é, quando parte-se do nível de capacidade zero em $t-1$. Por sua vez, o custo de incremento representa o aumento de capacidade em determinado local candidato, significando que o nível de capacidade em $t$ é superior a capacidade instalada em $t-1$, em que esta segunda é diferente de zero.

No caso de armazéns móveis os custos de abertura correspondem àqueles empregados no preparado do terreno (nivelamento, pavimentação, iluminação etc.) necessários para se instalar os armazéns, bem como os custos de aquisição de equipamentos de manuseio, paletes, rolos plásticos, prateleiras, além de equipamentos de TI e móveis de escritório e para os armazéns. Os custos de incremento de capacidade correspondem aos custos relativos ao preparo da área adicional de armazenagem e aos demais custos de aquisição de equipamentos necessários para a operação do armazém. 
As opções de armazéns de alvenaria elencadas na Figura 18, por sua vez, não possuem custos de preparo, pois se tratariam de estruturas alugadas preexistentes nas cidades candidatas. Assim, os custos que incidem na abertura referem-se apenas aos de aquisição de equipamentos, insumos e móveis, também presentes nos custos de abertura dos armazéns móveis. Por apresentar pouca flexibilidade na mudança de capacidade, os custos de incremento de capacidade nos armazéns de alvenaria foram considerados suficientemente grandes para que a expansão de capacidade não fosse considerada uma alternativa viável economicamente.

Figura 18: Custos de abertura.

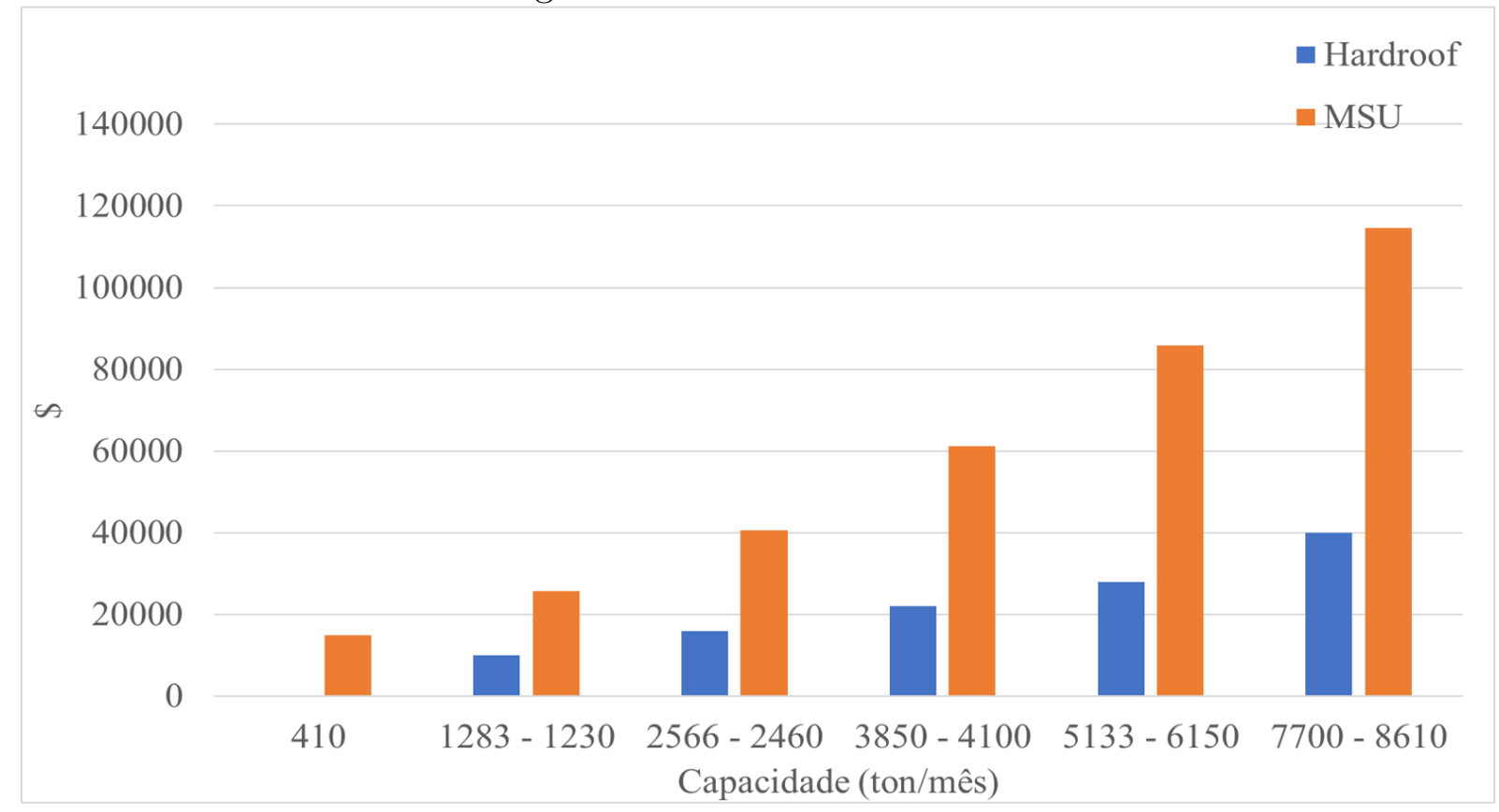

Fonte: Elaboração própria.

\subsubsection{Custos de desativação ou decréscimo de capacidade}

Os custos de decréscimo de capacidade representam os custos associados a mudança no nível de capacidade de um período a outro, em que a capacidade instalada em $t$ é inferior ao nível instalado em $t-1$. No caso dos armazéns móveis, este custos representam o valor empregado no desmantelamento das estruturas levantadas, o qual possui um valor fixo de U\$ 1.000 por armazém. Adotou-se a nomenclatura de custos de desativação quando o nível de capacidade do estado final é igual a zero.

Em contra partida, os armazéns de alvenaria são considerados estruturadas de difícil mobilização, e assumiu-se que os contratos firmados são de longa duração. Dessa forma, seus custos de desativação foram considerados suficientemente grandes para impedir seu 
fechamento ou decréscimos na capacidade instalada, anteriormente ao fim do horizonte de planejamento. Nesse tipo de instalação um decréscimo representaria uma mudança no local físico contratado para o armazenamento.

\subsubsection{Custos de operação}

Dentre os custos associados ao modelo proposto tem-se custos mensais de operação das instalações alocadas, que foram divididos entre custos fixos e variáveis. Os custos variáveis correspondem aos custos relativos as atividades de movimentação dos itens e carregamento dos caminhões para a distribuição. Dessa forma, não é considerado o custo financeiro associado a armazenagem dos itens. O desempenho dessas atividades irá demandar o uso de diferentes quantidade de recursos que dependerá do volume médio movimentado. Assim, assumiu-se que para armazéns móveis com tamanhos superiores a $1344 \mathrm{~m}^{2}$ o uso de empilhadeiras seria justificado pelo volume movimentado, reduzindo a necessidade de mão-de-obra empregada.

Em contra partida, os armazéns de alvenaria apresentam maiores possibilidades de automação, e o emprego de empilhadeiras é realizado mesmo em armazéns de $500 \mathrm{~m}^{2}$, o que tem impacto relevante nos custos de operação variáveis. A Figura 19 apresenta uma análise comparativa entra os custos variáveis das duas categorias de instalações, em que pode-se perceber os ganhos em mecanização dos armazéns de alvenaria.

Os custos fixos de operação dividem-se em custos empregados no transporte, armazenamento e manuseio de bens no armazém, e em custos relativos a gestão e administração. O primeiro componente é constituído por custos associados ao manuseio do estoque, que não representam recebimento ou despacho de itens, serviço de empilhadeiras (em que o aluguel e mão-de-obra necessários são empregados em quantias fixas mensais), mão-deobra empregada na gestão dos armazéns, aluguel de veículos utilizados na locomoção de colaboradores. Os custos de gestão e administração correspondem aos custos desprendido à equipe administrativa, que não dedicam-se exclusivamente a um único armazém, bem como custos recorrentes com aluguel da instalação, no caso dos armazéns de alvenaria. Os custos recorrentes também englobam taxas de comunicação, material de escritório, custos relativos a segurança do pessoal etc.

Para estimar os custos para cada nível de capacidade, apresentados na Figura 20, realizou-se extrapolações dos valores reais obtidos para os custos fixos na operação de 5 armazéns móveis (localizados em um dos campos do estudo) e um armazém de alvenaria de $1000 \mathrm{~m}^{2}$. Dos valores obtidos, identificou-se aqueles componentes que variariam com o 
Figura 19: Custos variáveis de operação.

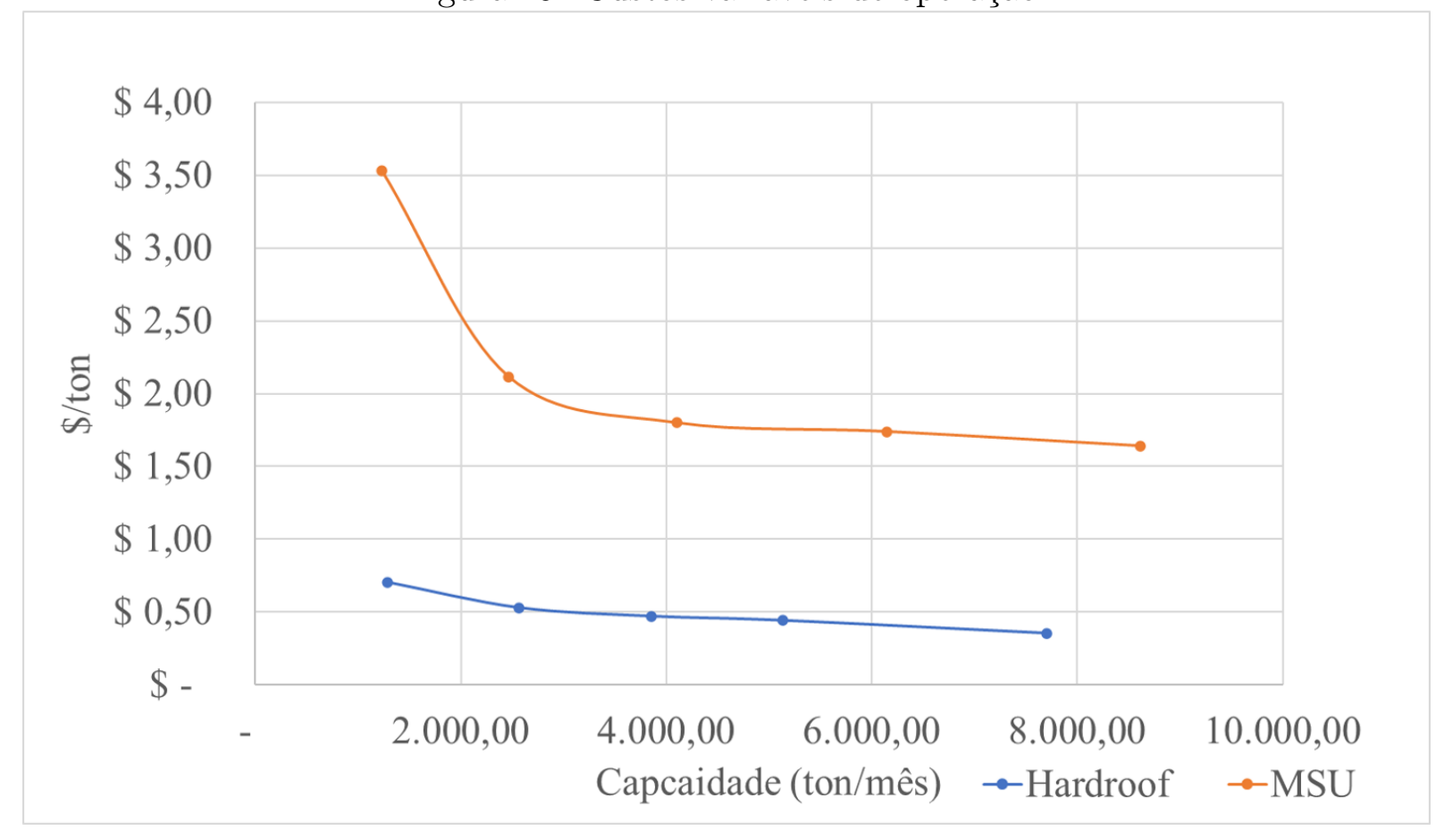

Fonte: Elaboração própria.

tamanho da instalação e obteve-se valores adequados a capacidade instalada, bem como foi feito um planejamento dos recursos necessários para cada tamanho de armazém. Além disso, considerou-se que os valores empregados na gestão e administração dos armazéns não apresentariam relação direta com o tamanho do armazém instalado.

\subsubsection{Custos de Transporte}

Durante a operação, as agências humanitárias detinham fácil acesso à contratação de serviços de transporte de cargas do tipo lotação, com a disponibilidade de veículos com capacidade de 8, 10 e 20 toneladas. Serviços do tipo carga fracionada não eram praticados (SANTOS, 2021). A partir de dados fornecidos pelo agente da operação, o autor calculou os custos de transporte por faixa de distância utilizando uma amostra de 26 pontos. Este estudo adota os veículos com capacidade de transporte de 10 toneladas para o primeiro trecho e 20 toneladas no segundo, e os valores gastos em frete são calculados em função da massa transportada mensalmente. Isto é, deixa-se de se considerar o custos de transporte por viagem, e passa-se a contabilizar por tonelada transportada. 
Figura 20: Custos fixos de operação.

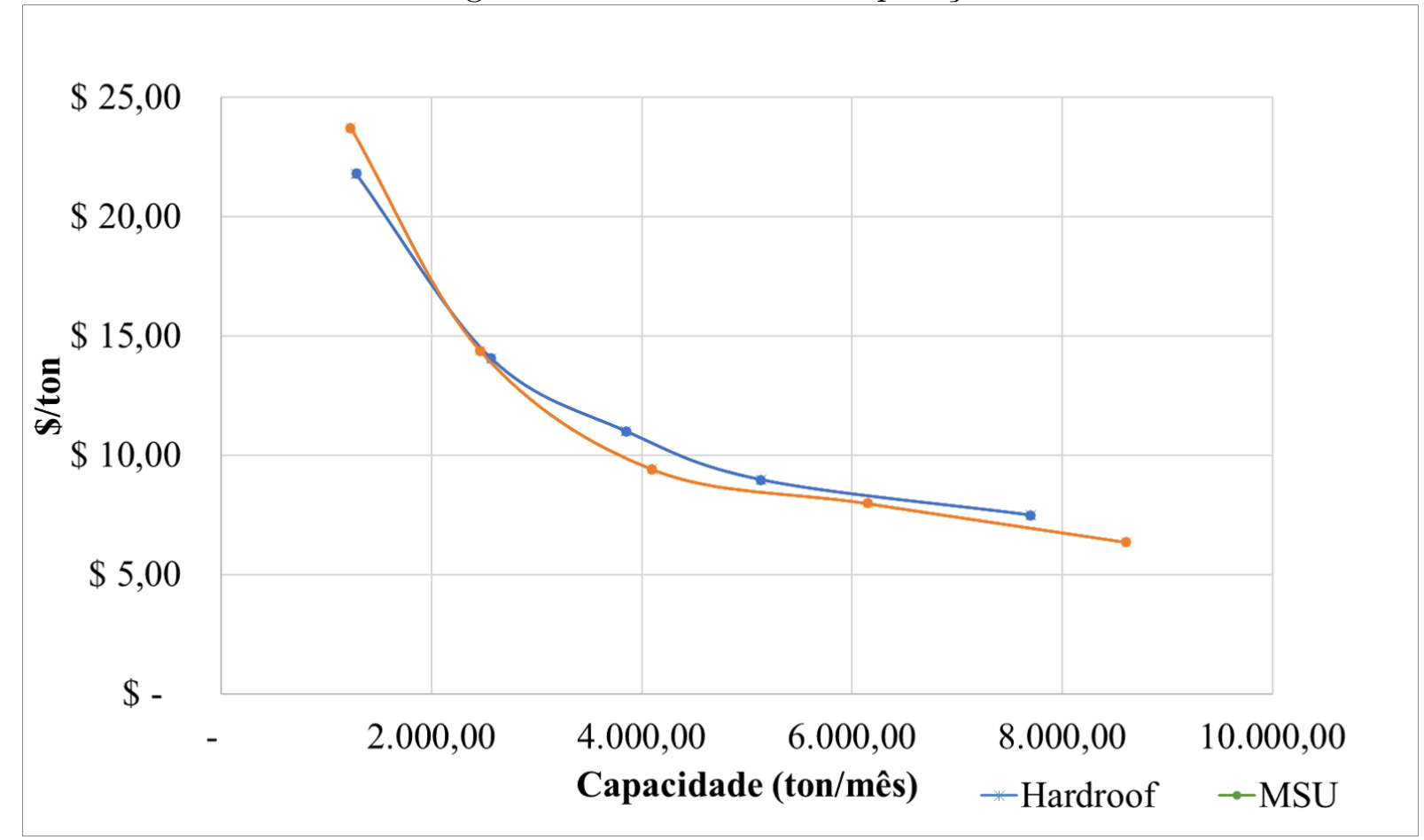

Fonte: Elaboração própria. 
Tabela 11: Distância máxima obtida entre local candidato para instalação do armazém do agrupamento e seus respectivos campos integrantes.

\begin{tabular}{|c|c|c|c|c|}
\hline Número de instalações & Modelo 1 & Modelo 2 & Modelo 3 & Modelo 4 \\
\hline 10 & 76,3 & 174,5 & 48,9 & 48,9 \\
\hline 11 & 76,3 & 174,5 & 48,1 & 48,1 \\
\hline 12 & 76,3 & 174,5 & 43,8 & 43,8 \\
\hline 13 & 56,4 & 174,5 & 37,8 & 37,8 \\
\hline 14 & 56,4 & 174,5 & 33,5 & 33,5 \\
\hline 15 & 56,4 & 174,5 & 30,2 & 30,2 \\
\hline 16 & 48,9 & 174,5 & 28,4 & 28,4 \\
\hline 17 & 48,9 & 174,5 & 27,0 & 27,0 \\
\hline 18 & 48,9 & 174,5 & 21,7 & 21,7 \\
\hline 19 & 46,5 & 174,5 & 16,9 & 16,9 \\
\hline 20 & 21,7 & 174,5 & 16,8 & 16,8 \\
\hline 21 & 21,7 & 174,5 & 15,7 & 15,7 \\
\hline 22 & 21,7 & 174,5 & 12,1 & 12,1 \\
\hline 23 & 21,7 & 174,5 & 10,3 & 10,3 \\
\hline 24 & 16,9 & 252,0 & 9,2 & 9,2 \\
\hline 25 & 12,1 & 252,0 & 8,0 & 8,0 \\
\hline 26 & 9,2 & 252,0 & 7,7 & 7,7 \\
\hline 27 & 9,2 & 253,5 & 7,2 & 7,2 \\
\hline 28 & 7,7 & 95,1 & 6,0 & 6,0 \\
\hline 29 & 7,7 & 105,7 & 5,3 & 5,3 \\
\hline 30 & 6,0 & 95,1 & 4,0 & 4,0 \\
\hline 31 & 3,3 & 95,1 & 3,3 & 3,3 \\
\hline 32 & 2,6 & 95,1 & 2,6 & 2,6 \\
\hline 33 & 1,9 & 95,1 & 1,9 & 1,9 \\
\hline 34 & 1,9 & 105,7 & 1,8 & 1,8 \\
\hline 35 & 1,8 & 105,7 & 1,4 & 1,4 \\
\hline 36 & 1,4 & 105,7 & 1,3 & 1,3 \\
\hline 37 & 1,3 & 105,7 & 1,1 & 1,1 \\
\hline 38 & 0,0 & 105,7 & 0,0 & 0,0 \\
\hline
\end{tabular}


Tabela 12: Distância total entre arcos da rede de distribuição formada.

\begin{tabular}{|c|c|c|c|}
\hline Número de Instalações & Modelo 3 & Modelo 4 & Variação (\%) \\
\hline 10 & 1133,5 & 920,5 & $-19 \%$ \\
\hline 11 & 1091,9 & 871,7 & $-20 \%$ \\
\hline 12 & 1178,2 & 980,9 & $-17 \%$ \\
\hline 13 & 988,1 & 915,3 & $-7 \%$ \\
\hline 14 & 816,5 & 604,5 & $-26 \%$ \\
\hline 15 & 551,7 & 503,9 & $-9 \%$ \\
\hline 16 & 515,8 & 460,8 & $-11 \%$ \\
\hline 17 & 472,0 & 385,1 & $-18 \%$ \\
\hline 18 & 418,0 & 331,2 & $-21 \%$ \\
\hline 19 & 356,0 & 326,9 & $-8 \%$ \\
\hline 20 & 335,9 & 310,0 & $-8 \%$ \\
\hline 21 & 288,6 & 276,4 & $-4 \%$ \\
\hline 22 & 190,9 & 189,8 & $-1 \%$ \\
\hline 23 & 178,8 & 177,7 & $-1 \%$ \\
\hline 24 & 127,4 & 126,4 & $-1 \%$ \\
\hline 25 & 114,9 & 104,3 & $-9 \%$ \\
\hline 26 & 87,0 & 63,4 & $-27 \%$ \\
\hline 27 & 57,9 & 55,8 & $-4 \%$ \\
\hline 28 & 45,3 & 40,0 & $-12 \%$ \\
\hline 29 & 35,2 & 34,0 & $-3 \%$ \\
\hline 30 & 25,5 & 23,4 & $-8 \%$ \\
\hline 31 & 17,2 & 14,5 & $-15 \%$ \\
\hline 32 & 11,2 & 11,2 & $0 \%$ \\
\hline 33 & 11,0 & 8,6 & $-22 \%$ \\
\hline 34 & 8,0 & 6,7 & $-17 \%$ \\
\hline 35 & 5,9 & 4,8 & $-18 \%$ \\
\hline 36 & 4,5 & 3,4 & $-23 \%$ \\
\hline 37 & 2,1 & 2,1 & $0 \%$ \\
\hline 38 & 0,0 & 0,0 & $0 \%$ \\
\hline
\end{tabular}

Fonte: Elaboração própria. 


\section{RESULTADOS E DISCUSSÕES}

O objetivo deste capítulo é apresentar e analisar os resultados obtidos através do modelo matemático proposto no Capítulo 4, considerando os horizontes de demandas obtidos e as hipóteses dispostas sobre o problema. Para resolução do modelo foi utilizada a linguagem de programação $\mathrm{C}++$ e o solver Gurobi v9.1, em um computador de 64 GB de memória RAM, processador Intel(R) Core(TM) i9-9900KF com oito núcleos, 16 threads, clock de 3.6 a $5.0 \mathrm{GHz}$, e o sistema operacional Windows 10.

Inicialmente foi construída uma instância ilustrativa e feita uma verificação do modelo proposto, analisando as restrições que expressão o estado do sistema, isto é, as restrições que garantem a abordagem multi-período do problema. As instâncias para esta etapa são apresentadas no Apêndice (A).

A Seção 6.1 expõe a solução do modelo estudado para casos com ou sem compartilhamento de recursos entre organizações humanitárias, destacando as diferenças entre as duas estratégias descritas na Seção 1.2. Para avaliar o impacto das ações coordenadas entre agências, foram realizados experimentos para as duas opções de configuração de malha. A estratégia original era marcada por forte descentralização das operações e redundâncias na cadeia de suprimentos, enquanto o estudo propõe uma nova configuração que permite a centralização das operações e cooperação entre agências humanitárias.

Em seguida, na Seção 6.2 avalia-se a adequação e o impacto da utilização do modelo multi-período em estudos sobre localização de armazéns e estoques humanitários. Através do caso prático, a solução do modelo multi-período é comparada a solução obtida para o modelo estático, que parte da demanda média no horizonte analisado para cada campo. A Seção 6.3 apresenta de forma detalhada a solução obtida através da abordagem de solução de horizontes rolantes, em que se objetiva destacar a utilização do modelo em períodos de replanejamento através da atualização dos dados sobre as expectativas de ocupação dos campos. Por fim, na Seção 6.4 as mudanças na configuração da malha são analisadas sob a ótica da restrição de cobertura da demanda. Isto é, verifica-se como a variação no limite aceito para o deslocamento entre pontos de armazenagem e pontos de demanda impacta 
as decisões sobre a localização.

Durante o processamento das análises não foram estabelecidos limites para tempo de processamento e para o gap (diferença entre os limites superior e inferior atuais). Dessa forma, o modelo centralizado apresentou 272.160 variáveis, das quais 239.040 são binárias e seu tempo de processamento foi de 19,23 segundos para atingir o gap de $0 \%$. O modelo descentralizado, por sua vez, apresentou 440.124 variáveis, das quais 96.647 são binárias e levou 100,10 segundos para seu processamento. Na análise de sensibilidade do modelo centralizado, executou-se o modelo em lotes através do terminal Windows, iniciando o parâmetro de distância máxima de cobertura em oito quilômetros e o incrementando em um quilômetro a cada iteração. Inicia-se em oito quilômetros, pois a distância máxima calculada através do modelo de agrupamentos é de 7,7 quilômetros. Dessa forma, o modelo foi executado 193 vezes até que se atingisse $200 \mathrm{~km}$ como distância máxima de cobertura.

\subsection{Impacto da adoção da estratégia de compartilha- mento de recursos}

Nesta seção os resultados para o caso colaborativo e não colaborativo são comparados através da demanda real, isto é, a ocupação real medida nos campos. Neste cenário cada campo ao ser aberto possui um armazém próprio, de forma que as decisões sobre abertura de armazéns apresentadas na Figura 23 acompanham a variação de demanda nos campos. O número de armazéns abertos é consideravelmente maior no cenário base, que manteve até 21 instalações abertas durante o horizonte analisado.

O mês de junho (período 8) possui maior demanda agregada, representando cerca de 10 mil toneladas. Entretanto, apresenta 20 armazéns operando, o que se deve aos padrões de demanda obtidos. O mês de fevereiro (período 4) apresenta aproximadamente metade da demanda de junho, enquanto maio (período 7) possuí uma demanda inferior em cerca de 1000 toneladas em relação à junho. No entanto, estes meses apresentaram uma instalação a mais do que o mês de junho devido à presença de demandas pontuais em dois campos, Al'Shamah sob a gerência da UNDP e em Zelikan gerido pelo governo iraquiano (MODM).

Pode-se observar que não existe uma mudança significativa na configuração da cadeia entre o mês de maio em junho, exceto pela desativação de Zelikan e expansão de As Salamyiah_2: N.GovUNHCR e Chamakor_UNHCR. A mesma comparação feita entre fevereiro e junho revela uma mudança mais acentuada nas decisões sobre localização, 
em que observa-se a desativação dos campos Al-Alam_MODM Al-Alam_UNHCR, e Al Sh'hamah_UNDP; o surgimento dos campos As Salamyiah_2: N.GovUNHCR e Hasansham U2_UNHCR; e expansões em Chamakor_UNHCR, Haj Ali_IOM, Hammam al-Alil_UNHCR e Qayyarah Jad'ah_MODM.

Ao observar toda a cadeia logística através da Figura 21, verifica-se que as decisões de localização de armazéns variam pouco sob o aspecto geográfico entre os períodos de fevereiro, maio e junho de 2017, apesar das alterações apontadas acima e do evidente aumento de demanda. Em contrapartida, observa-se através da Figura 22, que de outubro de 2016 a outubro de 2017 ocorre não só o aumento da demanda exigindo aumento na capacidade instalada nos armazéns, mas a malha se modifica através do surgimento de diversos novos pontos de suprimento no território iraquiano. A configuração em outubro é semelhante àquelas apresentadas na Figura 21, entretanto no mês de dezembro observa-se alterações mais destacadas. Neste último mês identifica-se a desativação de instalações próximas a As Salamyiah_2: N.GovUNHCR e o surgimento de novas instalações (Surdesh_MODM e Basateen Al Sheuokh_UNDP). 
Figura 21: Comparação entre a configuração da malha logística dos meses de fevereiro, maio e junho de 2017.

Fevereiro de 2017

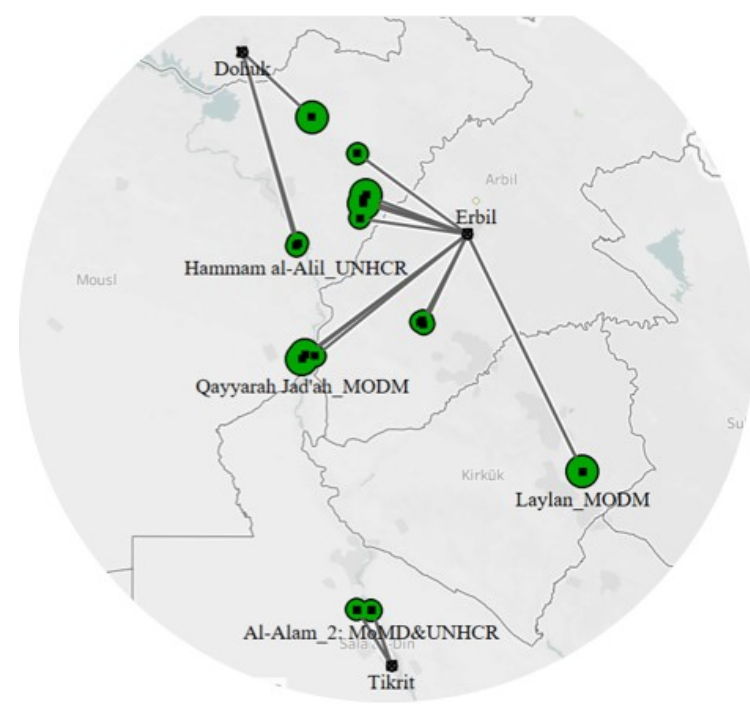

Maio de 2017

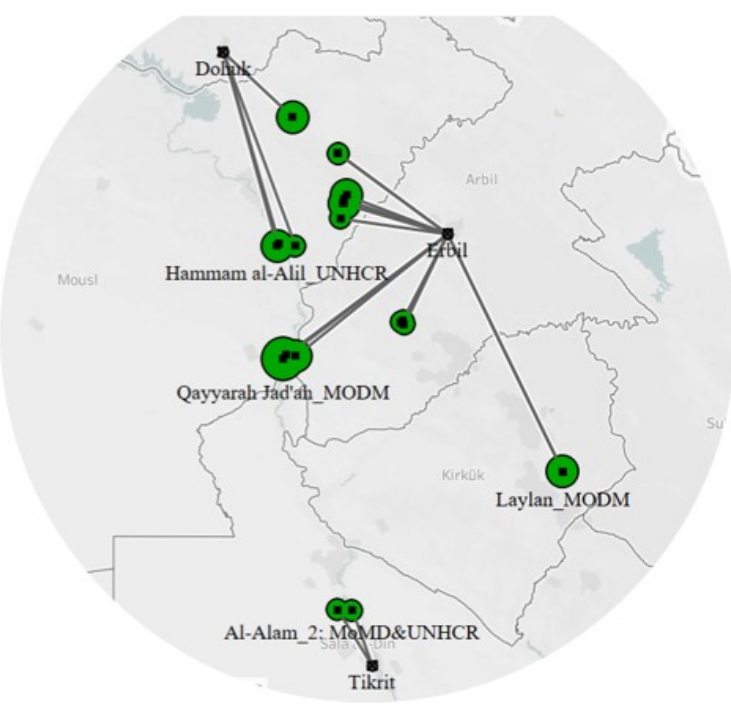

Junho de 2017

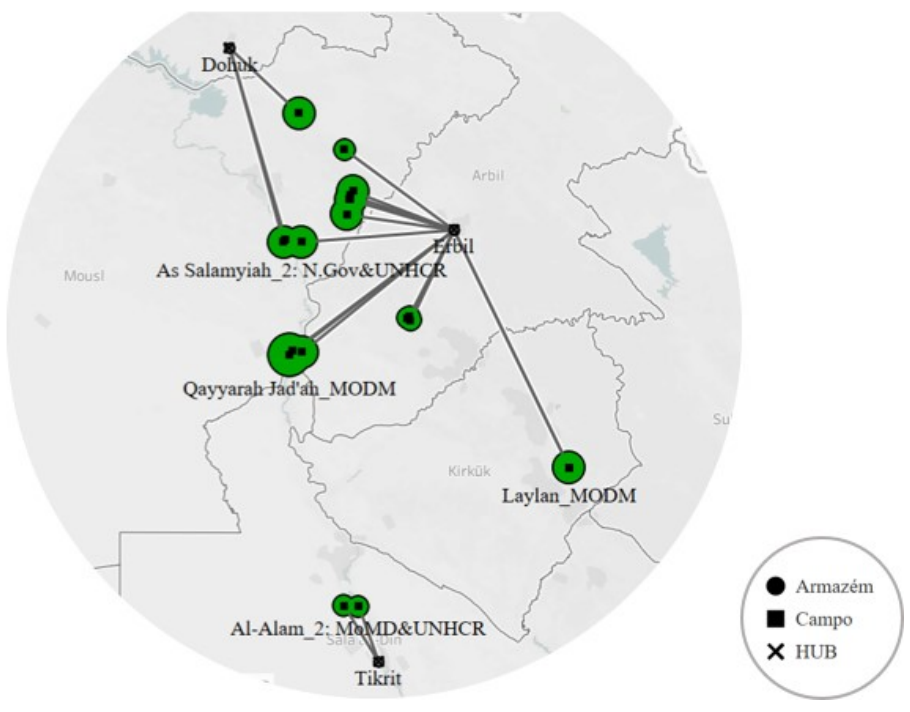

Fonte: Elaboração própria. 
Figura 22: Comparação entre a configuração da malha logística dos meses de outubro de 2016, maio e junho de 2017.

Outubro de 2016

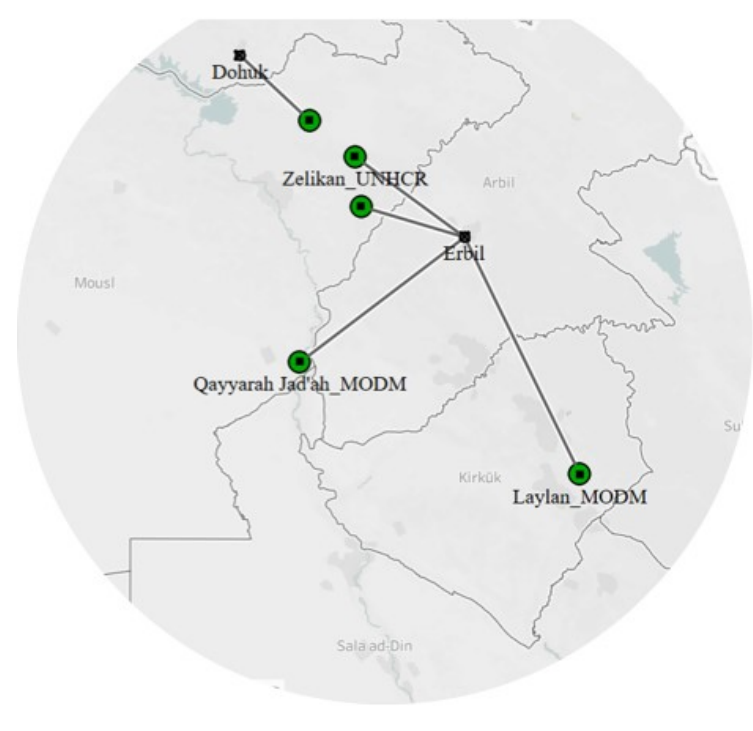

Outubro de 2017

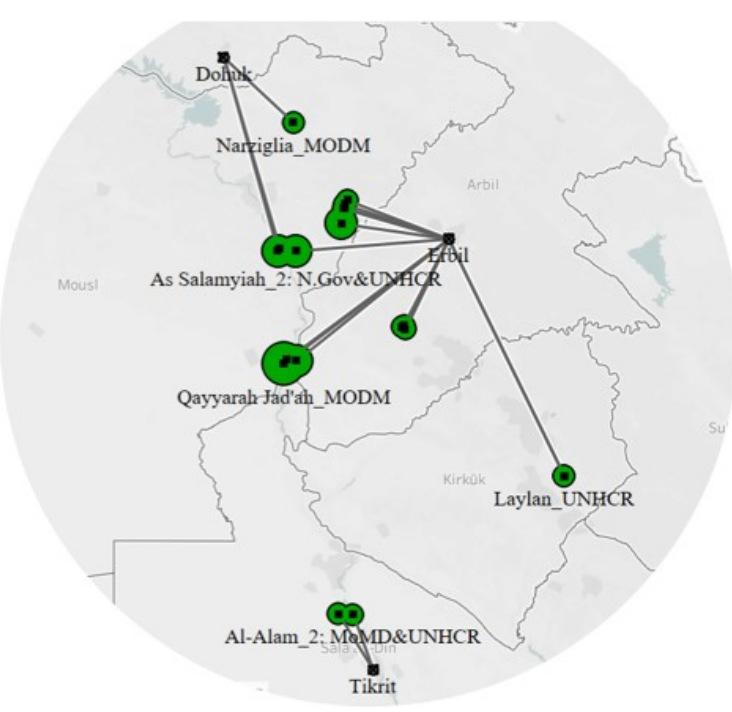

Fonte: Elaboração própria.
Dezembro de 2017

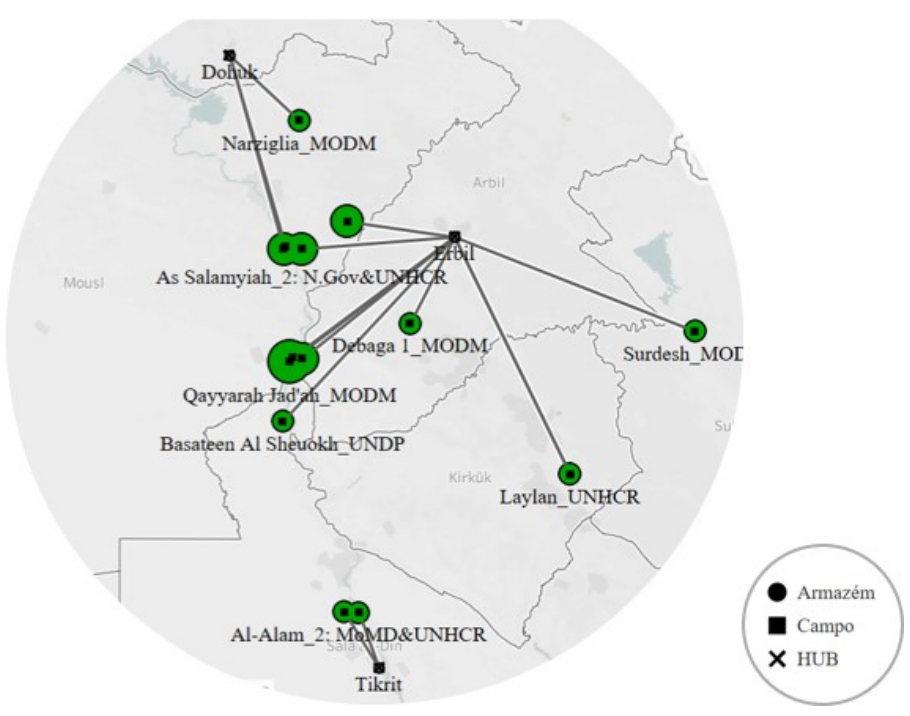


A solução obtida para malha logística proposta, Figura 24, apresenta uma cadeia mais compacta, o que reduziria o esforço de gestão empregado nas instalações, devido a menor quantidade de instalações. Desta forma, o mês com maior quantidade de instalações operando, 11 no total, agora passa a ser o mês de novembro, em que dois novos campos planejados no início da operação finalmente apresentam ocupações (Surdesh_MODM e Basateen Al Sheuokh_UNDP).

A redução no número de instalações requeridas na operação pode ser observada através da diferença entre a soma das quantidades mensais de instalações operando nos dois experimentos, o que revelou uma redução de 119 instalações. Isto significa que na malha proposta seriam utilizadas em média 7,9 instalações a menos por mês, e resultaria uma redução na capacidade instalada no sistema de 10 mil toneladas.

A análise dos custos logísticos, Tabela 13, revela uma economia de 2,4 milhões de dólares no horizonte de análise. Os custos de transportes apresentaram uma redução de 1\% no primeiro trecho, enquanto no segundo trecho o custo de transporte não é considerado na malha logística atual do sistema, pois os armazéns são instalados nos próprios campos. Os custos destes trechos representam respectivamente $19 \%$ e $16 \%$ do custo total da malha alternativa, enquanto o custo do primeiro trecho na malha atual seria equivalente a $14 \%$ do custo total da operação. Os ganhos relativos à armazenagem superam os custos de transporte, apresentando reduções em todos os seus componentes, sendo o custo fixo de instalação aquele que apresenta o ganho mais expressivo, cerca de 3 milhões de dólares. A redução nos custos de abertura e expansão, fechamento e redução demonstram também uma diminuição na necessidade de mobilização de recursos materiais e humanos para adaptação da malha logística ao longo do período, trazendo uma redução na complexidade da gestão, apesar da necessidade de maior interação e coordenação entre agências para que a configuração de malha proposta seja de fato possível.

A Tabela 14 apresenta as potenciais economias no caso da adoção da nova estratégia de armazenagem. Para verificação deste ponto desempenhou-se o rateio dos custos sob três estratégias: simples, proporcional e mista. O rateio simples compreendeu na distribuição uniforme dos custos de instalação e operação dos armazéns entre os campos atribuídos a estes. Nesta abordagem os custos destinados para movimentação dos bens na rede, entre as instalações, também foi divido igualmente entre os campos supridos por cada armazém. Desta forma, obteve-se economia para 4 das 6 entidades gestoras observadas. 
Tabela 13: Comparação entre custos da malha atual otimizada e custos da malha proposta no estudo otimizada para os 15 meses de demanda.

\begin{tabular}{|c|c|c|c|c|c|c|c|}
\hline Custos & $\begin{array}{l}\text { Transporte no } \\
\text { Primeiro Trecho }\end{array}$ & $\begin{array}{r}\text { Transporte no } \\
\text { Segundo Trecho }\end{array}$ & $\begin{array}{r}\text { Operacional } \\
\text { Fixo }\end{array}$ & $\begin{array}{r}\text { Operacional } \\
\text { Variável }\end{array}$ & $\begin{array}{l}\text { Aumento de } \\
\text { Capacidade }\end{array}$ & $\begin{array}{l}\text { Redução de } \\
\text { Capacidade }\end{array}$ & Custo Total \\
\hline Malha Logística Descentralizada & $\$ 1,333,881$ & - & $\$ 7,234,483$ & $\$ 355,730$ & $\$ 511,126$ & $\$ 21,000$ & $\$ 9,456,220$ \\
\hline Malha Logística Centralizada & $\$ 1,323,442$ & $\$ 1,148,550$ & $\$ 4,079,597$ & $\$ 231,172$ & $\$ 227,669$ & $\$ 17,000$ & $\$ 7,027,430$ \\
\hline Variação (\$) & $-\$ 10,439$ & $\$ 1,148,550$ & $-\$ 3,154,886$ & $-\$ 124,558$ & $-\$ 283,457$ & $-\$ 4,000$ & $-\$ 2,428,790$ \\
\hline Variação (\%) & $-1 \%$ & $100 \%$ & $-44 \%$ & $-35 \%$ & $-55 \%$ & $-19 \%$ & $-26 \%$ \\
\hline$\%$ do Custo Total (Atual) & $14 \%$ & $0 \%$ & $77 \%$ & $4 \%$ & $5 \%$ & $0 \%$ & - \\
\hline$\%$ do Custo Total (Alternativa) & $19 \%$ & $16 \%$ & $58 \%$ & $3 \%$ & $3 \%$ & $0 \%$ & - \\
\hline
\end{tabular}


Tabela 14: Economia por agência gerada pela adoção da nova estrutura de distribuição.

\begin{tabular}{lrrr}
\hline Entidades de Gestoras & Rateio simples & Rateio proporcional & Rateio misto \\
\hline MoMD \& UNHCR & $-\$ 226,587$ & $-\$ 77,406$ & $-\$ 80,897$ \\
N.Gov \& UNHCR & $-\$ 113,337$ & $-\$ 43,725$ & $-\$ 45,999$ \\
IOM & $\$ 83,433$ & $-\$ 8,779$ & $-\$ 4,882$ \\
MODM & $-\$ 1,165,169$ & $-\$ 999,661$ & $-\$ 1,012,781$ \\
UNDP & $\$ 43,367$ & $-\$ 35,805$ & $-\$ 33,952$ \\
UNHCR & $-\$ 1,050,496$ & $-\$ 1,263,415$ & $-\$ 1,250,279$ \\
Economia Total & $-\$ 2,428,791$ & $-\$ 2,428,791$ & $-\$ 2,428,791$
\end{tabular}


Local Candidato

Hasansham M1_MODM

Qayyarah Bridge_tb

Qayyarah Jad'ah_MODM

Haj Ali_IOM

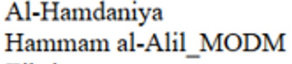

Tikrit

Kirkuk

Qayyarah Airstrip_IOM

Laylan_MODM

Debaga 2_UNHCR

Hasansham M2 MODM

Hammam al-Alil UNHCR

Chamakor_UNHCR

Zelikan UNHCR

As Salamyiah 2: N.Gov\&UNHCR

Laylan UNHCR

Hasansham U3 UNHCR

Debaga 1_MODM

Al Sh'hamah MODM

Al-Alam 2: MoMD\&UNHCR

Debaga Stadium_UNHCR

Hasansham U2_ŪNHCR

Al-Alam_MODM

Chamakor_IOM

Basateen Al Sheuokh_UNDP

Al-Alam_UNHCR

Surdesh_UNHCR

Surdesh_MODM

Zelikan_MODM

Al Sh'hamah_UNDP

Tipo de Armazém

G HardRoof

HardRoo
MSU
Figura 23: Locais candidatos selecionados na malha logística atual.

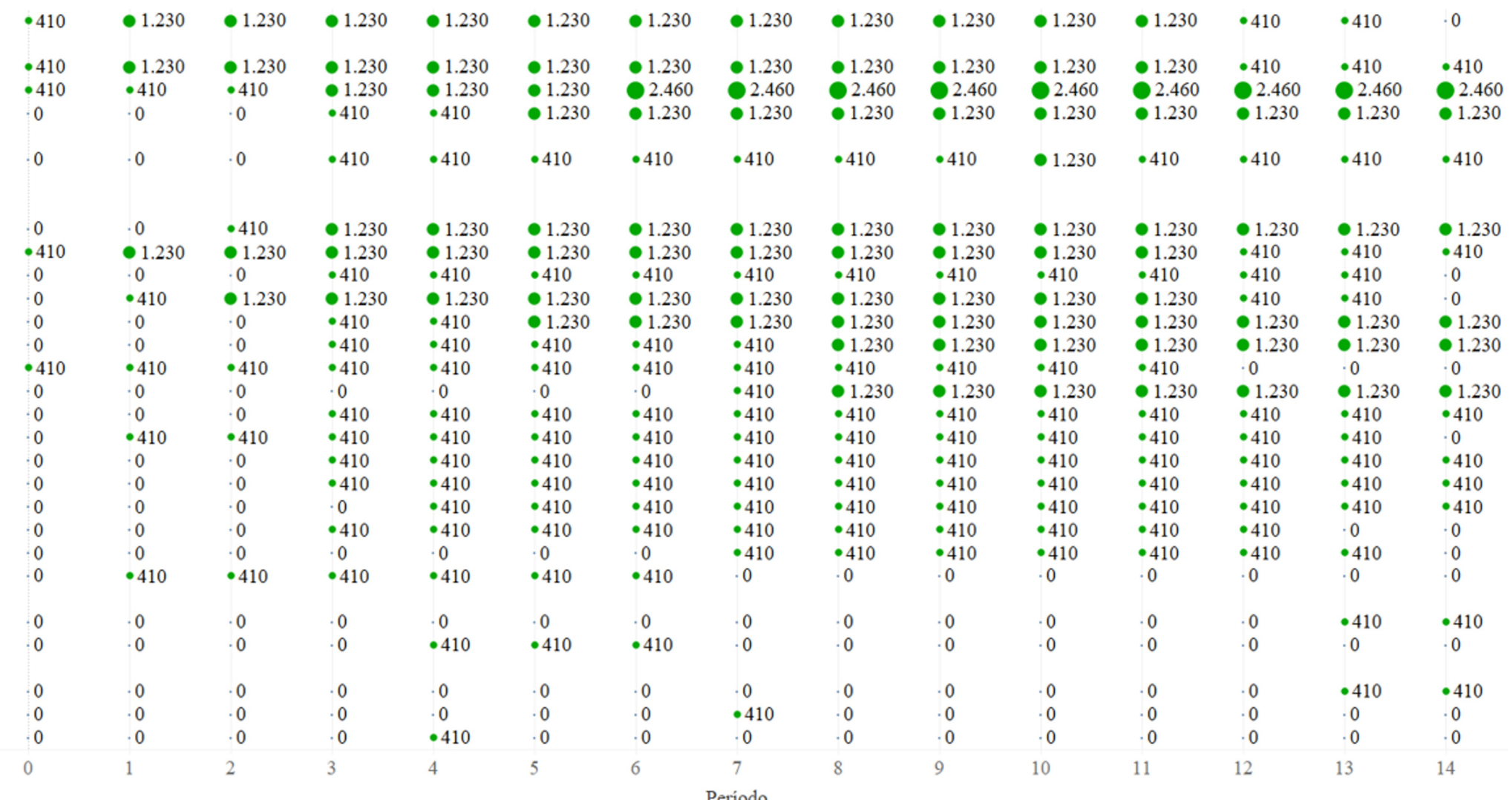

Fonte: Elaboração própria. 
Local Candidato Hasansham M1_MODM Qayyarah Bridge_tb Qayyarah Jad'ah_MODM
Haj Ali_IOM

Al-Hamdaniya

Hammam al-Alil_MODM Tikrit

Qayyarah Airstrip_IOM

Qayyarah Airstrip_

Laylan_MODM

Debaga 2_UNHCR

Hammam al-Alil UNHCR

Chamakor_UNHC

Zelikan_UNHCR

Laylan_UNHCR

Hasansham U3 UNHCR

Debaga 1_MODM

Al Sh'hamah MODM

Al-Alam 2: MoMD\&UNHCR

Debaga Stadium UNHCR

Hasansham U2__UNHCR

Al-Alam_MODM

Chamakor_IOM

Basateen Al Sheuo

Al-Alam_UNHCR

Surdesh_UNHCR

Surdesh_MODM

Zelikan_MODM

\section{Tipo de Armazén}

HardRoof

MSU
Figura 24: Locais candidatos selecionados na malha logística proposta.

\begin{tabular}{|c|c|c|c|c|c|c|c|c|c|c|c|c|c|c|}
\hline • 410 & - 1.230 & 2.460 & 2.460 & 2.460 & 2.460 & 2.460 & 2.460 & 2.460 & 2.460 & 2.460 & $\bullet 1.230$ & $\bullet 1.230$ & $\bullet 1.230$ & 0 \\
\hline 0 & 0 & 0 & $\bullet 410$ & $\bullet 410$ & - 1.230 & $\bullet 1.230$ & $\bullet 1.230$ & - 1.230 & $\bullet 1.230$ & - 1.230 & $\bullet 1.230$ & - 1.230 & - 1.230 & - 1.230 \\
\hline 0 & .0 & 0 & $\bullet 410$ & $\bullet 1.230$ & - 1.230 & - 1.230 & - 1.230 & - 1.230 & $\bullet 1.230$ & $\bullet 1.230$ & - 1.230 & • 1.230 & $\bullet 1.230$ & $\bullet 1.230$ \\
\hline 0 & $\bullet 1.283$ & • 1.283 & 1.283 & - 1.283 & • 1.283 & $\bullet 1.283$ & - 1.283 & $\bullet 1.283$ & • 1.283 & 1.283 & 1.283 & $\bullet 1.283$ & $\bullet 1.283$ & $\bullet 1.283$ \\
\hline & & & & & 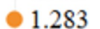 & 1.283 & 1.283 & & 1.283 & 1.283 & 1.283 & 1.283 & 1.283 & \\
\hline
\end{tabular}

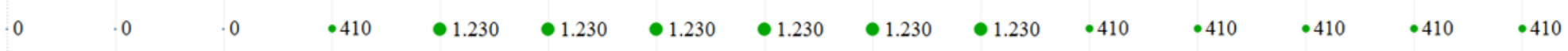

$\cdot 410 \quad \cdot 410 \quad \cdot 410 \quad \cdot 410$

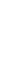

Fonte: Elaboração própria. 
A estratégia de rateio proporcional trata-se de uma abordagem de custeio por absorção, em que todos os custos, de instalação, operação, transporte, fixos e variáveis são rateados baseados na demanda de cada campo. Isto significa que considerou-se que os custos fixos referentes a armazenagem, custos de abertura e desativação seriam rateados proporcionalmente ao volume de bens requeridos por determinado campo.

Por fim, na estratégia mista os custos fixos de operação, custos de transporte e custo variável de operação são proporcionais a volume, enquanto custos fixos de abertura e desmobilização dos armazéns são divididos uniformemente entre os campos supridos por um determinado armazém. Através das duas abordagens a nova configuração se mostra vantajosa economicamente para as três agências responsáveis durante a operação, IOM, UNDP e UNHCR, bem como para o governo Iraquiano (MoMD e N.Gov).

\subsection{Comparativo entre modelo estático e multi-período}

Para avaliar a performance do modelo multí-perído realizou-se dois experimentos utilizando as ocupações nos campos observadas no horizonte de 15 meses, realizando uma análise comparativa entre a solução do modelo multi-período e o modelo estático. Dessa forma, o modelo estático foi solucionado utilizando a demanda média do horizonte analisado, e as decisões tomadas permanecem inalteradas ao longo dos meses analisados. Os locais selecionados em ambos os experimentos são os mesmos, exceto por Chamakor_IOM e Laylan. No modelo estático o local candidato de Chamakor_IOM, não é selecionado, de forma que a demanda dos campos deste cluster é atribuída ao armazém de Al-Hamadaniya, também responsável pelos campos de Hasansham U2_UNHCR, As Salamyiah_2: N.GovUNHCR.

No experimento multi-período o armazém de Chamakor_IOM abre em janeiro de 2017 mantendo sua capacidade constante até o encerramento de suas atividades em abril de 2017, em seguida a demanda passa a ser suprida por Al-Hamadainya. O local candidato de Laylan_UNHCR, por sua vez, só opera no primeiro período do caso dinâmico, pois é imposto ao sistema que os armazéns neste período já estivessem operando previamente. A demandas dos campos do cluster de Laylan_UNHCR nos períodos posteriores a 0 (outubro de 2016) são atribuídas ao hardroof de Kirkuk, assim como ocorre na solução estática.

Outra análise desempenhada se deu quanto a eficiência do sistema para as duas alternativa avaliadas. Dessa forma, comparou-se o uso das capacidades instaladas ao longo 
do horizonte de 15 meses e foi analisado o desempenho no atendimento das demandas. A Tabela 25 apresenta as relações entre a capacidade instalada e demanda agregadas do sistema. Dessa forma é possível perceber que a capacidade total instalada do modelo estático em teoria é suficiente para suprir a demanda nos períodos de análise. Entretanto a utilização da capacidade no caso dinâmico apresenta-se mais balanceada, variando de $9 \%$ a $68 \%$, enquanto no caso estático esta utilização varia de $1 \%$ a $77 \%$. O valor médio de utilização seria de $53 \%$ para ambos os modelos, entretanto ao desvios-padrões seriam de 0,13 e 0,22, destacando novamente a maior dispersão no caso estático.

Apesar de oferecer capacidade suficiente para a operação deve-se analisar a decisão tomada considerando as atribuições realizadas, pois considera-se que a demanda deverá ser suprida a um raio de $40 \mathrm{~km}$. Ao comparar as duas Tabelas 26 e 27 observa-se grande ociosidade no sistema para a decisão estática, que manteria instalações abertas sem utilização em todos os períodos analisados em pelo menos um dos locais instalados. Seriam em média 3 instalações sem utilização por período. Em contraste a ociosidade, também iria se enfrentar uma falta de capacidade instalada em 4 dos armazéns instalados, e em 13 dos 15 meses de operação, e em média seria cerca de 1,8 instalações apresentando falta de capacidade por mês. O modelo estático mantém 12 armazéns instalados mensalmente, sendo um total de 180 pontos operando durante os 15 meses, enquanto o modelo dinâmico matéria um total de pontos de 137, e uma quantidade máxima de 11 armazéns instalados por mês.

Conforme comentando, o sistema apresenta capacidade total agregada suficiente para atender a demanda nos períodos, entretanto a performance do sistema é comprometida devido à presença das restrições de cobertura e atribuição única da demanda. Assim a utilização da capacidade disponível de uma instalação para suprir a falta de capacidade de outra pode implicar no não atendimento dos pressupostos impostos inicialmente. Isto é, a solução torna-se uma alternativa inviável para o sistema, e por consequência impactará o nível de serviço oferecido e segurança do sistema. Desta forma, não é possível realizar uma comparação entre a performance em termos de custos das dos dois experimentos pois o custo da falta ou não atendimento não foi modelado 
Figura 25: Ocupação agregada dos armazéns no horizonte de planejamento de 15 meses para o modelo estático e o modelo multi-período.

\begin{tabular}{|lcccccccccccccc|c|}
\hline Modelo & out/16 & nov/16 & dez/16 & jan/17 & fev/17 & mar/17 & abr/17 & mai/17 & jun/17 & jul/17 & ago/17 & set/17 & out/17 & nov/17 & dez/17 \\
\hline Multi-período & $9 \%$ & $42 \%$ & $43 \%$ & $56 \%$ & $50 \%$ & $55 \%$ & $64 \%$ & $56 \%$ & $58 \%$ & $57 \%$ & $58 \%$ & $62 \%$ & $68 \%$ & $57 \%$ & $56 \%$ \\
Estático & $1 \%$ & $19 \%$ & $27 \%$ & $42 \%$ & $44 \%$ & $57 \%$ & $66 \%$ & $67 \%$ & $77 \%$ & $76 \%$ & $74 \%$ & $72 \%$ & $64 \%$ & $57 \%$ & $51 \%$ \\
\hline
\end{tabular}

Fonte: Elaboração própria.

Figura 26: Ocupação dos armazéns no horizonte de 15 meses para a decisões do modelo multi-período.

\begin{tabular}{|c|c|c|c|c|c|c|c|c|c|c|c|c|c|c|c|}
\hline Local candidato & out $/ 16$ & nov/16 & dez/16 & jan/17 & fev/17 & mar/17 & abr/17 & mai/17 & jun/17 & jul/17 & ago/17 & set/17 & out $/ 17$ & nov/17 & dez/17 \\
\hline Al-Hamdaniya & - & - & - & - & - & - & - & $8 \%$ & $52 \%$ & $56 \%$ & $56 \%$ & $90 \%$ & $69 \%$ & $66 \%$ & $66 \%$ \\
\hline Basateen Al Sheuokh_UNDP & - & - & - & - & - & - & - & - & - & - & - & - & - & $12 \%$ & $12 \%$ \\
\hline Chamakor_IOM & - & - & - & $34 \%$ & $31 \%$ & $35 \%$ & $34 \%$ & - & - & - & - & - & - & - & - \\
\hline Debaga 2_UNHCR & - & - & - & $89 \%$ & $38 \%$ & $37 \%$ & $35 \%$ & $35 \%$ & $35 \%$ & $34 \%$ & $92 \%$ & $91 \%$ & $61 \%$ & $52 \%$ & $46 \%$ \\
\hline Haj Ali_IOM & - & - & - & $10 \%$ & $41 \%$ & $36 \%$ & $64 \%$ & $64 \%$ & $67 \%$ & $61 \%$ & $61 \%$ & $54 \%$ & $54 \%$ & $50 \%$ & $56 \%$ \\
\hline Hammam al-Alil_MODM & - & - & - & $79 \%$ & $34 \%$ & $58 \%$ & $85 \%$ & $86 \%$ & $87 \%$ & $82 \%$ & $95 \%$ & $74 \%$ & $68 \%$ & $64 \%$ & $71 \%$ \\
\hline Hasansham M1_MODM & $7 \%$ & $72 \%$ & $54 \%$ & $63 \%$ & $54 \%$ & $66 \%$ & $66 \%$ & $67 \%$ & $65 \%$ & $63 \%$ & $61 \%$ & $68 \%$ & $79 \%$ & $52 \%$ & \\
\hline Kirkuk & - & $51 \%$ & $51 \%$ & $77 \%$ & $64 \%$ & $76 \%$ & $75 \%$ & $76 \%$ & $75 \%$ & $70 \%$ & $62 \%$ & $55 \%$ & $45 \%$ & $36 \%$ & $28 \%$ \\
\hline Laylan_UNHCR & $7 \%$ & - & - & - & - & - & - & - & - & - & - & - & - & - & - \\
\hline Narziglia_MODM & $7 \%$ & $54 \%$ & $54 \%$ & $63 \%$ & $49 \%$ & $62 \%$ & $61 \%$ & $62 \%$ & $62 \%$ & $57 \%$ & $49 \%$ & $41 \%$ & $97 \%$ & $69 \%$ & $46 \%$ \\
\hline Qayyarah Bridge_tbc & $25 \%$ & $27 \%$ & $49 \%$ & $76 \%$ & $98 \%$ & $71 \%$ & $96 \%$ & $98 \%$ & $66 \%$ & $68 \%$ & $63 \%$ & $63 \%$ & $100 \%$ & $97 \%$ & $92 \%$ \\
\hline Surdesh_UNHCR & - & - & - & - & - & - & - & - & - & - & - & - & - & $10 \%$ & $10 \%$ \\
\hline Tikrit & - & $0 \%$ & $5 \%$ & $9 \%$ & $28 \%$ & $26 \%$ & $26 \%$ & $17 \%$ & $16 \%$ & $16 \%$ & $17 \%$ & $26 \%$ & $21 \%$ & $19 \%$ & $16 \%$ \\
\hline Zelikan_UNHCR & $1 \%$ & $28 \%$ & $28 \%$ & $34 \%$ & $28 \%$ & $17 \%$ & $12 \%$ & $16 \%$ & $7 \%$ & $6 \%$ & $5 \%$ & $3 \%$ & - & - & - \\
\hline
\end{tabular}

Fonte: Elaboração própria. 
Figura 27: Ocupação dos armazéns no horizonte de 15 meses para a decisões do modelo estático.

\begin{tabular}{|c|c|c|c|c|c|c|c|c|c|c|c|c|c|c|c|}
\hline Local candidato & out $/ 16$ & nov/16 & dez/16 & jan$/ \mathbf{1 7}$ & fev/17 & $\mathrm{mar} / \mathbf{1 7}$ & abr/17 & mai/17 & jun/17 & jul/17 & ago/17 & set/17 & out $/ 17$ & nov/17 & dez/17 \\
\hline Al-Hamdaniya & $0 \%$ & $0 \%$ & $0 \%$ & $11 \%$ & $10 \%$ & $11 \%$ & $11 \%$ & $29 \%$ & $118 \%$ & $124 \%$ & $122 \%$ & $148 \%$ & $143 \%$ & $135 \%$ & $132 \%$ \\
\hline Basateen Al Sheuokh_UNDP & $0 \%$ & $0 \%$ & $0 \%$ & $0 \%$ & $0 \%$ & $0 \%$ & $0 \%$ & $0 \%$ & $0 \%$ & $0 \%$ & $0 \%$ & $0 \%$ & $0 \%$ & $12 \%$ & $12 \%$ \\
\hline Chamakor_IOM & - & - & - & - & - & - & - & - & - & - & - & - & - & - & - \\
\hline Debaga 2_UNHCR & $0 \%$ & $0 \%$ & $0 \%$ & $89 \%$ & $113 \%$ & $110 \%$ & $105 \%$ & $106 \%$ & $104 \%$ & $103 \%$ & $92 \%$ & $91 \%$ & $61 \%$ & $52 \%$ & $46 \%$ \\
\hline Haj Ali_IOM & $0 \%$ & $0 \%$ & $0 \%$ & $3 \%$ & $14 \%$ & $36 \%$ & $64 \%$ & $64 \%$ & $67 \%$ & $61 \%$ & $61 \%$ & $54 \%$ & $54 \%$ & $50 \%$ & $56 \%$ \\
\hline Hammam al-Alil_MODM & $0 \%$ & $0 \%$ & $0 \%$ & $26 \%$ & $34 \%$ & $58 \%$ & $85 \%$ & $86 \%$ & $87 \%$ & $82 \%$ & $95 \%$ & $74 \%$ & $68 \%$ & $64 \%$ & $71 \%$ \\
\hline Hasansham M1_MODM & $2 \%$ & $72 \%$ & $107 \%$ & $125 \%$ & $109 \%$ & $132 \%$ & $131 \%$ & $120 \%$ & $116 \%$ & $114 \%$ & $112 \%$ & $101 \%$ & $74 \%$ & $49 \%$ & $0 \%$ \\
\hline Kirkuk & $2 \%$ & $51 \%$ & $51 \%$ & $77 \%$ & $64 \%$ & $76 \%$ & $75 \%$ & $76 \%$ & $75 \%$ & $70 \%$ & $62 \%$ & $55 \%$ & $45 \%$ & $36 \%$ & $28 \%$ \\
\hline Laylan_UNHCR & - & - & - & - & - & - & - & - & - & - & - & - & - & - & - \\
\hline Narziglia_MODM & $2 \%$ & $54 \%$ & $54 \%$ & $63 \%$ & $49 \%$ & $62 \%$ & $61 \%$ & $62 \%$ & $62 \%$ & $57 \%$ & $49 \%$ & $41 \%$ & $32 \%$ & $23 \%$ & $15 \%$ \\
\hline Qayyarah Bridge_tbc & $4 \%$ & $4 \%$ & $25 \%$ & $38 \%$ & $49 \%$ & $71 \%$ & $96 \%$ & $98 \%$ & $110 \%$ & $113 \%$ & $106 \%$ & $105 \%$ & $100 \%$ & $97 \%$ & $92 \%$ \\
\hline Surdesh_UNHCR & $0 \%$ & $0 \%$ & $0 \%$ & $0 \%$ & $0 \%$ & $0 \%$ & $0 \%$ & $0 \%$ & $0 \%$ & $0 \%$ & $0 \%$ & $0 \%$ & $0 \%$ & $10 \%$ & $10 \%$ \\
\hline Tikrit & $0 \%$ & $0 \%$ & $5 \%$ & $9 \%$ & $28 \%$ & $26 \%$ & $26 \%$ & $17 \%$ & $16 \%$ & $16 \%$ & $17 \%$ & $26 \%$ & $21 \%$ & $19 \%$ & $16 \%$ \\
\hline Zelikan_UNHCR & $1 \%$ & $28 \%$ & $28 \%$ & $34 \%$ & $28 \%$ & $17 \%$ & $12 \%$ & $16 \%$ & $7 \%$ & $6 \%$ & $5 \%$ & $3 \%$ & $0 \%$ & $0 \%$ & $0 \%$ \\
\hline
\end{tabular}

Fonte: Elaboração própria. 


\subsection{Comparativo entre horizontes fixo e rolante}

O modelo multi-período é resolvido repetidamente para cada período do horizonte em um mecanismo de horizonte rolante que considera todas as mudanças na configuração da cadeia ao longo do tempo. No horizonte rolante proposto utiliza-se um horizonte de planejamento de $t=6$ meses com replanejamentos mensais $(p)$, o que caracteriza $p=9$ períodos de replanejamento para os 15 meses de ocupações consideradas na estudo. Dessa forma, no período $p=0$, um plano é criado para demonstrar as decisões onde as instalações serão ativadas para cada período $t$ do horizonte de planejamento de 6 meses.

Baseado no plano criado em $p=0$, as decisões para o período $t=0$ do horizonte de 6 meses são aplicadas e o plano para os períodos $t$ futuros são gravadas. No próximo período $p=1$ de replanejamento, um novo plano é criado considerando as decisões tomadas no $t=0$ de $p=0$, e esse processo consecutivo é repetido para os outros períodos através do uso das informações disponíveis mais recentes.

Para manter o registro apropriado entre as decisões durante os períodos de planejamento, um grupo de parâmetros é atualizado constantemente externamente ao modelo de otimização e são adotados nas iterações futuras. Estes apresentam a geração do plano para os períodos futuros, assim como o status das instalações que estão abertas no $t=0$ do próximo período de replanejamento, que será empregado na inicialização do sistema. Assim, no período $p=1$ as decisões tomadas no $p=0$ servirão de ponto de partida para o planejamento dos próximos 6 meses.

Assim, as Figuras 28, 29, 30 e 31 apresentam as soluções obtidas para cada replanejamento realizado. Os círculos sem preenchimento representam as decisões tomadas de fato em $p-1$, bem como representam a inicialização do sistema no replanejamento seguinte, em $p$. No nono período de replanejamento estes círculos sem preenchimento representam as decisões planejadas para $t \neq 0$. E a solução dos horizontes rolantes são, então, comparadas a solução obtida pelo modelo multi-período para os 15 meses de ocupação. 
Figura 28: Comparação entre locais candidatos selecionados para cada período de replanejamento e os locais selecionados através do horizonte rolante. Local Candidato Al-Hamdaniya $\quad$ Planementos

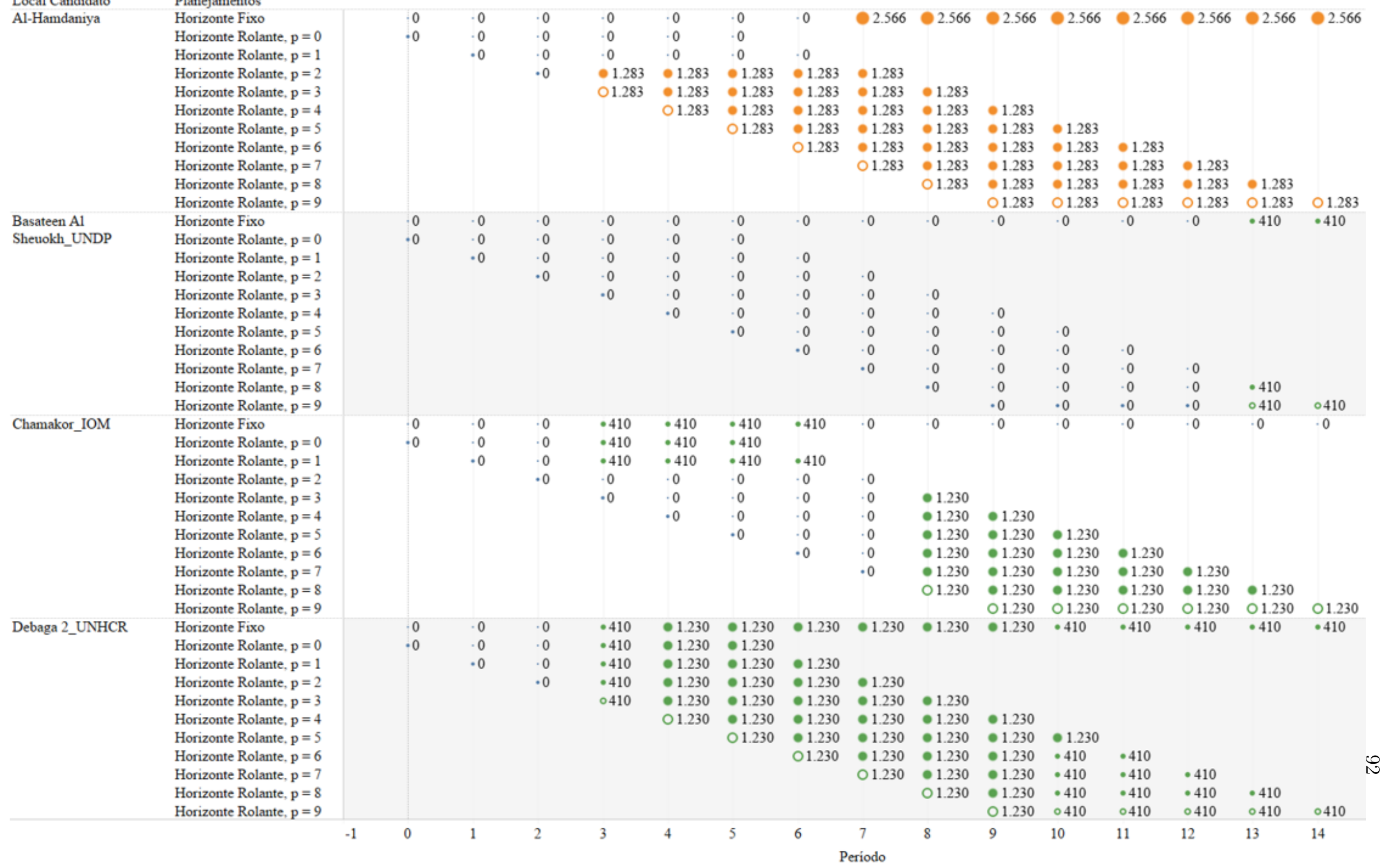


Figura 29: Continuação. Comparação entre locais candidatos selecionados para cada período de replanejamento e os locais selecionados através do horizonte rolante.

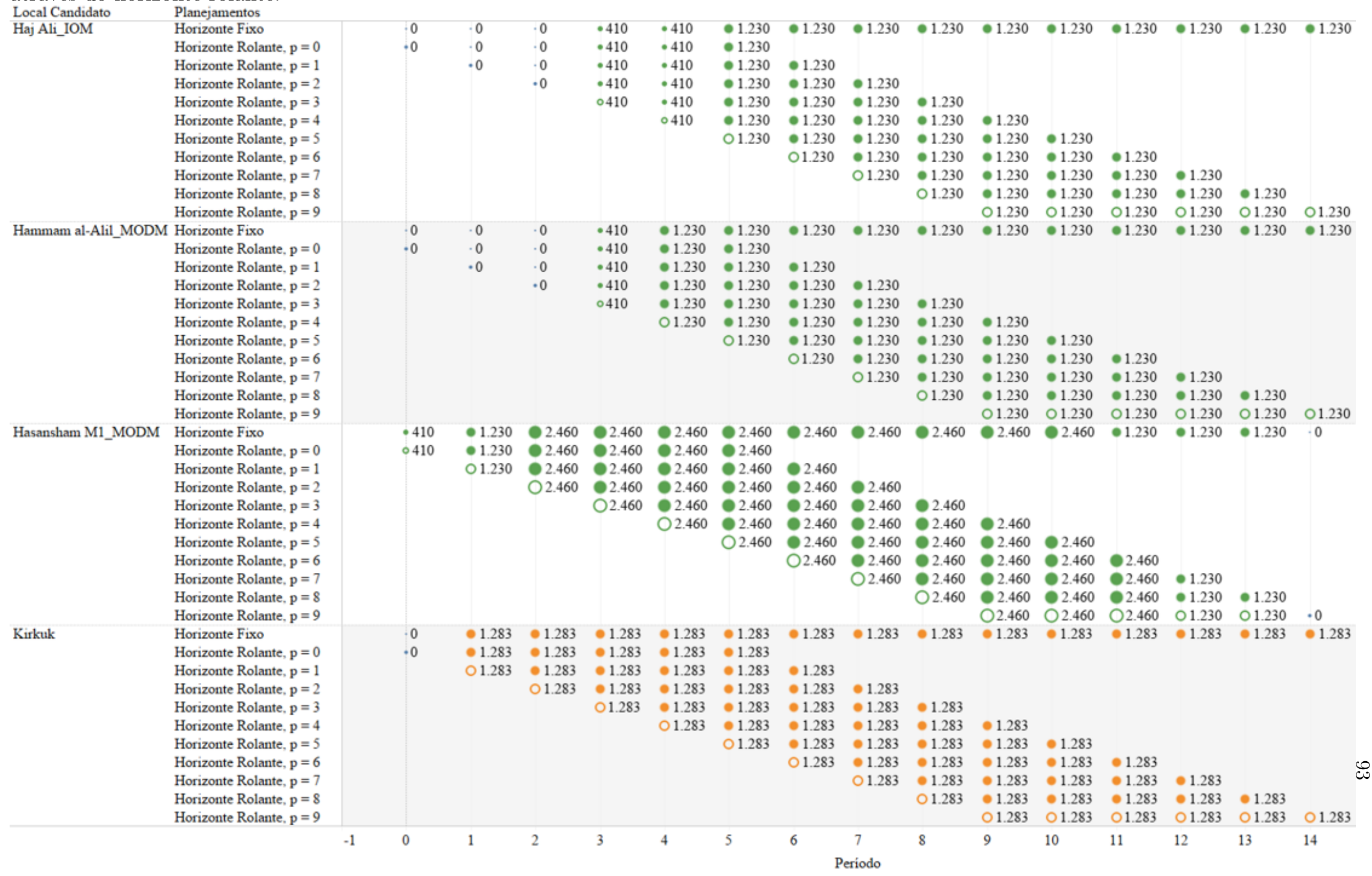


Figura 30: Continuação. Comparação entre locais candidatos selecionados para cada período de replanejamento e os locais selecionados através do horizonte rolante

Local Candidato Planejamentos

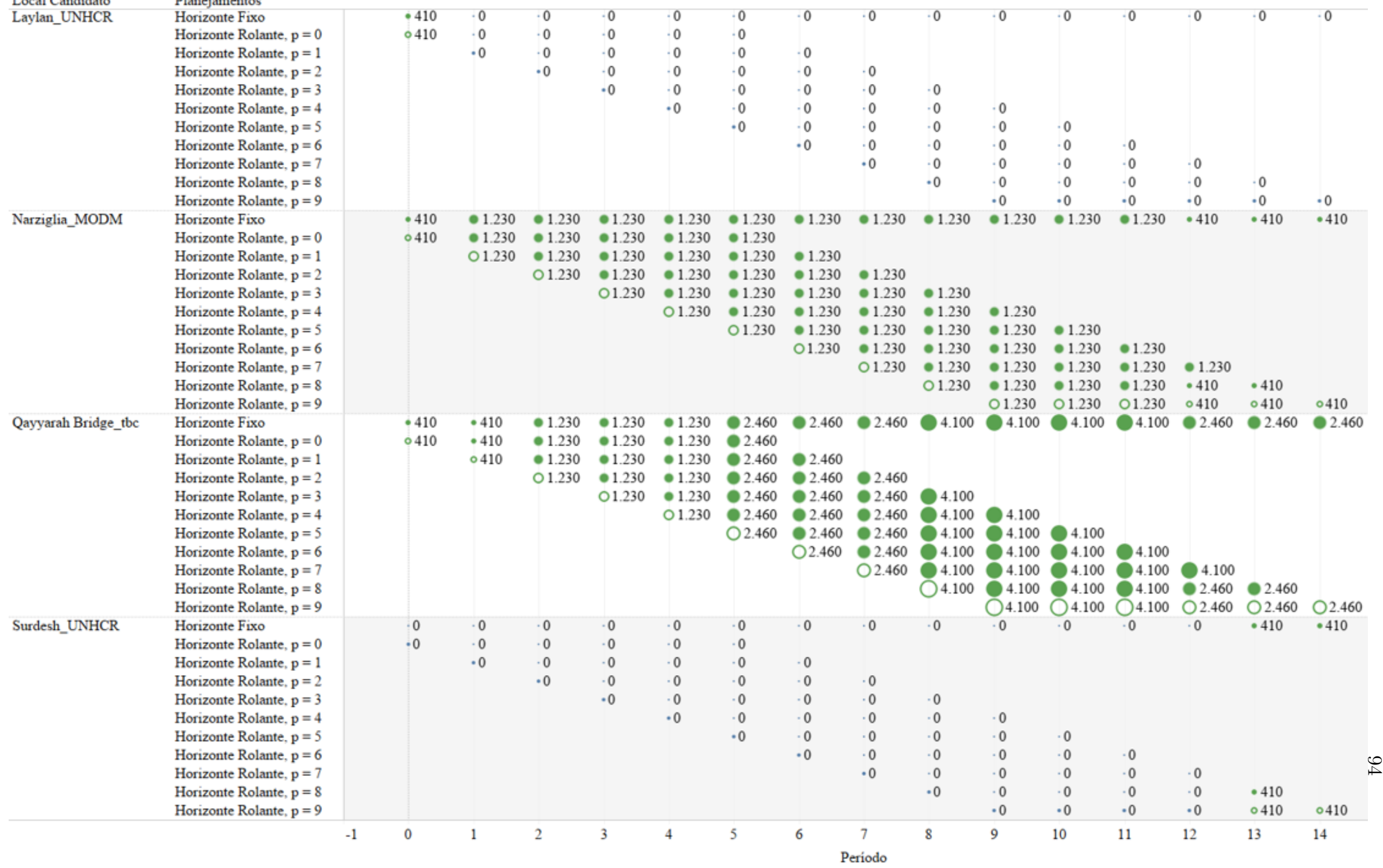


Figura 31: Continuação. Comparação entre locais candidatos selecionados para cada período de replanejamento e os locais selecionados através do horizonte rolante

\begin{tabular}{|c|c|c|c|c|c|c|c|c|c|c|c|c|c|c|c|c|c|}
\hline \multirow{2}{*}{$\begin{array}{l}\text { Local Candidato } \\
\text { Tikrit }\end{array}$} & \multicolumn{17}{|l|}{ Planejamentos } \\
\hline & Horizonte Fixo & & 0 & $\bullet 1.283$ & - 1.283 & - 1.283 & - 1.283 & $\bullet 1.283$ & - 1.283 & - 1.283 & $\bullet 1.283$ & $\bullet 1.283$ & $\bullet 1.283$ & $\bullet 1.283$ & - 1.283 & - 1.283 & $\bullet 1.283$ \\
\hline & Horizonte Rolante, $\mathrm{p}=0$ & & $\cdot 0$ & - 1.283 & - 1.283 & - 1.283 & - 1.283 & - 1.283 & & & & & & & & & \\
\hline & Horizonte Rolante, $\mathrm{p}=1$ & & & 01.283 & 1.283 & 1.283 & - 1.283 & 1.283 & e 1.283 & & & & & & & & \\
\hline & Horizonte Rolante, $p=2$ & & & & 01.283 & - 1.283 & - 1.283 & - 1.283 & - 1.283 & e 1.283 & & & & & & & \\
\hline & Horizonte Rolante, $\mathrm{p}=3$ & & & & & 01.283 & e 1.283 & e 1.283 & - 1.283 & e 1.283 & - 1.283 & & & & & & \\
\hline & Horizonte Rolante, $\mathrm{p}=4$ & & & & & & 01.283 & - 1.283 & - 1.283 & - 1.283 & - 1.283 & - 1.283 & & & & & \\
\hline & Horizonte Rolante, $p=5$ & & & & & & & 01.283 & 1.283 & 1.283 & - 1.283 & 1.283 & - 1.283 & & & & \\
\hline & Horizonte Rolante, $p=6$ & & & & & & & & 01.283 & e 1.283 & e 1.283 & e 1.283 & - 1.283 & - 1.283 & & & \\
\hline & Horizonte Rolante, $\mathrm{p}=7$ & & & & & & & & & 01.283 & - 1.283 & - 1.283 & - 1.283 & - 1.283 & - 1.283 & & \\
\hline & Horizonte Rolante, $\mathrm{p}=8$ & & & & & & & & & & 01.283 & - 1.283 & - 1.283 & - 1.283 & e 1.283 & - 1.283 & \\
\hline & Horizonte Rolante, $p=9$ & & & & & & & & & & & 01.283 & 01.283 & 01.283 & 01.283 & 01.283 & 01.283 \\
\hline \multirow[t]{18}{*}{ Zelikan_UNHCR } & Horizonte Fixo & & $\cdot 410$ & $\cdot 410$ & $\cdot 410$ & $\cdot 410$ & $\cdot 410$ & $\cdot 410$ & $\cdot 410$ & $\cdot 410$ & $\cdot 410$ & $\bullet 410$ & $\bullet 410$ & $\cdot 410$ & 0 & 0 & 0 \\
\hline & Horizonte Rolante, $\mathrm{p}=0$ & & $\circ 410$ & $\bullet 410$ & $\bullet 410$ & $\bullet 410$ & $\bullet 410$ & $\bullet 410$ & & & & & & & & & \\
\hline & Horizonte Rolante, $\mathrm{p}=1$ & & & $\circ 410$ & $\cdot 410$ & $\cdot 410$ & $\bullet 410$ & $\bullet 410$ & $\cdot 410$ & & & & & & & & \\
\hline & Horizonte Rolante, $\mathrm{p}=2$ & & & & $\circ 410$ & $\cdot 410$ & $\cdot 410$ & $\cdot 410$ & $\cdot 410$ & $\cdot 410$ & & & & & & & \\
\hline & Horizonte Rolante, $\mathrm{p}=3$ & & & & & $\circ 410$ & $\bullet 410$ & $\bullet 410$ & $\bullet 410$ & $\bullet 410$ & $\cdot 410$ & & & & & & \\
\hline & Horizonte Rolante, $\mathrm{p}=4$ & & & & & & $\circ 410$ & $\bullet 410$ & $\bullet 410$ & $\bullet 410$ & $\bullet 410$ & $\cdot 410$ & & & & & \\
\hline & Horizonte Rolante, $\mathrm{p}=5$ & & & & & & & $\circ 410$ & $\cdot 410$ & $\cdot 410$ & $\cdot 410$ & $\cdot 410$ & $\cdot 410$ & & & & \\
\hline & Horizonte Rolante, $p=6$ & & & & & & & & $\circ 410$ & $\cdot 410$ & $\cdot 410$ & $\cdot 410$ & $\cdot 410$ & $\cdot 410$ & & & \\
\hline & Horizonte Rolante, $\mathrm{p}=7$ & & & & & & & & & $\circ 410$ & $\cdot 410$ & $\cdot 410$ & $\cdot 410$ & $\bullet 410$ & .0 & & \\
\hline & Horizonte Rolante, $\mathrm{p}=8$ & & & & & & & & & & $\circ 410$ & $\bullet 410$ & $\cdot 410$ & $\bullet 410$ & 0 & 0 & \\
\hline & Horizonte Rolante, $p=9$ & & & & & & & & & & & $\circ 410$ & $\circ 410$ & $\circ 410$ & $\cdot 0$ & $\cdot 0$ & $\cdot 0$ \\
\hline & & -1 & 0 & 1 & 2 & 3 & 4 & 5 & 6 & 7 & 8 & 9 & 10 & 11 & 12 & 13 & 14 \\
\hline & & & & & & & & & & eriodo & & & & & & & \\
\hline & & & & & & & & & & & & & & \multicolumn{2}{|c|}{ Tamanho (ton/Mês) } & \\
\hline & & & & & & & & & & & & & & & & \multicolumn{2}{|c|}{$\begin{array}{l}\text { Tipo de Armazém } \\
\text { HardRoof }\end{array}$} \\
\hline & & & & & & & & & & & & & & \multicolumn{2}{|l|}{$\circ 1.000$} & \multicolumn{2}{|c|}{$\overline{\mathrm{MSU}}$} \\
\hline & & & & & & & & & & & & & & \multicolumn{2}{|l|}{$\begin{array}{r}2.000 \\
3.000\end{array}$} & \multirow{2}{*}{\multicolumn{2}{|c|}{$\begin{array}{l}\text { Decisões em } \\
\mathrm{t}=0\end{array}$}} \\
\hline & & & & & & & & & & & & & & $\begin{array}{l}3.000 \\
4.100\end{array}$ & & & \\
\hline
\end{tabular}

Fonte: Elaboração própria. 
A partir do horizonte rolante, pode-se perceber que as decisões de abertura dos planos de 6 meses se alteram à medida que novas informações sobre as ocupações nos campos são inseridas. Este comportamento é observado nos locais candidatos de Chamakor_IOM, Debaga 2_UNHCR, Narziglia_MOM e Qayyarah Bridge_tbc. Por exemplo, neste último local no sétimo replanejamento decide-se que em outubro de $2017(t=12)$ ao invés de manter a capacidade do armazém em 4.100 ton/mês, deve-se reduzir seu tamanho para 2.460 ton/mês.

Realizando a comparação entre as decisões do horizonte rolante e as decisões do horizonte de 15 meses, observa-se que as decisões sobre os locais candidatos de Al-Hamdaniya, Chamakor_IOM e Hasansham apresentam divergências. Os três locais têm localização próxima entre si, e a análise das soluções revela um relacionamento e interação entre estes locais.

Devido a limitação de informações do horizonte rolante aos próximos 6 meses, a decisão sobre abertura do armazém tipo hardroof em Al-Hamdaniya é atencipada e o sistema deve se adaptar ao longo dos replanejamentos. Assim no período 3 (Figura 32) Al-Hamdaniya abre com uma capacidade de 500 sendo utilizado para suprir Chamakor, enquanto no horizonte fixo, instala-se um MSU no cluster de Chamakor, que fecha no período 7 (Figura 33) dando lugar a um armazém em Al-Hamdaniya com capacidade 1000.

Tabela 15: Legenda para leitura dos mapas comparativos entre horizonte fixo e rolante.

\begin{tabular}{lc}
\hline Local candidato & Código \\
\hline Chamakor_IOM & A \\
Al-Hamdaniya & B \\
Hasansham M1_MODM & C \\
Hammam al-Alil_MODM & D \\
Zelikan_UNHCR & E \\
Narziglia_MODM & F \\
\hline
\end{tabular}

No período 7 do horizonte rolante, o armazém de 500 ainda possui capacidade suficiente para suprir Chamakor e Al Salamiah, entretanto no período 8 (Figura 34), a demanda aumenta e é preciso que Chamakor abra no horizonte rolante, para que o sistema seja capaz de atender a demanda, enquanto o no Horizonte fixo o armazém de 1000 ainda é capaz de suprir estes ponto mesmo havendo um aumento na demanda.

Algo que pode ser notado é que o armazém de 1000 instalado em períodos posteriores no sistema (no horizonte fixo), proporciona uma redução no número de locais instalados 
Figura 32: Comparação da configuração da malha entre a abordagem de horizonte fixo e rolante do modelo multi-período em janeiro de $2017, p=3$.

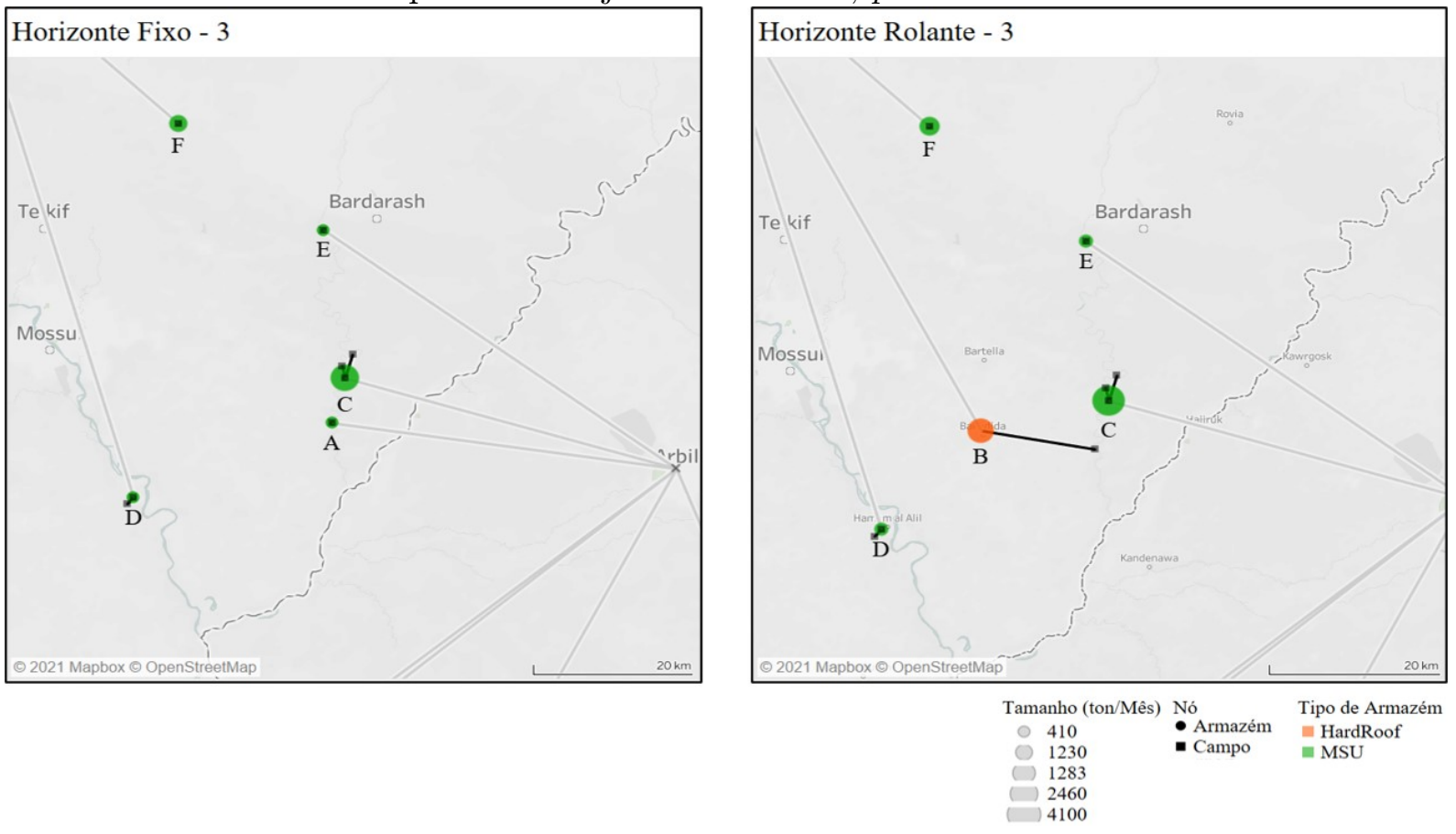

Fonte: Elaboração própria.

e supri os campos dos agrupamentos de Al-Salamia, Chamakor e Hasansham, enquanto o hardroof de 500 não possuí capacidade suficiente para atender também a Hasansham, como apresentado no período 11, e no período 14 (Figura 35 e 36) não é capaz de suprir Al-Salamia e Chamakor e mantém o armazém MSU de Chamakor aberto. Esse comportamento se deu devido ao horizonte de visualização dos eventos limitado do horizonte rolante.

Dessa forma o modelo foi capaz de capturar o aumento brusco nas demandas dos cluster de Chamakor_IOM e Hasanshan_M1_MODM no sétimo período, apresentado na Figura 37, mas não foi capaz de se prever os eventos dos períodos seguintes, e a ocorrência do pico de demanda no período 11, para o qual o horizonte fixo se preparou optando pela postergação na instalação do hardroofs de Al-Hamdaniya para que o instalasse com uma maior capacidade. As decisões tomadas através do horizonte rolante implicariam em uma aumento de $\$ 57$ mil dólares empregados na operação ao longo dos 15 meses. 
Figura 33: Comparação da configuração da malha entre a abordagem de horizonte fixo e rolante do modelo multi-período em maio de 2017, $p=7$.

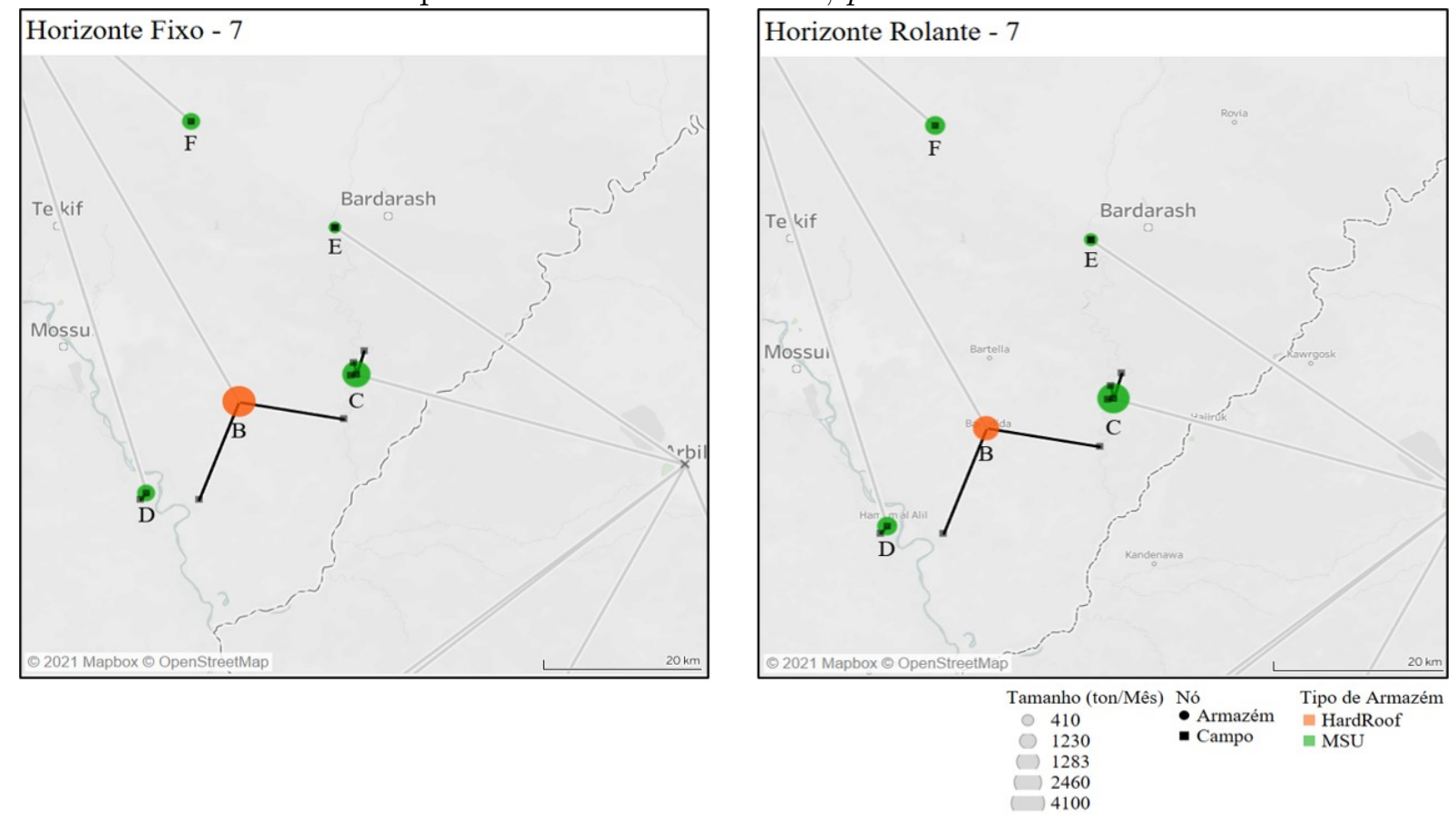

Fonte: Elaboração própria.

Figura 34: Comparação da configuração da malha entre a abordagem de horizonte fixo e rolante do modelo multi-período em junho de 2017, $p=8$.
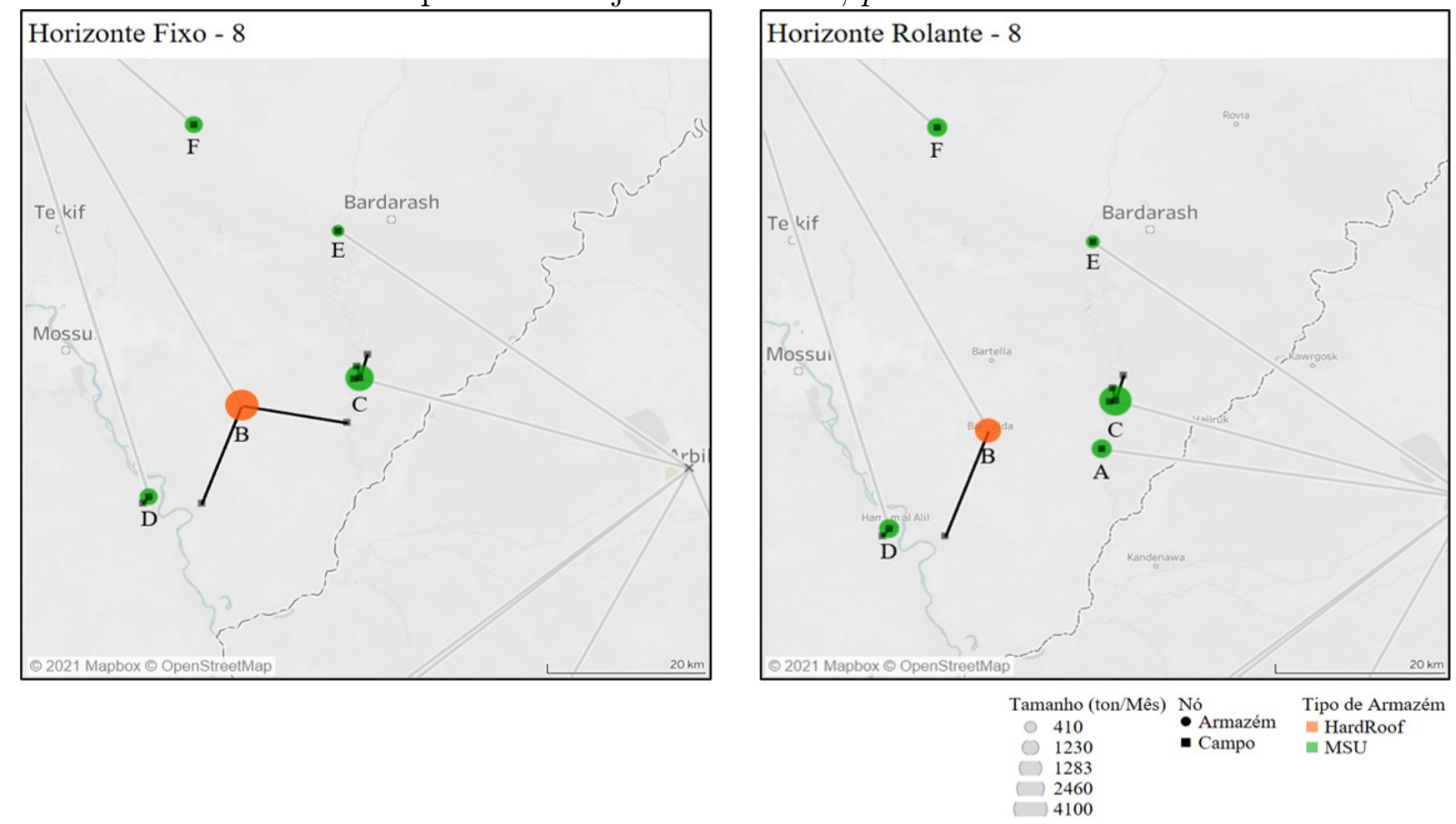

Fonte: Elaboração própria. 
Figura 35: Comparação da configuração da malha entre a abordagem de horizonte fixo e rolante do modelo multi-período em setembro de 2017, $p=11$.

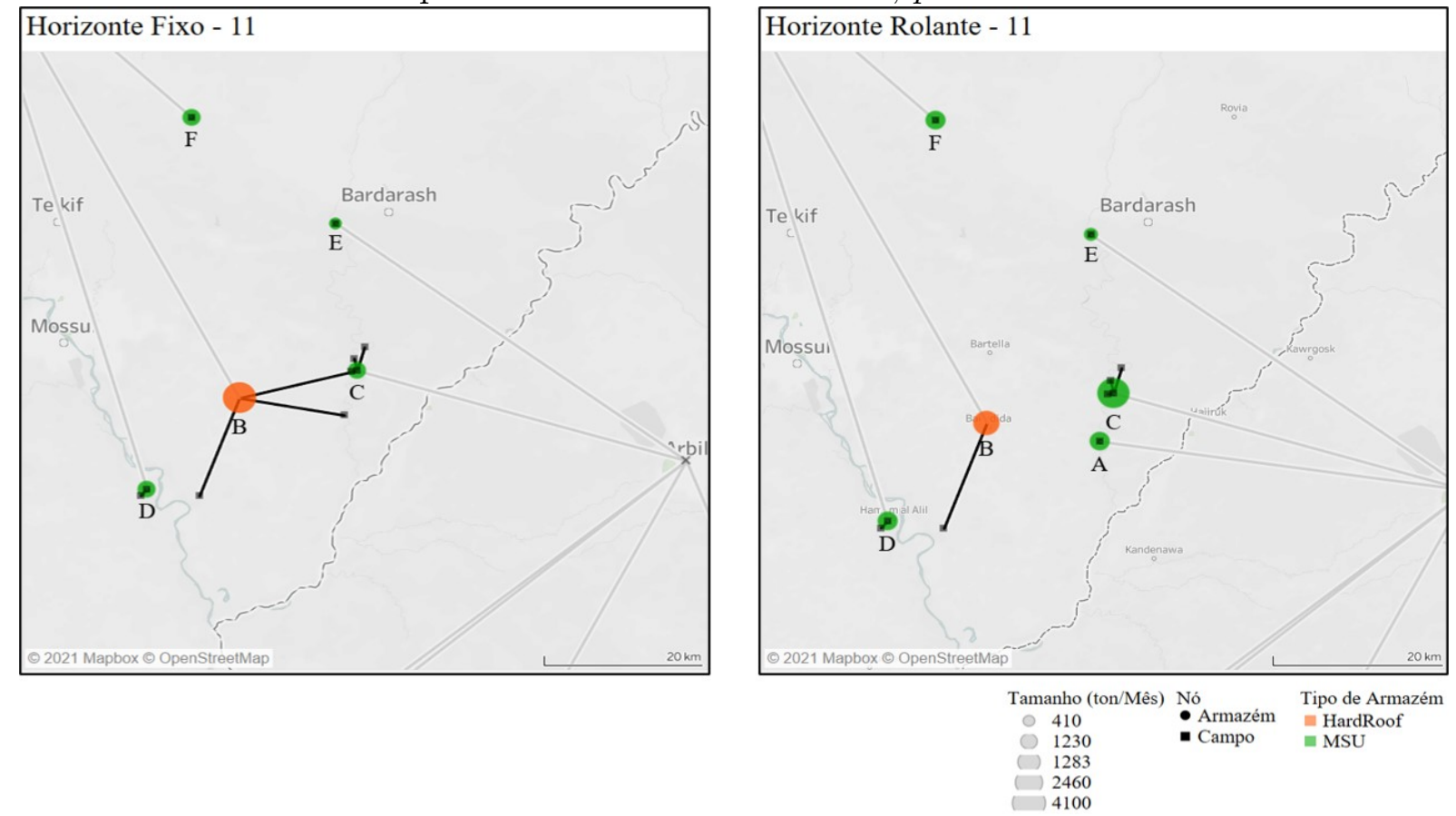

Fonte: Elaboração própria.

Figura 36: Comparação da configuração da malha entre a abordagem de horizonte fixo e rolante do modelo multi-período em dezembro de 2017, $p=14$.
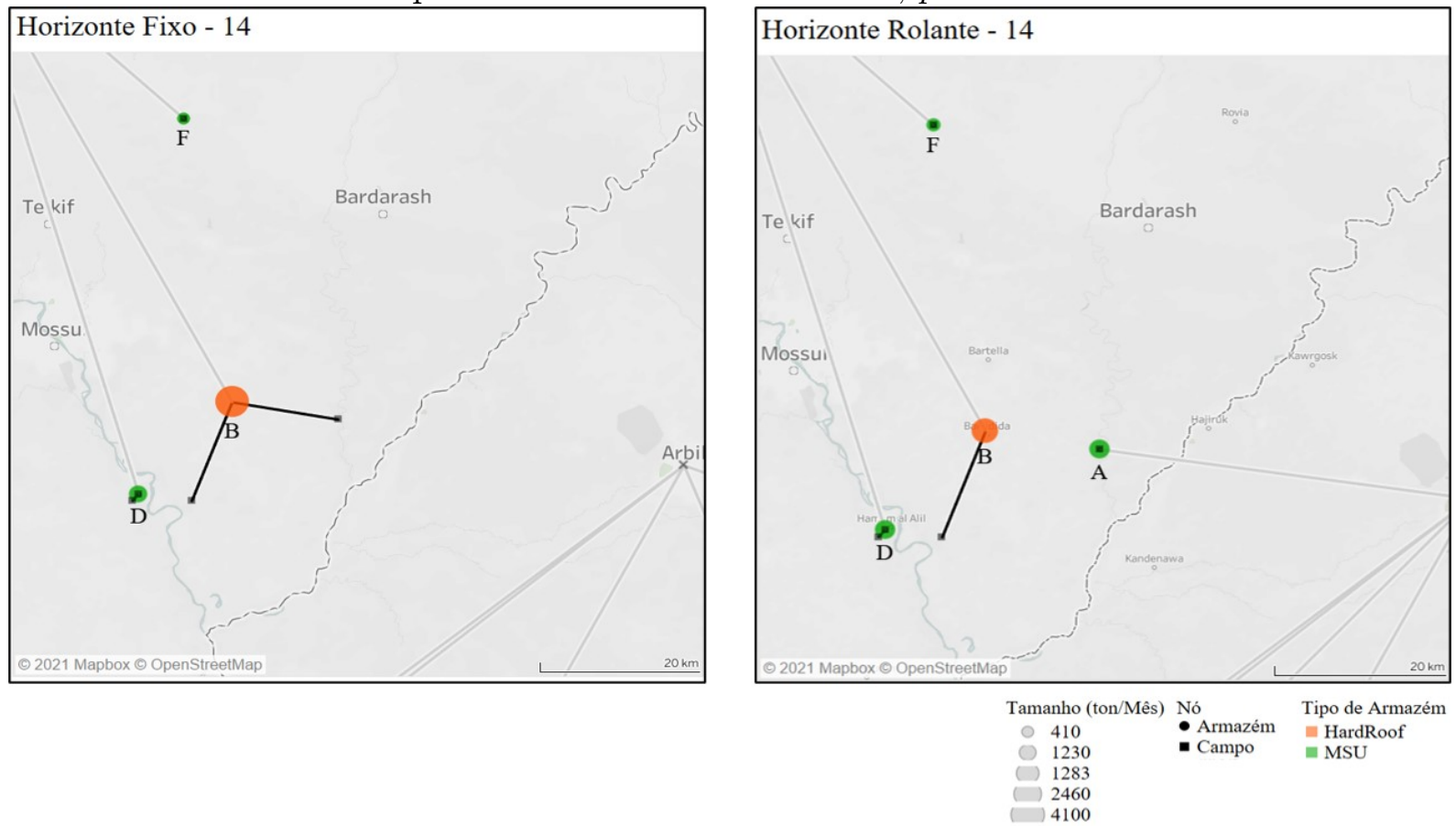

Fonte: Elaboração própria. 
Figura 37: Demanda agregada por clusters.

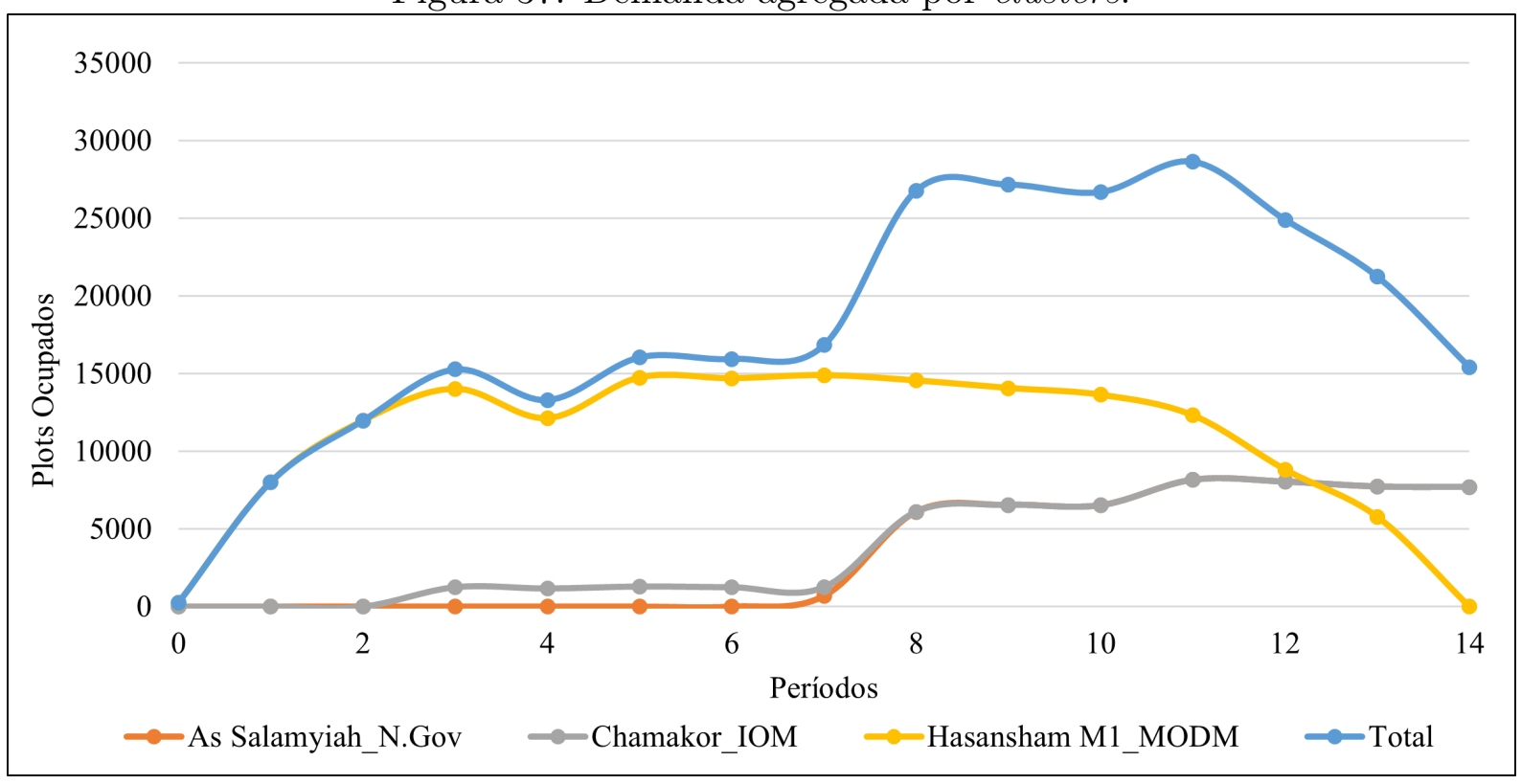

Fonte: Elaboração própria.

\subsection{Impacto da restrição de distância máxima na loca- lização das instalações}

Buscando avaliar o impacto da restrição sobre o raio de cobertura dos armazéns, foram realizados experimentos variando o parâmetro de distância máxima para valores entre 8 e $200 \mathrm{~km}$. Desta forma, a análise sobre os custos revela que os custos de transporte representam uma parcela importante na composição do custo total, entretanto são os custos referentes às instalações que têm maior impacto nas decisões. Através das análises, observou-se que o custo total de transporte é aquele que apresenta o menor coeficiente de variação, 8\%, destacando seu comportamento mais estável, enquanto o custo de operação total apresenta um coeficiente de variação de 47\%. Analisando as amplitudes percebe-se o impacto dos custos das instalações, que variam na ordem de milhões, enquanto os de transporte variam em milhares.

O custo total gasto em transportes se mantém relativamente estável, apresentando uma variação de 2,35 milhões a 3 milhões de dólares, havendo uma relação inversamente proporcional entre seus dois componentes (custos no primeiro e segundo trecho). O tradeoff existente entre os custos de transporte do primeiro e do segundo trecho faz com que o custo total de transporte se balanceie conforme o aumento do raio. Por exemplo, se as soluções para raio de $8 \mathrm{~km}$ e raio de $200 \mathrm{~km}$ forem comparadas, observa-se uma redução 
de 11 mil quilômetros rodados no primeiro trecho e um aumento de cerca de 21 mil quilômetros rodados no segundo trecho, o que resulta em um aumento global de 10 mil quilômetros. Apesar do aumento de $83 \%$ na distância total percorrida, o aumento nos custos totais foi de $27 \%$, pois para cada quilômetros reduzido no primeiro trecho existe uma redução de $\$ 51,67$, enquanto para o segundo trecho para cada quilômetro a mais existe um aumento de $\$ 58,20$.

O gráfico da Figura 38 apresenta os custos totais obtidos para todos os cenários de raio de cobertura, em que estão destacados seus componentes. Os resultados revelam o aumento nos custos de transporte para o segundo trecho (entre armazém e campo), fato confirmado no gráfico da Figura 39, que apresenta a distância total percorrida nos dois trechos. Devido à redução no número total de instalações observada na Figura 40, o segundo trecho torna-se mais custoso à medida que estas instalações tendem a concentrar a demanda de um maior número de campos, provocando o aumento na distância total percorrida neste trecho. Além disso, o primeiro trecho (entre Hubs e armazéns) mostra-se menos presente conforme o aumento do raio de cobertura, revelando a tendência de que estas instalações sejam localizadas mais próximas dos Hubs.

Os demais custos, exceto pelos custos de operação variáveis,

Figura 38: Variação dos custos totais pela distância de cobertura.

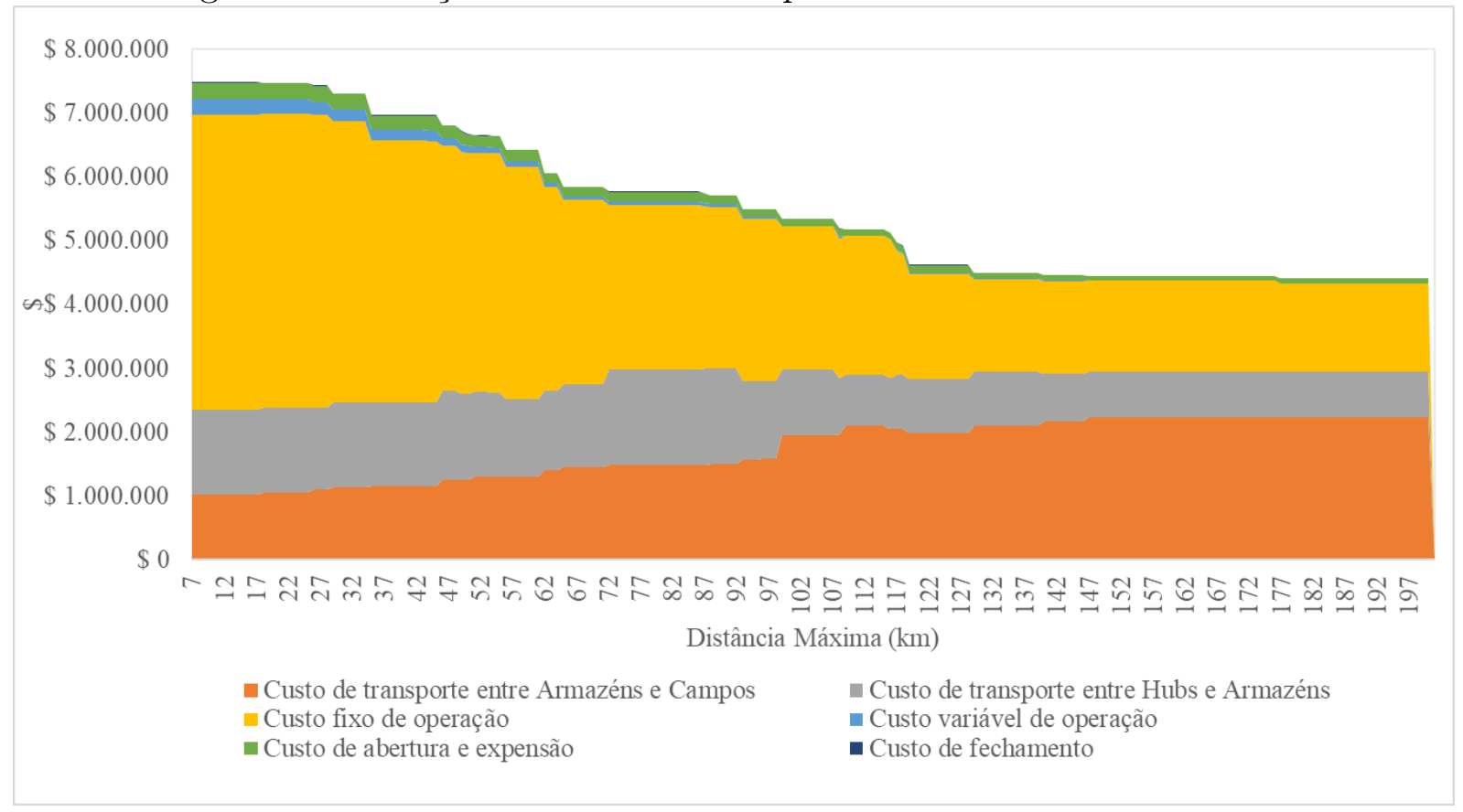

Fonte: Elaboração própria.

também apresentam forte redução relacionada a quantidade de armazéns instalados. O 
Figura 39: Variação na distância total percorrida pela distância de cobertura.

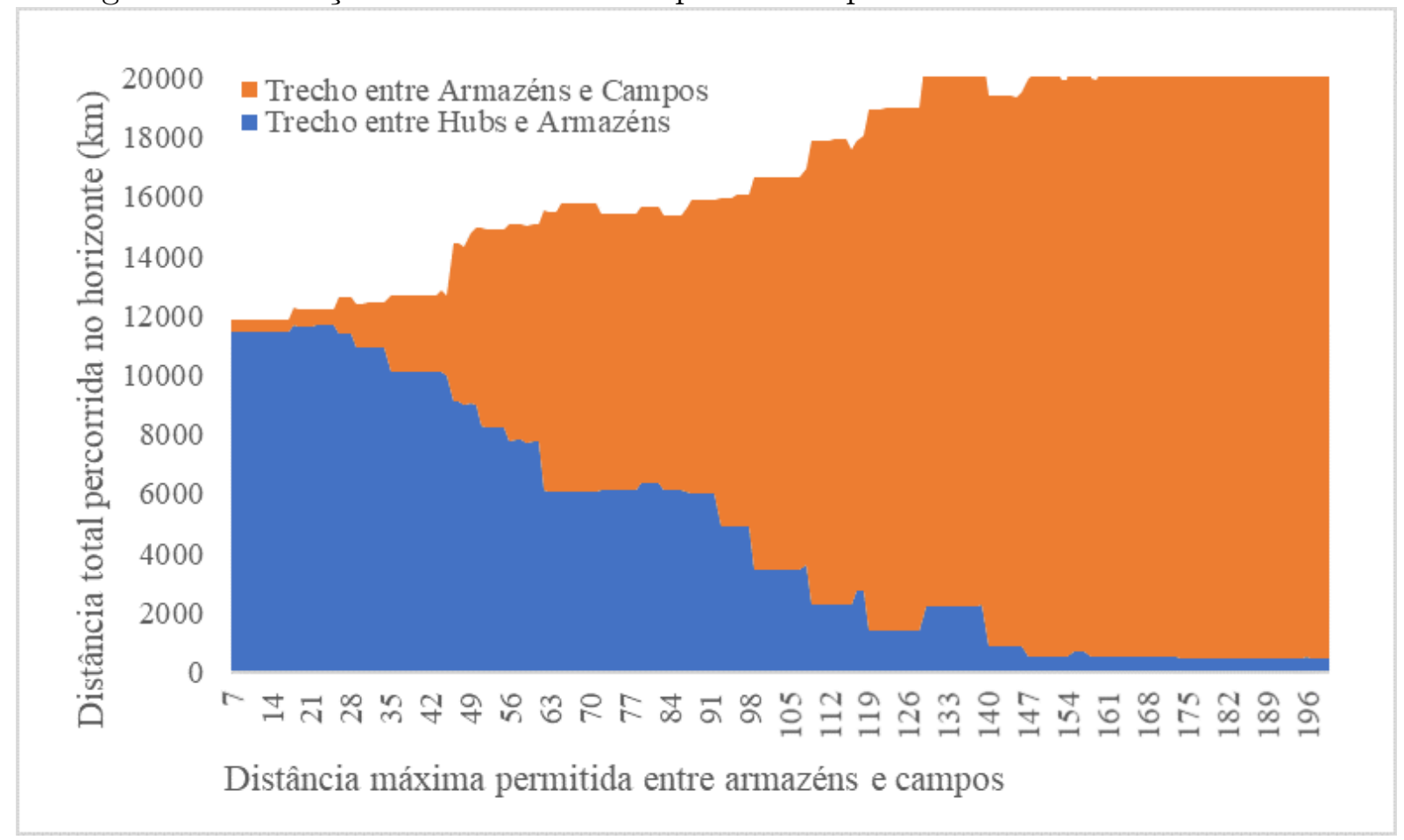

Fonte: Elaboração própria.

custo fixo de operação é aquele que apresenta maior impacto no custo total e se mantém praticamente estável a partir do raio de $119 \mathrm{~km}$, em que a quantidade de instalações médias fica abaixo de quatro por período. A partir da distância de $148 \mathrm{~km}$ esta quantidade média de instalações se mantém constante (Figura 40).

Os custos variáveis também sofrem redução, mas não estão vinculados à quantidade de pontos de suprimento, pois dependem do volume de insumos movimentados em cada tipo de instalação. Dessa forma, o volume total movimentando (demanda) não varia entre os cenários, sendo a redução no custo variável atribuída às condições de mecanização favoráveis em armazéns hardroofs, mais presentes nas decisões conforme o aumento no raio de cobertura. Ao analisar os custos de operação variáveis percebe-se que, apesar da tendência de redução, este componente apresenta alguns picos associados às decisões de tipo de armazém apresentadas na Figura 40. Dessa forma, ocorre uma mudança nas categorias e tamanhos de armazéns instalados, ocasionando a oscilação nos custos de operação variáveis. Os custos variáveis apresentam grande dispersão, entretanto em uma ordem de grandeza em milhares, assim como os custos de abertura e fechamento, tendo uma menor participação na composição do custo total.

Por fim, os custo de abertura e fechamento também apresentam tendência de de- 
Figura 40: Variação na quantidade de armazéns média operando por período pela distância de cobertura

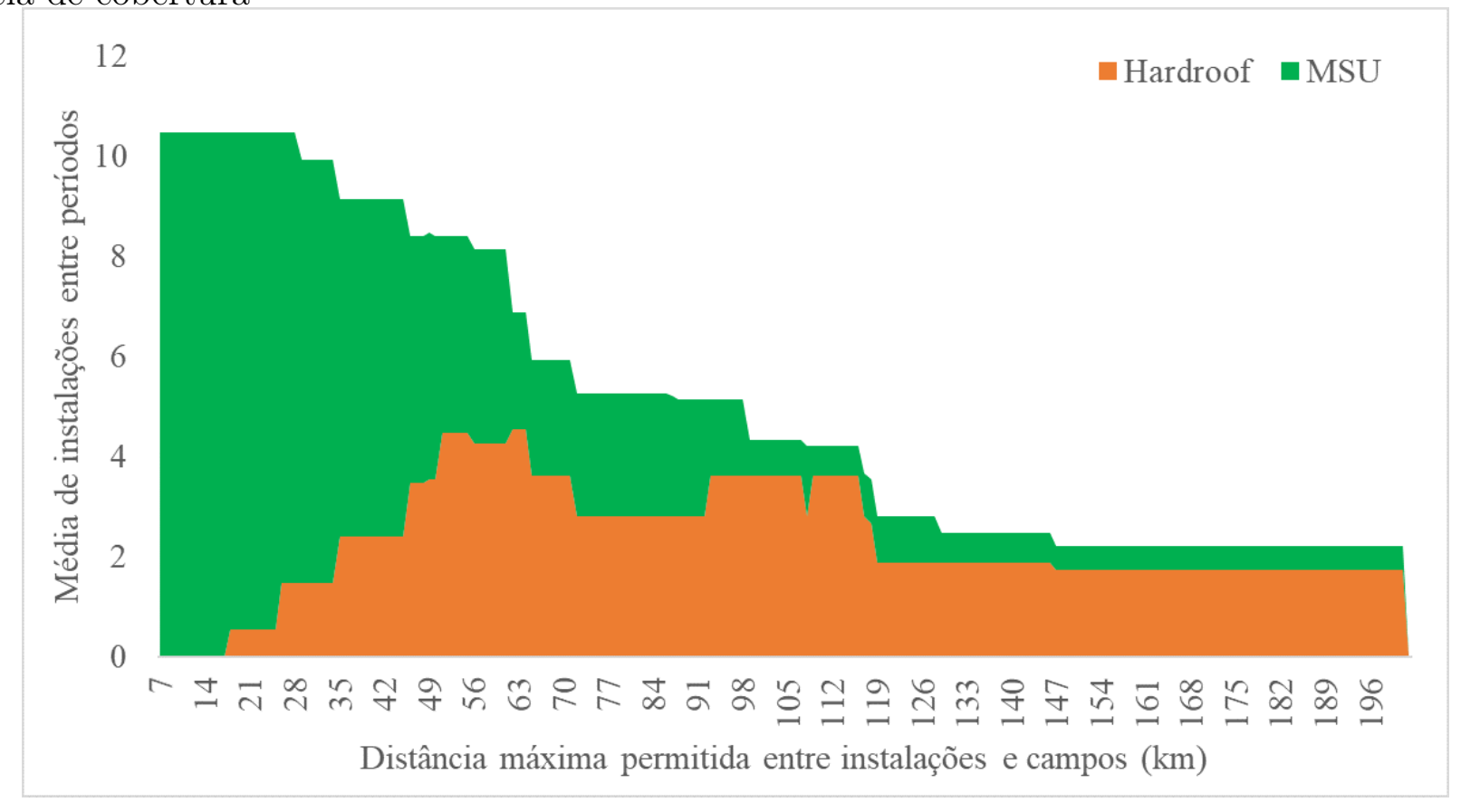

Fonte: Elaboração própria.

créscimo com oscilações devido ao aumento no uso de armazéns do tipo hardroofs, que apresentam menor flexibilidade de expansão e redução. Neste estudo, considerou-se que a capacidade destes candidatos não seria expansível ou redutível, pois implicaria em uma nova negociação e contratação de serviços. Além disso, a construção de armazéns de alvenaria não foi uma prática adotada no operação analisada devido ao seu caráter transitório. Apesar de apresentarem valores altos, os custos de abertura e expansão, bem como fechamento e decréscimo de capacidade possuem uma ordem de grandeza de milhares tendo um impacto menor na composição dos custos.

A Figura 41 apresenta a quantidade de instalações em cada período do horizonte analisado para todos casos de raio de cobertura. É possível perceber uma maior variação no número de armazéns instalados no horizonte de 15 meses para distâncias menores e um comportamento mais constante à medida que o raio aumenta. Este comportamento é causado devido ao aumento na utilização de hardroofs, o que impede a adaptação da rede para acomodação da demanda, isto é, a abertura e o fechamento de instalações são limitados. Por serem menos flexíveis a expansões, os armazéns de alvenaria se mantêm operando ao longo do período de planejamento sem alterações. Dessa forma, quanto maior o raio de cobertura menor a quantidade de armazéns, havendo uma predominância de instalações do tipo hardroofs com níveis de capacidade maiores. 
Figura 41: Quantidade de armazéns operando para cada período do horizonte de 15 meses variando a restrição de cobertura.

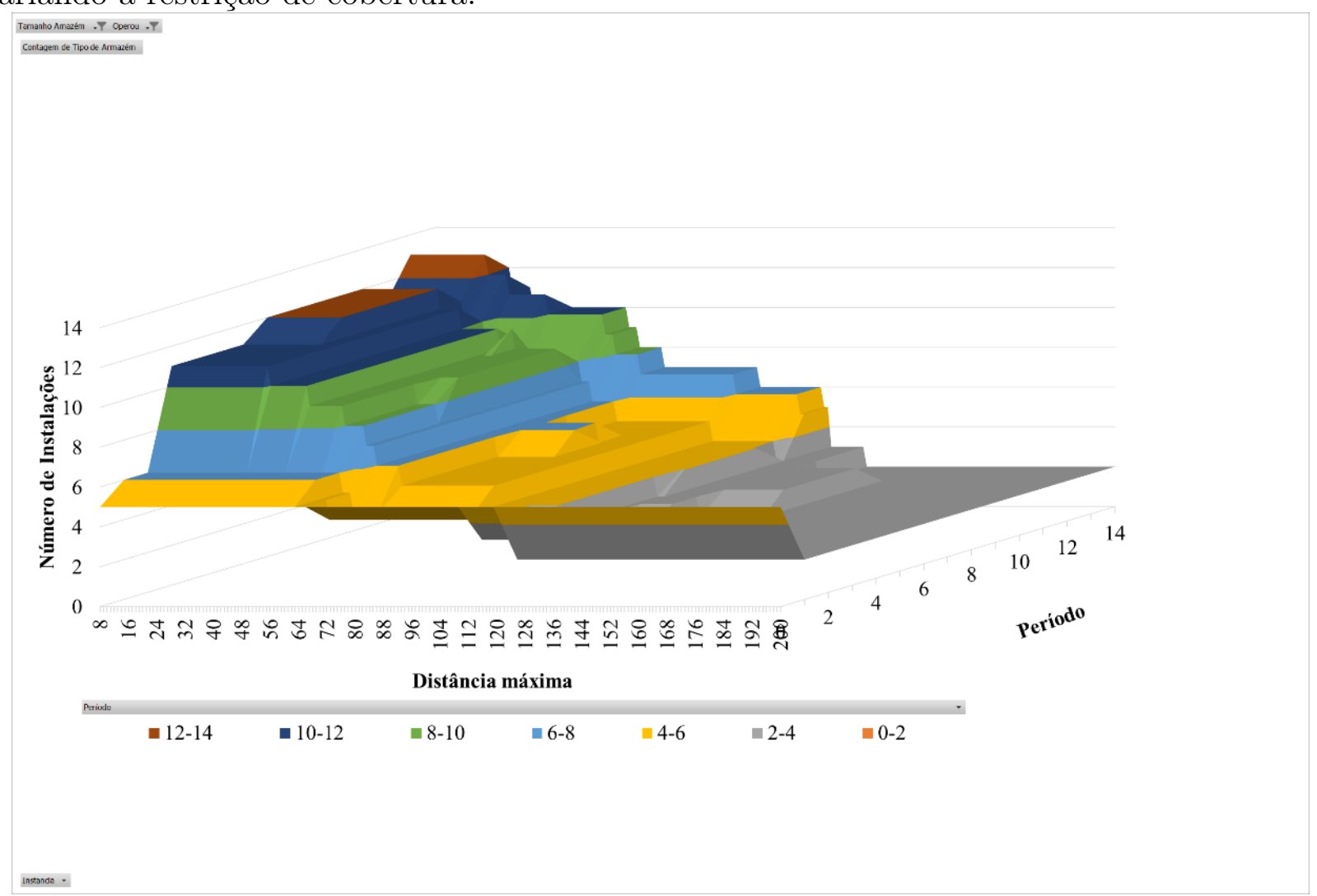

Fonte: Elaboração própria. 


\section{CONCLUSÕES E TRABALHOS FUTUROS}

Esta dissertação visou analisar o impacto da abordagem de múltiplos-períodos no planejamento de instalações humanitárias e da colaborações na ações humanitárias através da proposição de uma nova malha logística ao caso estudado. Dessa forma, a partir da pesquisa bibliográfica realizada constatou-se oportunidades de pesquisa relativas à abordagem proposta ao se identificar uma escassez em trabalhos que abordem múltiplos períodos através da colaboração de agências humanitárias. Outro ponto observado é relativo ao tipo de aplicação e caso estudado, em que se observa uma maior concentração de estudos sobre desastres naturais, sendo raros os trabalhos que abordam conflitos armados. A natureza do desastre condiciona o operação instalada, e por consequência o modelo de planejamento proposto, destacando-se a importância sobre este estudo.

Outro ponto observado na pesquisa bibliográfica, é um aumento na utilização da modelagem estocástica em trabalhos sobre logística humanitária. Dada a natureza incerta dos eventos catastróficos e das emergências complexas, abordadas nestes estudo. A utilização destes modelos pode ser uma alternativa futura para aumentar a robustez do modelo apresentado nestes trabalho.

O trabalho fez uso de um método para definição dos locais candidatos e agrupamentos de campos que podem ser supridos por estes, através dos campos planejados para a operação. Neste processo procurou-se locais que se localizassem o mais próximo possível de seus campos, ou pontos de demanda, mas que também pudesse reduzir custos total empregado no transporte. Outra abordagem poderia ser testada, considerando estes dois objetivos, mas que considera durante a minimização dos custos aos fluxos de demanda. Isto é, que pondere as distâncias percorridas pelas demandas e o custos unitário de transporte. Não se considerou durante os replanejamentos mudanças nestas decisões quanto a formação de agrupamentos e locais candidatos, mas que seria um situação que poderia ocorrer em um processo real de tomada de decisão.

Quanto aos resultados encontrados, observa-se um ganho relativo à coordenação entre as agências humanitárias, em que ocorre uma redução expressiva no número de instalações 
selecionadas. Por consequência, tem-se uma maior centralização da operação promovendo uma melhor utilização dos recursos, ganhos de escala.

Dessa forma, a partir do novo modelo colaborativo, analisou-se a adequação do modelo multi-período ao planejamento das operações humanitária. Inicialmente comparou-se a abordagem estática a abordagem multi-período, em que se verificou o melhor desempenho desta última na localização e designação das demandas quando se tem variações temporais e espaciais dos pontos supridos. O modelo estático não apresenta robustez em sua solução, de forma que a decisão se torna impraticável, exigindo alterações em seu plano e até mesmo no desrespeito de restrições impostas.

Visando analisar a utilização do modelo mais realista, observou-se através do horizonterolante, que as perdas relativas a atualização das informações disponíveis e dos planos elaborados são pequenas. Entretanto os valores de ocupação não foram variados ao longo dos replanejamentos, assim as novas informações eram relativas apenas ao novo período adicionado ao replanejamento. Dessa forma, seria interessante que se analisa em outros estudos a utilização do modelo, por exemplo, através de cenários de planejamento variando as expectativas de demanda também nos replanejamentos.

Por fim, observou-se que os custos das instalações são decisivos. Ao realizar o relaxamento de restrição de cobertura, que delimita as distâncias máximas permitidas entre pontos de armazenagem e pontos de demanda, observa-se a tendência de concentração das demandas em grandes centros de armazenagem.

O modelo multi-período provou-se mais eficiente para atender as necessidades do sistema analisado, caracterizado por variações de demanda temporais e espaciais, proporcionando resultados flexíveis e a melhor utilização dos recursos disponíveis. Entretanto, seria interessante a investigação do modelo utilizando mais cenários de demanda. Além disso, poderia-se estender o modelo fazendo uso de otimização estocástica, ou incluir decisões de níveis táticos ou operacionais, como gestão de estoques e a avaliação da possibilidade de falta de insumos para o suprimento. O evento analisado apresenta aspectos críticos que podem retardar a distribuição dos insumos causando a ruptura parcial dos elos de ligação dos nós, como a existência de pontos de checagem, assim como podem haver rupturas nas instalações. Questões que poderiam também ser incorporadas ao modelo. 


\section{REFERÊNCIAS}

ALIZADEH, R.; NISHI, T. Hybrid set covering and dynamic modular covering location problem: Application to an emergency humanitarian logistics problem. Applied Sciences (Switzerland), v. 10, n. 20, p. 1-23, 2020. ISSN 20763417.

AREnAles, M. et al. Pesquisa Operacional. Rio de Janeiro: Editora Campus. [S.l.]: Elsevier, 2007.

ARNOLD, T. D.; FIORE, N. Five Operational Lessons from the Battle for Mosul. [S.1.]: Military Review, 2019.

AYMERICH, O.; ZEYNELOGLU, S. House Damage Revisited: How Type of Damage and Perpetrating Actor Affect Intentions and Actions of IDPs in Iraq. International Migration, v. 57, n. 2, p. 65-79, 2019. ISSN 14682435.

BALCIK, B. et al. Collaborative Prepositioning Network Design for Regional Disaster Response. Production and Operations Management, v. 28, n. 10, p. 2431-2455, 2019. ISSN 19375956.

BALDINI, G. et al. Securing disaster supply chains with cryptography enhanced rfid. Disaster Prevention and Management: An International Journal, Emerald Group Publishing Limited, v. 21, n. 1, p. 51-70, 2012.

BALLOU, R. H. Business logistics/supply chain management: planning, organizing, and controlling the supply chain. [S.1.]: Pearson Education India, 2007.

BALLOU, R. H. Gerenciamento da Cadeia de Suprimentos-: Logística Empresarial. [S.l.]: Bookman Editora, 2009.

BASHIRI, M. et al. Mathematical modeling for a p-mobile hub location problem in a dynamic environment by a genetic algorithm. Applied Mathematical Modelling, Elsevier Inc., v. 54, p. 151-169, 2018. ISSN 0307904X. Disponível em: < https: //doi.org/10.1016/j.apm.2017.09.032>.

BERTRAND, J. W. M.; FRANSOO, J. C. Operations management research methodologies using quantitative modeling. International Journal of Operations and Production Management, v. 22, n. 2, p. 241-264, 2002. ISSN 01443577.

CAUCHIK, P. A. et al. Metodologia de pesquisa em engenharia de produção e gestão de operações. Rio de Janeiro: Elzevir, 2010.

CCCM Cluster. Camp Coordination and Camp Management (CCCM) Cluster. 2017. Https://reliefweb.int/. [Online; accessed Dez-2018].

CRS. Catholic Relief Services (CRS) - Emergency Field Operations Manual. 2019. Https://efom.crs.org/. Online; accessed Dez-2019]. 
DASKIN, M. S. Network and discrete location: models, algorithms, and applications. [S.l.]: John Wiley \& Sons, 2011.

DOODMAN, M. et al. Pre-positioning and dynamic operations planning in pre- and post-disaster phases with lateral transhipment under uncertainty and disruption. Journal of Industrial Engineering International, Springer Berlin Heidelberg, v. 15, n. s1, p. 53-68, 2019. ISSN 2251712X. Disponível em: < https://doi.org/10.1007/s40092-019-0317-7>.

DUPUY, K.; RUSTAD, S. A. Trends in Armed Conflict, 1946-201\%. Oslo:PRIO: Conflict Trends, 2018.

EM-DAT. The International Disaster Database. 2018. < https://www.emda1.be/>. [Online; accessed Dez-2019].

FANG, X. et al. Research on Improved NSGA-II Algorithm and Its Application in Emergency Management. Mathematical Problems in Engineering, v. 2018, 2018. ISSN 15635147.

FEMA. Emergency Management Institute. 2019. Https://training.fema.gov/emi.aspx. Online; accessed jan-2020].

GAZANI, M. H.; Akhavan Niaki, S. A.; Akhavan Niaki, S. T. The capacitated maximal covering location problem with heterogeneous facilities and vehicles and different setup costs: An effective heuristic approach. International Journal of Industrial Engineering Computations, v. 12, n. 1, p. 79-90, 2020. ISSN 19232934.

GHASEMI, P. et al. Uncertain multi-objective multi-commodity multi-period multi-vehicle location-allocation model for earthquake evacuation planning. Applied Mathematics and Computation, Elsevier Inc., v. 350, p. 105-132, 2019. ISSN 00963003. Disponível em: <https://doi.org/10.1016/j.amc.2018.12.061>.

HALL, R. Handbook of transportation science. [S.1.]: Springer Science \& Business Media, 2012. v. 23.

HASANI, A.; MOKHTARI, H. Redesign strategies of a comprehensive robust relief network for disaster management. Socio-Economic Planning Sciences, Elsevier, v. 64, n. February, p. 92-102, 2018. ISSN 00380121. Disponível em: $<$ https://doi.org/10.1016/j.seps.2018.01.003>.

ICB. Iraq Body Count. 2019. < https://www.iraqbodycount.org/>. [Online; accessed Dez-2019].

IFRC. International Federation Of Red Cross And Red Crescent Societies - Types of disasters: Definition of hazard. 2019. Http://www.ifrc.org/en/what-we-do/disastermanagement/aboutdisasters/definition-of-hazard. Online; accessed Dez-2019].

INCA, L. R.; NIKORN, S. The location-allocation decision under the dynamic increment of demand for selecting the local distribution centers to face sumatra megathrust: Study case of Padang City. International Journal on Advanced Science, Engineering and Information Technology, v. 9, n. 1, p. 293-299, 2019. ISSN 24606952.

IOM. Iraq Mission - Displacement Tracking Matrix(DTMs). 2019. < http://iraqdtm.iom. int/>. Online; accessed Dez-2019]. 
IOM. Families Internally Displaced by ISIL Conflict Safely Return Home Through Government of Iraq, IOM Project. 2020. < https://www.iom.int/news/

families-internally-displaced-isil-conflict-safely-return-home-through-government-iraq-iom $>$. [Online; accessed Jan-2021].

KLIBI, W.; ICHOUA, S.; MARTEL, A. Prepositioning emergency supplies to support disaster relief: A case study using stochastic programming. Infor, Taylor \& Francis, v. 56, n. 1, p. 50-81, 2018. ISSN 19160615. Disponível em: $<$ http://dx.doi.org/10.1080/03155986.2017.1335045>.

KLOSE, A.; DREXL, A. Facility location models for distribution system design. European journal of operational research, Elsevier, v. 162, n. 1, p. 4-29, 2005.

KOVACS, G.; SPENS, K. M. Relief supply chain management for disasters: humanitarian aid and emergency logistics. [S.l.]: Information Science Reference Hershey, PA, 2012.

LEIRAS, A. et al. Literature review of humanitarian logistics research: trends and challenges. Journal of Humanitarian Logistics and Supply Chain Management, v. 4, n. 1, p. 95-130, 2014. ISSN 20426755.

LI, X.; RAMSHANI, M.; HUANG, Y. Cooperative maximal covering models for humanitarian relief chain management. Computers and Industrial Engineering, Elsevier, v. 119, n. February 2017, p. 301-308, 2018. ISSN 03608352. Disponível em: $<$ https://doi.org/10.1016/j.cie.2018.04.004>.

Logistic Cluster. Logistics Operational Guide. 2015. < https://dlca.logcluster.org/> . Online; accessed Dez-2019].

Logistic cluster. Concept of Operations - Mosul Operation, June 2017. 2017.

Https://logcluster.org/document/concept-operations-mosul-28-june-2017. Online; accessed jan-2020].

MENG, L. et al. Determining the Optimal Location of Terror Response Facilities under the Risk of Disruption. IEEE Transactions on Intelligent Transportation Systems, IEEE, v. 19, n. 2, p. 476-486, 2018. ISSN 15249050.

MUNYAKA, J. C. B.; YADAVALLI, V. S. S. Using transportation problem in humanitarian supply chain to prepositioned facility locations: a case study in the Democratic Republic of the Congo. International Journal of Systems Assurance Engineering and Management, Springer India, 2020. ISSN 09764348. Disponível em: <https://doi.org/10.1007/s13198-020-01031-5>.

OCHA. World Humanitarian Data and Trends 2017. 2019. < https://interactive.unocha. org/publication/datatrends2017/>. Online; accessed Dez-2019].

PETTERSSON, T.; ECK, K. Organized violence, 1989-2017. Journal of Peace Research, SAGE Publications Sage UK: London, England, v. 55, n. 4, p. 535-547, 2018.

ReliefWeb. Humanitarian Information Portal. 2017.

Https://cccmcluster.org/operations/iraq. [Online; accessed Dez-2019]. 
RODRÍGUEZ-ESPÍNDOLA, O.; ALEM, D.; Pelegrin Da Silva, L. A shortage risk mitigation model for multi-agency coordination in logistics planning. Computers and Industrial Engineering, Elsevier, v. 148, n. May, p. 106676, 2020. ISSN 03608352. Disponível em: < https://doi.org/10.1016/j.cie.2020.106676>.

ROWLEY, J.; SLACK, F. Conducting a literature review. Management research news, Emerald Group Publishing Limited, v. 27, n. 6, p. 31-39, 2004.

SAHAY, B. S.; GUPTA, S.; Vinod Chandra Menon, N. Managing humanitarian logistics. [S.l.: s.n.], 2015. 1-311 p. ISBN 9788132224167.

SANTOS, F. A. A. de A. Otimização visual interativa com múltiplos critérios: sistema de apoio à decisão para treinamento em logística humanitária. Universidade de São Paulo, 2021.

TANCREZ, J. S.; LANGE, J. C.; SEMAL, P. A location-inventory model for large three-level supply chains. Transportation Research Part E: Logistics and Transportation Review, v. 48, n. 2, p. 485-502, 2012. ISSN 13665545.

The New York Times. Before and After Satellite Images of Mosul Reveal the Devastation After the Islamic State Was Forced Out. 2017. Https:www.nytimes.com/interactive/2017/07/15/world/middleeast/mosul-beforeafter.html. Online; accessed Dez-2019].

UN-HABITAT. City Profile of Mosul, Iraq - Multi-sector assessment of a city under siege. [S.1.]: https://unhabitat.org/, 2016.

UNHCR. Population Statistics. 2019. < http://popstats.unhcr.org>. Online; accessed Dez-2019].

UNISDR. United Nations Office for Disaster Risk Reduction. Terminology. 2017. Https://www.unisdr.org/we/inform/terminology. Online; accessed Dez-2019].

VELASQUEZ, G. A.; MAYORGA, M. E.; CRUZ, E. A. Prepositioning inventory for disasters: a robust and equitable model. OR Spectrum, Springer Berlin Heidelberg, v. 41, n. 3, p. 757-785, 2019. ISSN 14366304. Disponível em: < https: //doi.org/10.1007/s00291-019-00554-Z>.

WANG, J.; SITU, C.; YU, M. The post-disaster emergency planning problem with facility location and people/resource assignment. Kybernetes, v. 49, n. 10, p. 2385-2418, 2019. ISSN 0368492X.

WANG, Y.; SHI, Q.; HU, Q. Dynamic multi-objective optimization for multi-period emergency logistics network. Journal of Intelligent and Fuzzy Systems, v. 37, n. 6, p. 8471-8481, 2019. ISSN 18758967.

WHO. Environmental health in emergencies. 2019. < https://www.who.int/ environmental_health_emergencies/complex_emergencies/en $/>$. Online; accessed jan-2020].

XIANG, Y.; WEI, H. Joint optimizing network interdiction and emergency facility location in terrorist attacks. Computers and Industrial Engineering, Elsevier, v. 144, n. June 2019, p. 106480, 2020. ISSN 03608352. Disponível em: $<$ https://doi.org/10.1016/j.cie.2020.106480>. 
ZAREI, M. H.; CARRASCO-GALLEGO, R.; RONCHI, S. On the role of regional hubs in the environmental sustainability of humanitarian supply chains. Sustainable Development, v. 27, n. 5, p. 846-859, 2019. ISSN 10991719. 


\section{APÊNDICE A}

\section{A.1 Modelagem matemática da malha logística descen- tralizada}

O modelo algébrico descrito na Seção 4.3 apresenta a modelagem adotada para representar a malha logística da cadeia de suprimentos humanitária centraliza. Portanto, para representação do cenário descentralizado adaptou-se aquela modelagem resultando no modelo que será descrito a seguir. As Tabelas 16, 17 e 18 apresentam a notação adotada nesta seção.

Tabela 16: Lista de conjuntos do modelo de localização descentralizado.

\begin{tabular}{cl}
\hline Conjuntos & Descrição \\
\hline$i \in \mathrm{I}$ & Hubs fornecedores de produtos. \\
$j \in \mathrm{J}$ & Locais candidatos \\
$k \in \mathrm{K}$ & Campos para abrigamento de famílias deslocadas. \\
$t \in \mathrm{T}$ & Horizonte de operação. \\
$r \in \mathrm{R}$ & Índice de capacidade final da instalação no instante $t=1$ \\
& $R=\{0,1, \ldots, 11\}$, onde $R$ é o conjunto das capacidades. \\
$s \in \mathrm{S}$ & Índice de capacidade inicial da instalação no instante $t ;$ \\
& $S=\{0,1, \ldots, 11\}$, onde $S$ é o conjunto das capacidades. \\
\hline
\end{tabular}

A função objetivo minimiza o custo total da rede, Equação A.1, a qual abrange os custos relativos a movimentação dos bens entre os hubs e armazéns intermediários. Os demais termos de custos referem-se aos custos fixos de operação, de abertura ou expansão da capacidade, e encerramento ou redução da capacidade. Assim como no modelo centralizado, a o último termo referente aos custos variáveis é não linear, exigindo a linearização do modelo análoga a apresentada da Seção 4.3.1. 
Tabela 17: Lista de parâmetros do modelo de localização descentralizado.

\begin{tabular}{|c|c|c|}
\hline Parâmetro & Descrição & Unidade \\
\hline$a_{s j}$ & $\begin{array}{l}\text { Parâmetro binário que possuí } \\
\text { valor igual a } 1 \text { se o local candidato } j \\
\text { pode receber armazém do tipo } s \text {. }\end{array}$ & Adimensional \\
\hline $\mathrm{a}_{j k}$ & $\begin{array}{l}\text { Parâmetro binário que possuí } \\
\text { valor igual a } 1 \text { se o local candidato } j \\
\text { pode suprir o campo } k \text {. }\end{array}$ & Adimensional \\
\hline q & Volume médio do kit. & Toneladas/mês x família \\
\hline $\mathrm{d}_{k t}$ & $\begin{array}{l}\text { Demanda, famílias no campo } k \text { no } \\
\text { período } t \text {. }\end{array}$ & Famílias \\
\hline $\mathrm{f}_{i j}$ & Frete entre o Hub $i$ e o campo $j$. & USD/tonelada \\
\hline $\mathrm{cf}_{s}$ & Custo fixo de operação mensal do armazém $s$. & USD/mês \\
\hline $\mathrm{cv}_{s}$ & Custo variável de operação mensal do armazém $s$. & USD/tonelada \\
\hline $\mathrm{ca}_{r s}$ & $\begin{array}{l}\text { Custo de abertura dos armazéns } \\
\text { do tipo } r \in\{0, R-1\} \text { para o tipo } \mathrm{s} \in\{r+1, R\} \text {. }\end{array}$ & USD \\
\hline$c \mathrm{f}_{r s}$ & $\begin{array}{l}\text { Custo de fechamento dos armazéns do tipo } \\
r \in\{r+1, R\} \text { para o tipo } s \in\{0, r\}\end{array}$ & USD \\
\hline cap $_{r s}$ & $\begin{array}{l}\text { Capacidade disponível após a mudança } \\
\text { de capacidade de } r \text { para } s .\end{array}$ & Toneladas/mês \\
\hline
\end{tabular}

A primeira restrição do modelo, Equação A.2, aborda o balanço na fluxo de materiais da rede. Assim, cada local candidato em cada período deve apresentar fluxos de entrada e saída iguais, desconsiderando-se a formação de estoques entre períodos. Em seguida, a Equação A.3, garante a demanda de cada campo em cada período deverá ser suprida completamente.

A Equação A.18 estabelece que a capacidade do armazém instalado deve ser capaz de processar todo o volume de produtos necessários ao respectivo campo atendido pelo armazém. 
Tabela 18: Lista de variáveis do modelo de localização descentralizado.

\begin{tabular}{|c|c|c|}
\hline Variável & Descrição & Unidade \\
\hline $\mathrm{X}_{i j t}$ & $\begin{array}{l}\text { Variável de fluxo entre o Hub } i \text { e o local } \\
\text { candidato } j \text { no período } t \text {. }\end{array}$ & Toneladas \\
\hline $\mathrm{X}_{j k t}$ & $\begin{array}{l}\text { Variável de fluxo entre o local candidato } j \text { e } \\
\text { o campo de indivíduos em deslocamento } k \text { no período } t \text {. }\end{array}$ & Toneladas \\
\hline $\mathrm{O}_{r s j t}$ & $\begin{array}{l}1 \text {, se o local candidato } j \text { no período } t \text { sofre } \\
\text { uma mudança de nível de } \mathrm{n} \text { para } \mathrm{m} \text { indicando } \\
\text { aumento de capacidade, } r<s \text {. }\end{array}$ & Binária \\
\hline $\mathrm{W}_{r s j t}$ & $\begin{array}{l}\text { 1, se o local candidato } j \text { opera no período } t \\
\text { com a capacidade disponível após a mudança } \\
\text { de estado (nível) } r \rightarrow s \text {. }\end{array}$ & Binária \\
\hline $\mathrm{Z}_{r s j t}$ & $\begin{array}{l}\text { 1, se o local j no período t sofre uma } \\
\text { mudança de nível de } r \text { para } s \text { indicando } \\
\text { diminuição de capacidade, } r>s \text {. }\end{array}$ & Binária \\
\hline
\end{tabular}

$$
\begin{aligned}
& \text { Min Custo Total }=\sum_{t \in T} \sum_{j \in J} \sum_{i \in I} f_{i j} X_{i j t} \\
& \quad+\sum_{t \in T} \sum_{j \in J} \sum_{r \in R} \sum_{s \in S}\left(\left(c f_{s} W_{r s j t}+c a_{r s} O_{r s j t}+c f_{r s} Z_{r s j t}\right)+\sum_{k \in K} c v_{r s} X_{j k t} W_{r s j t}\right)
\end{aligned}
$$

Sujeito a,

$$
\begin{gathered}
\sum_{i \in I} X_{i j t}-\sum_{k \in K} X_{j k t}=0 ; \forall t \in T, j \in J \\
\sum_{j \in J} a_{j k} X_{j k t} \geq q d_{k t} ; \forall t \in T, k \in K \\
\sum_{r \in R} \sum_{s \in S} a_{s j} \operatorname{cap}_{r s} W_{r s j t} \geq \sum_{k \in K} X_{j k t} ; \forall t \in T, j \in J \\
W_{r s j t}=Z_{r s j t} ; \forall t>0 \in T, j \in J, r \in R, s \in S \mid(r>s) \\
W_{r s j t}=O_{r s j t} ; \forall t \in T, j \in J, r \in R, s \in S \mid(r<s) \\
\sum_{r \in R} W_{r a j(t-1)} \geq \sum_{s \in S} W_{a s j t} ; \forall t>0 \in T, j \in J, a \in R \\
W_{0 a j 0} \geq \sum_{s \in S} W_{a s j 1} ; \forall j \in J, a \in R
\end{gathered}
$$




$$
\begin{gathered}
\sum_{r \in R} \sum_{s \in S} W_{r s j t}=1 ; \forall t \in T, j \in J \\
X_{j \mathrm{kt}} \geq 0, X_{i j t} \geq 0 \\
O_{r s j t} \in\{0,1\}, W_{r s j t} \in\{0,1\} \\
Z_{r s j t} \in\{0,1\}
\end{gathered}
$$

Semelhante ao modelo de localização centraliza, tem-se um conjunto de restrições encarregadas em estabelecer a dimensão temporal do modelo. Estas restrição garante ao modelo a possibilidade de alterações nas capacidades instaladas ao longo do horizonte analisado. Este conjunto de restrições é composto pelas equações A.5, A.6, A.7, A.8 e A.9. As expressões A.5 e A.6 capturam o comportamento de $W_{r s j t}$, enquanto A.7 e A.8 estabelecem a conexão temporal entre os períodos. A Equação A.9 é necessária para que apenas umas das capacidades disponíveis seja instalada, e por fim, as Equações A.10, A.11 e A.12 definem os espaço de soluções do modelo.

Neste modelo não são aplicadas as restrições de cobertura, e os locais candidatos adotados correspondem aos próprios abrigos levantados no estudo. Cada local candidato é responsável pelo suprimento do campo em que se encontra, não sendo permitida a troca de produtos entre armazéns, nem que campos sejam atendidos por armazéns localizados em outros abrigos. Desta forma, o parâmetro $a_{j k}$ é responsável por impor a designação dos armazéns aos campos de desabrigados.

\section{A.2 Modelagem matemática do horizonte estático}

A fim de avaliar a aplicação do modelo multi-período através da comparação apresentada na Seção 6.2, desenvolveu-se o modelo estático a seguir. Os conjuntos, parâmetros e variáveis consideradas estão dispostos nas Tabelas 19, 20 e 21.

Tabela 19: Lista de conjuntos do modelo de localização estático.

\begin{tabular}{cl}
\hline Conjuntos & Descrição \\
\hline$i \in \mathrm{I}$ & Hubs fornecedores de produtos. \\
$j \in \mathrm{J}$ & Locais candidatos a receber armazéns intermediários. \\
$k \in \mathrm{K}$ & Campos para abrigamento de famílias deslocadas. \\
$r \in \mathrm{R}$ & Índice de capacidade da instalação \\
& $R=\{0,1, \ldots, 11\}$, onde $R$ é o conjunto das capacidades.
\end{tabular}


Tabela 20: Lista de parâmetros do modelo de localização estático.

\begin{tabular}{|c|c|c|}
\hline Parâmetro & Descrição & Unidade \\
\hline$a_{r j}$ & $\begin{array}{l}\text { Parâmetro binário que possuí } \\
\text { valor igual a } 1 \text { se o local candidato } j \\
\text { pode receber armazém do tipo } r \text {. }\end{array}$ & Adimensional \\
\hline$q$ & Volume médio do kit. & Toneladas/mês x família \\
\hline $\mathrm{d}_{k}$ & Demanda, famílias no campo $k$ & Famílias \\
\hline $\mathrm{f}_{i j}$ & Frete entre o Hub $i$ e o campo $j$. & USD/tonelada \\
\hline $\mathrm{f}_{j k}$ & Frete entre o local candidato $j$ e o campo $k$. & USD/tonelada \\
\hline $\mathrm{d}_{i j}$ & Distância entre o local candidato $i$ e o campo $j$. & Quilômetros \\
\hline $\mathrm{d}_{\max }$ & Frete entre Hub $i$ e campo $j$. & Quilômetros \\
\hline $\mathrm{cf}_{r}$ & Custo fixo de operação mensal do armazém $r$. & USD/mês \\
\hline $\mathrm{cv}_{r}$ & Custo variável de operação mensal do armazém $r$. & USD/tonelada \\
\hline $\mathrm{ca}_{r}$ & $\begin{array}{l}\text { Custo de abertura dos armazéns } \\
\text { do tipo } r \text {. }\end{array}$ & USD \\
\hline $\operatorname{cap}_{r}$ & Capacidade do armazém do tipo $r$. & Toneladas/mês \\
\hline M & Valor suficientemente grande. & Adimensional \\
\hline
\end{tabular}

Tabela 21: Lista de variáveis do modelo de localização estático.

\begin{tabular}{lll}
\hline Variável & Descrição & Unidade \\
\hline $\mathrm{X}_{i j}$ & Variável de fluxo entre o Hub $i$ e o local & Toneladas \\
& candidato $j$. & \\
$\mathrm{X}_{j k}$ & Variável de fluxo entre o local candidato $j$ e & Toneladas \\
$\mathrm{W}_{r j}$ & o campo de indivíduos em deslocamento $k$. & \\
$\mathrm{Y}_{j k}$ & 1, se o local candidato $j$ abre com capacidade $r \rightarrow s$. & Binária \\
& candidato $j$. & Binária \\
\hline
\end{tabular}

A Equação A.13, correspondente a função objetivo, minimiza o custo total da rede. Esta é composta pelos custos de transporte entre hubs e armazéns intermediários, e entre armazéns intermediários e campos. Os demais termos referem-se aos custos fixos de instalação de operação e de abertura, assim como pelos custos variáveis de operação. 
Como no modelo da Seção 4.3, tem-se uma restrição responsável pelo balanço de produtos recebidos e enviados pelos armazéns, representada pela Equação . Em seguida, a Equação A.15 garante o atendimento da demanda dos campos, não sendo permitida a falta de itens. As restrições A.16 e A.17 são utilizadas na determinação das atribuições dos campos, em que a primeira equação estabelece uma ligação entre as variáveis $X_{j k} \mathrm{e}$ $Y_{j k}$, enquanto a segunda indica que cada campo em cada período será suprido por apenas um armazém.

Em seguida a Equação A.18 garante que a capacidade instalada seja suficiente para atender o volume de produtos demandados para cada armazém.

$$
\begin{aligned}
& \text { Min Custo Total }=\sum_{j \in J}\left(\sum_{i \in I} f_{i j} X_{i j}+\sum_{k \in K} f_{j k} X_{j k}\right) \\
& +\sum_{j \in J} \sum_{r \in R}\left(\left(c f_{r}+c a_{r}\right) W_{r j}+\sum_{k \in K} c v_{r} X_{j k}\right) \\
& \qquad \begin{array}{c}
\sum_{i \in I} X_{i j}-\sum_{k \in K} X_{j k}=0 ; \forall j \in J \\
\sum_{j \in J} a_{j k} X_{j k} \geq q d_{k} ; \forall k \in K \\
X_{j k} \leq M_{j k} ; \forall j \in J, k \in K \\
\sum_{j \in J} Y_{j k}=1 ; \forall k \in K \\
\sum_{r \in R} a_{r j} \operatorname{cap}_{r} W_{r j} \geq \sum_{k \in K} X_{j k} ; \forall j \in J \\
\sum_{r \in R} W_{r j}=1 ; \forall j \in J \\
\mathrm{~d}_{\mathrm{jk}} * \mathrm{Y}_{\mathrm{jk}} \leq \mathrm{d}_{\mathrm{max}} ; \quad \forall j \in J, \mathrm{k} \in \mathrm{K} \\
X_{\mathrm{jk}} \geq 0, X_{i j} \geq 0 \\
O_{r j} \in\{0,1\}, W_{r j} \in\{0,1\}, \\
Y_{j k} \in\{0,1\} .
\end{array}
\end{aligned}
$$

A equação A.19 estabelece que apenas um dos níveis de capacidade disponíveis seja instalado no local candidato, enquanto a restrição A.20 estabelece um raio máximo de cobertura dos armazéns, devido a premissa de que o suprimento da demanda será feito diretamente dos veículos à população em necessidade em alguns casos. Enfim, as Equações 
A.21, A.22 e estabelecem o espaço de soluções do modelo.

\section{A.3 Dados da rede de distribuição de insumos de ajuda humanitária}

Tabela 22: Listagem das coordenadas dos campos planejados.

\begin{tabular}{|c|c|c|}
\hline Índice & Campo Planejado & Coordenadas \\
\hline 0 & Al Bweyer_MODM & $35.991496,42.887406$ \\
\hline 1 & Al Hasudiya_IOM & $36.080494,43.477459$ \\
\hline 2 & Al Hasudiya_UNDP & $36.080494,43.477459$ \\
\hline 3 & Al Khidhir_IOM & $36.12516,43.41091$ \\
\hline 4 & Al Khidhir_tbc & $36.12516,43.41091$ \\
\hline 5 & Al Sh'hamah_MODM & $34.82049,43.51328$ \\
\hline 6 & Al Sh'hamah_UNDP & $34.82049,43.51328$ \\
\hline 7 & Al-Alam_2: MoMD\&UNHCR & $34.818708,43.578686$ \\
\hline 8 & Al-Alam_MODM & $34.818708,43.578686$ \\
\hline 9 & Al-Alam_UNHCR & $34.818708,43.578686$ \\
\hline 10 & Amalla_UNHCR & $36.656025,42.429089$ \\
\hline 11 & As Salamyiah_2: N.Gov\&UNHCR & $36.153736,43.320886$ \\
\hline 12 & As Salamyiah_IOM & $36.153736,43.320886$ \\
\hline 13 & As Salamyiah_N.Gov & $36.153736,43.320886$ \\
\hline 14 & As Salamyiah_UNHCR & $36.153736,43.320886$ \\
\hline 15 & Bartella_N.Gov & $36.345952,43.36765$ \\
\hline 16 & Basateen Al Sheuokh_MODM & $35.5238283,43.234783$ \\
\hline
\end{tabular}


Tabela 22 continuação da página anterior.

\begin{tabular}{|c|c|c|}
\hline Índice & Campo Planejado & Coordenadas \\
\hline 17 & Basateen Al Sheuokh_UNDP & $35.5238283,43.234783$ \\
\hline 18 & Chamakor_ & $36.25312,43.52575$ \\
\hline 19 & Chamakor_IOM & $36.25312,43.52575$ \\
\hline 20 & Chamakor_tbc & $36.25312,43.52575$ \\
\hline 21 & Chamakor_UNDP & $36.25312,43.52575$ \\
\hline 22 & Chamakor_UNHCR & $36.25312,43.52575$ \\
\hline 23 & Chamchamal_MODM & $35.565775,44.789638$ \\
\hline 24 & Dawajin__ & $35.60818,43.18937$ \\
\hline 25 & Dawajin_IOM & $35.60818,43.18937$ \\
\hline 26 & Dawajin_tbc & $35.60818,43.18937$ \\
\hline 27 & Debaga 1_MODM & $35.88232611,43.8091$ \\
\hline 28 & Debaga 2_UNHCR & $35.87514194,43.79986472$ \\
\hline 29 & Debaga Stadium_UNHCR & $35.86771861,43.8140075$ \\
\hline 30 & Haj Ali_IOM & $35.751975,43.3220083$ \\
\hline 31 & Hammam al-Alil_MODM & $36.16203389,43.24697056$ \\
\hline 32 & Hammam al-Alil_UNHCR & $36.15413083,43.23802722$ \\
\hline 33 & Hasansham M1_MODM & $36.30807,43.54371$ \\
\hline 34 & Hasansham M1_UNHCR & $36.30807,43.54371$ \\
\hline 35 & Hasansham M2_MODM & $36.33697,43.55426$ \\
\hline 36 & Hasansham M3_Kuwait & $36.3171,43.5186$ \\
\hline 37 & Hasansham M3_MODM & $36.3171,43.5186$ \\
\hline 38 & Hasansham U2_UNHCR & $36.30727,43.53602$ \\
\hline
\end{tabular}


Tabela 22 continuação da página anterior.

\begin{tabular}{|c|c|c|}
\hline Índice & Campo Planejado & Coordenadas \\
\hline 39 & Hasansham U3_UNHCR & $36.32304,43.5395$ \\
\hline 40 & Kidhir Alyas_MODM & $36.10286,43.41797$ \\
\hline 41 & Laylan_MODM & $35.32956667,44.53015972$ \\
\hline 42 & Laylan_UNHCR & $35.32956667,44.53015972$ \\
\hline 43 & Narziglia_IKL & $36.618981,43.309526$ \\
\hline 44 & Narziglia_MODM & $36.618981,43.309526$ \\
\hline 45 & North Flifal_MODM & $36.60204,43.0142$ \\
\hline 46 & North Flifal_tbc & $36.60204,43.0142$ \\
\hline 47 & North of Kanhish Village_IOM & $36.059532,43.473695$ \\
\hline 48 & North of Kanhish Village_MODM & $36.059532,43.473695$ \\
\hline 49 & North of Kanhish Village_tbc & $36.059532,43.473695$ \\
\hline 50 & Olympic Stadium_MODM & $34.595994,43.683735$ \\
\hline 51 & Olympic Stadium_UNHCR & $34.595994,43.683735$ \\
\hline 52 & Qayyarah (NE of Q.)_MODM & $35.80879,43.30793$ \\
\hline 53 & Qayyarah (Warehouse)_MODM & $35.85121,43.10971$ \\
\hline 54 & Qayyarah Airstrip_IOM & $35.757337,43.278476$ \\
\hline 55 & Qayyarah Bridge_MODM & $35.7099873,43.283765$ \\
\hline 56 & Qayyarah Bridge_tbc & $35.7099873,43.283765$ \\
\hline 57 & Qayyarah Jad'ah_MODM & $35.742061,43.265796$ \\
\hline 58 & Samarra_MODM & $34.192332564,43.871163182$ \\
\hline 59 & Surdesh_MODM & $35.853415,45.093014$ \\
\hline 60 & Surdesh_UNHCR & $35.853415,45.093014$ \\
\hline
\end{tabular}


Tabela 22 continuação da página anterior.

\begin{tabular}{lll}
\hline Índice & Campo Planejado & Coordenadas \\
\hline 61 & Wadi Murr_IOM & $35.69929,43.25762$ \\
62 & Wadi Murr_MODM & $35.69929,43.25762$ \\
63 & Wadi Murr_tbc & $35.69929,43.25762$ \\
64 & Zelikan_MODM & $36.488783,43.514031$ \\
65 & Zelikan_UNHCR & $36.488783,43.514031$ \\
\hline
\end{tabular}


Tabela 23: Tabela 23 Lista de campos planejados durante

a operação de resposta e suas respectivas ocupações du-

rante o horizonte de análise.

\begin{tabular}{|c|c|c|c|c|c|c|c|c|c|c|c|c|c|c|c|}
\hline Índice & out-16 & nov-16 & dez-16 & jan-17 & fev-17 & mar-17 & abr-17 & mai-17 & jun-17 & jul-17 & ago-17 & set-17 & out-17 & nov-17 & dez-17 \\
\hline 6 & 935 & 1.000 & 3.107 & 4.500 & 6.000 & 6.000 & 11.365 & 11.900 & 14.709 & 15.350 & 15.197 & 15.285 & 14.226 & 13.785 & 12.825 \\
\hline 12 & - & - & 2.380 & 3.940 & 5.000 & 9.960 & 10.000 & 10.000 & 9.953 & 9.840 & 8.415 & 8.192 & 8.080 & 7.823 & 7.773 \\
\hline 60 & 245 & 6.000 & 6.000 & 7.000 & 5.467 & 6.930 & 6.843 & 6.940 & 6.880 & 6.420 & 5.493 & 4.753 & 3.607 & 2.547 & 1.699 \\
\hline 5 & 245 & 6.000 & 6.000 & 7.000 & 5.467 & 6.930 & 6.843 & 6.940 & 6.880 & 6.420 & 5.493 & 4.753 & 3.607 & 2.547 & - \\
\hline 61 & - & - & - & 1.331 & 1.519 & 4.060 & 7.120 & 7.174 & 7.435 & 6.805 & 6.786 & 6.038 & 6.019 & 5.532 & 6.276 \\
\hline 26 & - & - & - & 350 & 1.519 & 4.060 & 7.120 & 7.174 & 7.435 & 6.805 & 6.786 & 6.038 & 6.019 & 5.532 & 6.276 \\
\hline 64 & - & - & - & - & - & - & - & 686 & 6.108 & 6.544 & 6.520 & 8.161 & 8.039 & 7.725 & 7.702 \\
\hline 48 & - & - & - & 1.582 & 2.327 & 2.397 & 2.391 & 2.374 & 2.339 & 2.336 & 3.833 & 2.269 & 1.618 & 1.564 & 1.699 \\
\hline
\end{tabular}


Tabela 23 continuação da página anterior.

\begin{tabular}{|c|c|c|c|c|c|c|c|c|c|c|c|c|c|c|c|}
\hline Índice & out-16 & nov-16 & dez-16 & jan-17 & fev-17 & mar-17 & abr-17 & mai-17 & jun-17 & jul-17 & ago-17 & set-17 & out-17 & nov-17 & dez-17 \\
\hline 52 & - & - & - & 1.582 & 2.327 & 2.397 & 2.391 & 2.374 & 2.339 & 2.336 & 2.307 & 2.269 & 1.618 & 1.564 & 1.699 \\
\hline 54 & - & - & - & 1.975 & 1.965 & 1.954 & 1.937 & 1.894 & 1.832 & 1.790 & 1.760 & 1.707 & 1.608 & 1.622 & 1.608 \\
\hline 33 & - & 1.936 & 1.936 & 2.019 & 1.873 & 1.936 & 1.896 & 1.718 & 1.725 & 1.597 & 1.683 & 1.547 & 1.012 & 747 & - \\
\hline 63 & - & - & - & - & 1.168 & 1.297 & 1.250 & 1.250 & 1.275 & 1.250 & 1.318 & 2.100 & 1.852 & 1.604 & 1.196 \\
\hline 53 & - & - & - & 1.331 & 1.500 & 1.332 & 1.191 & 1.223 & 1.184 & 1.166 & 888 & 877 & 558 & 375 & - \\
\hline 34 & - & - & - & - & - & - & - & 1.476 & 1.560 & 1.322 & 1.165 & 989 & 608 & 322 & - \\
\hline 3 & - & - & - & 305 & 450 & 521 & 540 & 715 & 614 & 645 & 658 & 931 & 627 & 596 & 658 \\
\hline 7 & 49 & 1.029 & 1.030 & 1.250 & 1.029 & 623 & 453 & 336 & 239 & 219 & 164 & 119 & - & - & - \\
\hline 4 & - & 40 & 525 & 750 & 750 & 750 & 740 & - & - & - & - & - & - & - & - \\
\hline 55 & - & - & - & 383 & 400 & 377 & 316 & 353 & 344 & 335 & 239 & 234 & 92 & - & - \\
\hline 51 & - & - & - & - & 500 & 500 & 500 & - & - & - & - & - & - & - & - \\
\hline 15 & - & - & - & - & - & - & - & - & - & - & - & - & - & 441 & 446 \\
\hline 46 & - & - & - & - & - & - & - & - & - & - & - & - & - & 363 & 361 \\
\hline
\end{tabular}


Tabela 23 continuação da página anterior.

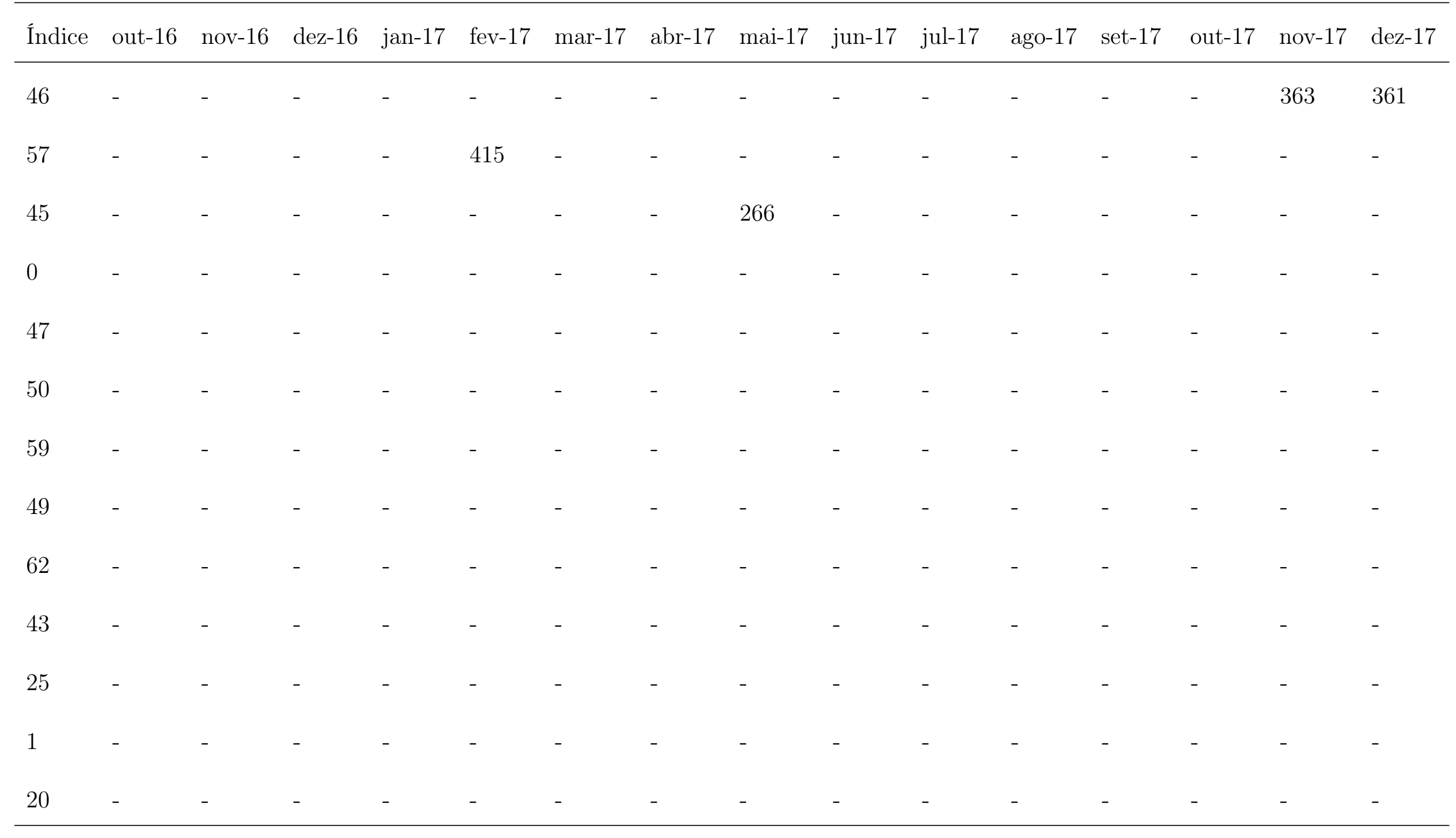


Tabela 23 continuação da página anterior.

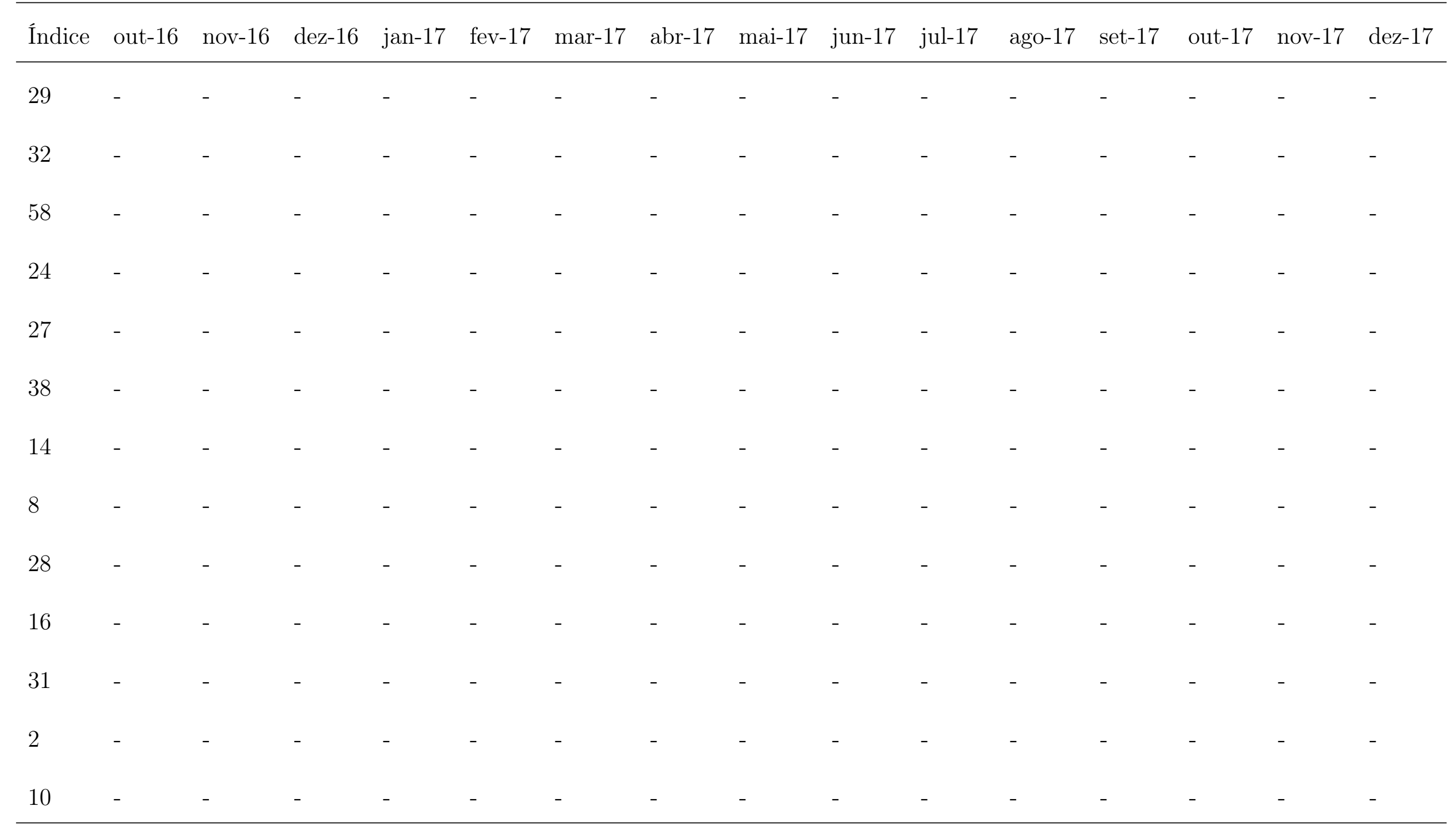


Tabela 23 continuação da página anterior.

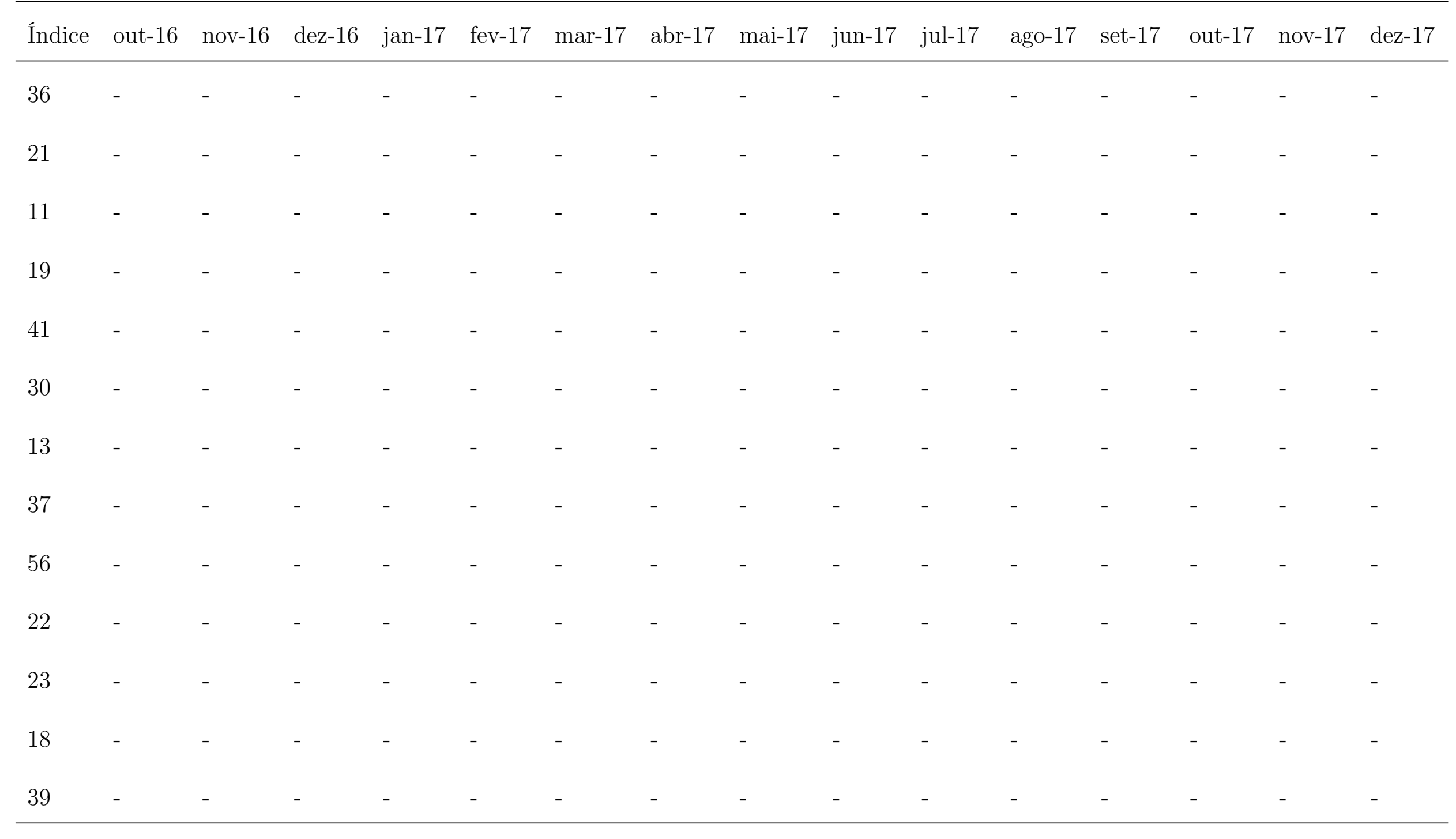


Tabela 23 continuação da página anterior.

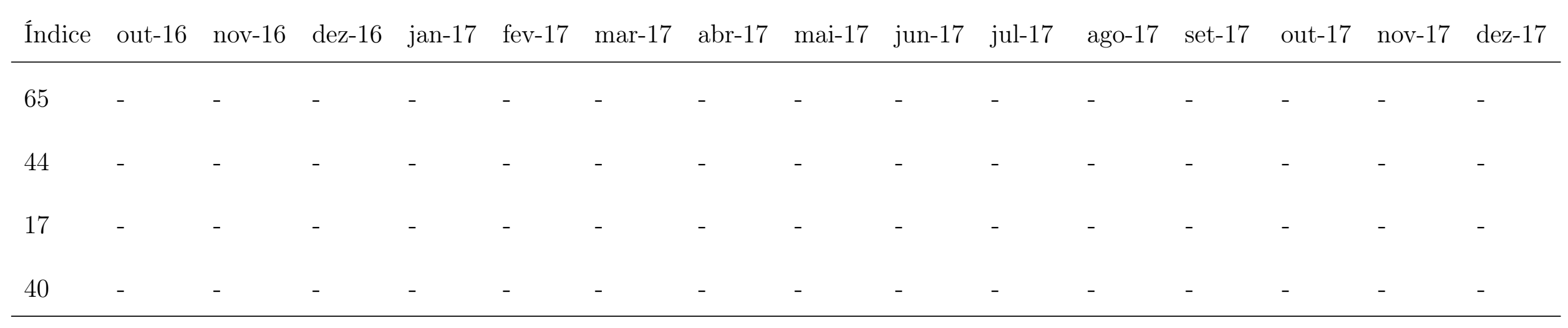




\section{A.4 Verificação do modelo matemático}

Para avaliar a capacidade de solução do modelo matemático proposto em problemas que abrangem as características apresentadas nas no Capítulo 4, realizou-se experimentos com dimensões reduzidas utilizando os dados fictícios apresentados a seguir.

Na Figura 42 tem-se uma instância em que se considerou a utilização de um armazém central (HUB), três locais candidatos e três pontos de demanda pra dois períodos de operação. Além disso adotou-se outras três possibilidades para níveis de capacidade ( 10 , 20 e 40 toneladas/período). Neste experimento o conceito de clusters ou de se utilizar armazéns com características físicas diferentes (armazém móvel ou de alvenaria) não foi considerado, assim como considerou-se que o suprimento de um ponto pode ser realizado por mais de uma armazém. Neste primeiro experimento procurou-se avaliar principalmente a capacidade abertura e expansão dos locais candidatos, bem como o respeito às restrições de fluxo do modelo.

Figura 42: Instância de teste para modelo reduzido

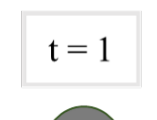

$\mathrm{H}$

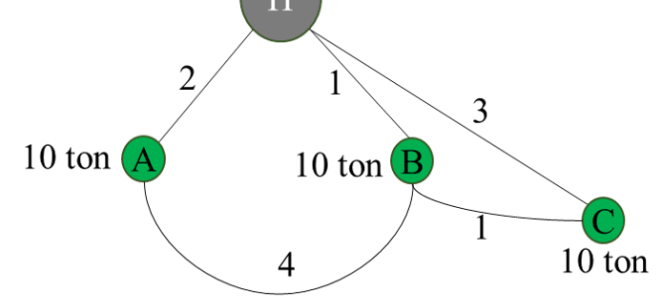

$\mathrm{t}=2$

$\mathrm{H}$

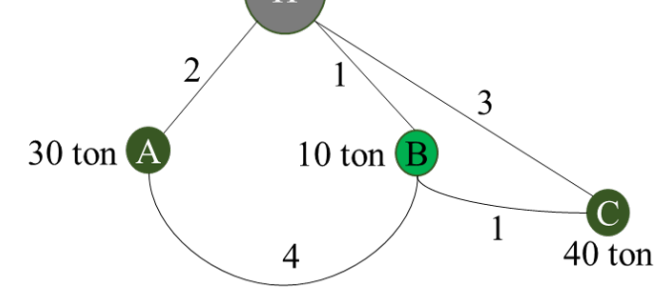

Decisões esperadas
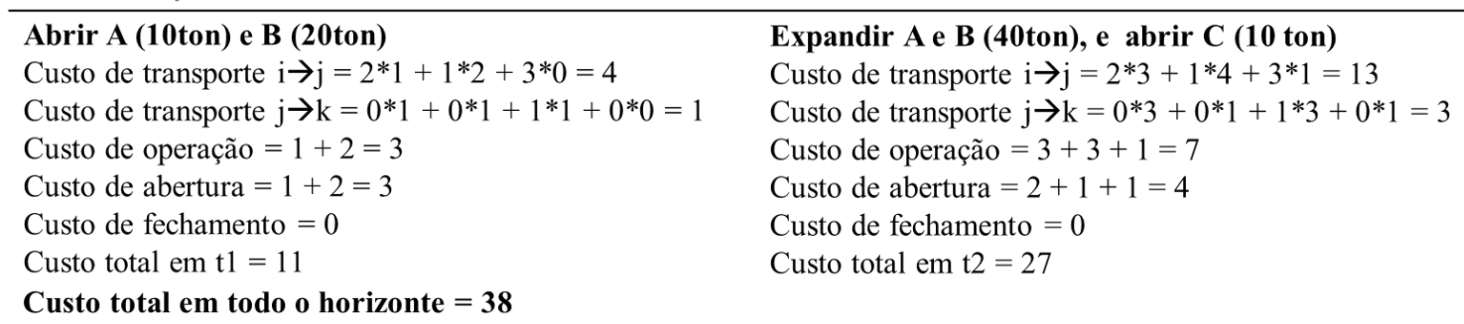

Fonte: Elaboração própria.

Em um segundo experimento, apresentado na Figura 43, adotou-se um único armazém central, 2 locais candidatos e 2 campos (correspondendo ao mesmo local físico dos candidatos a armazenagem). Também considerou-se três períodos de operação, e os parâmetros de níveis de capacidade e custos são semelhantes ao caso anterior. Neste experimento o intuito foi avaliar a capacidade de mudança nos níveis de capacidade, mas em especial avaliar a capacidade de redução de desabilitação dos armazéns. 
Figura 43: Instância de teste para modelo reduzido

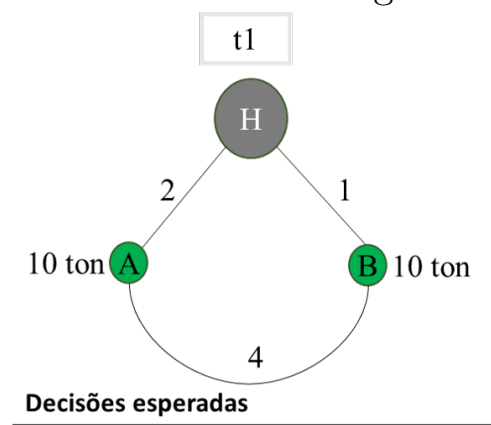

Abrir A (10 ton)

Custo de transporte $\mathrm{i} \rightarrow \mathrm{j}=2 * 1+1 * 1=3$

Custo de transporte $\mathrm{j} \rightarrow \mathrm{k}=0$

Custo de operação $=1+1=2$

Custo de abertura $=1+1=2$

Custo de fechamento $=0$

Custo total em $\mathrm{t} 1=7$

Custo total em todo o horizonte $=\mathbf{2 3}$ t2

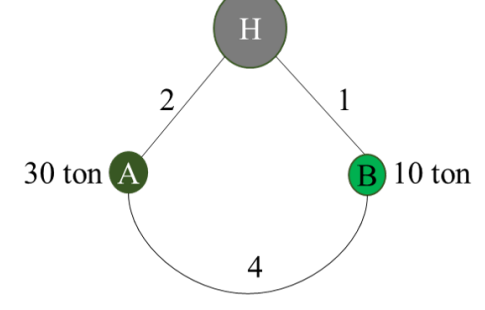

Expandir A (40ton) e manter B (10ton)

Custo de transporte $\mathrm{i} \rightarrow \mathrm{j}=2 * 3+1 * 1=7$

Custo de transporte $\mathrm{j} \rightarrow \mathrm{k}=0$

Custo de operação $=3+1=2$

Custo de abertura $=2$

Custo de fechamento $=0$

Custo total em $\mathrm{t} 2=13$

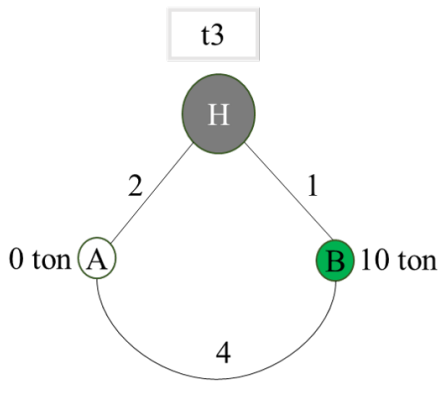

Fechar A e manter B (10ton)

Custo de transporte $\mathrm{i} \rightarrow \mathrm{j}=2 * 0+1 * 1=1$

Custo de transporte $\mathrm{j} \rightarrow \mathrm{k}=0$

Custo operação $=0+1=1$

Custo de abertura $=0$

Custo de fechamento $=1$

Custo total em $\mathrm{t} 3=3$

Fonte: Elaboração própria. 